\title{
Effects of sustained lung inflations in the prematurely born lamb : clinical applications
}

Citation for published version (APA):

Klopping-Ketelaars, W. A. A. (1994). Effects of sustained lung inflations in the prematurely born lamb : clinical applications. [Doctoral Thesis, Maastricht University]. Rijksuniversiteit Limburg. https://doi.org/10.26481/dis.19940317wk

Document status and date:

Published: 01/01/1994

DOI:

10.26481/dis.19940317wk

Document Version:

Publisher's PDF, also known as Version of record

\section{Please check the document version of this publication:}

- A submitted manuscript is the version of the article upon submission and before peer-review. There can be important differences between the submitted version and the official published version of record.

People interested in the research are advised to contact the author for the final version of the publication, or visit the DOI to the publisher's website.

- The final author version and the galley proof are versions of the publication after peer review.

- The final published version features the final layout of the paper including the volume, issue and page numbers.

Link to publication

\footnotetext{
General rights rights.

- You may freely distribute the URL identifying the publication in the public portal. please follow below link for the End User Agreement:

www.umlib.nl/taverne-license

Take down policy

If you believe that this document breaches copyright please contact us at:

repository@maastrichtuniversity.nl

providing details and we will investigate your claim.
}

Copyright and moral rights for the publications made accessible in the public portal are retained by the authors and/or other copyright owners and it is a condition of accessing publications that users recognise and abide by the legal requirements associated with these

- Users may download and print one copy of any publication from the public portal for the purpose of private study or research.

- You may not further distribute the material or use it for any profit-making activity or commercial gain

If the publication is distributed under the terms of Article $25 \mathrm{fa}$ of the Dutch Copyright Act, indicated by the "Taverne" license above, 
EFFECTS OF SUSTAINED LUNG INFLATIONS IN THE PREMATURELY BORN LAMB.

CLINICAL APPLICATIONS. 


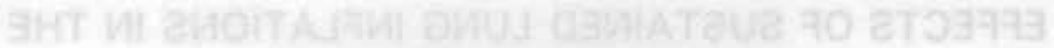

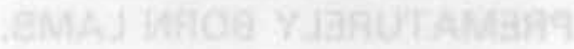

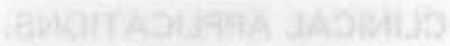




\section{EFFECTS OF SUSTAINED LUNG INFLATIONS IN THE PREMATURELY BORN LAMB. CLINICAL APPLICATIONS.}

\section{PROEFSCHRIFT}

ter verkrijging van de graad van doctor aan de Rijksuniversiteit Limburg te Maastricht, op gezag van de Rector Magnificus, Prof.Dr. H. Philipsen, volgens het besluit van het College van Dekanen, in het openbaar te verdedigen op donderdag, 17 maart 1994 om 16.00 uur

door

Wilhelmina Antonia Ansfrida Klöpping-Ketelaars 
Promotor:

Prof. dr. C.E. Blanco

Beoordelingscommissie:

Prof. dr. S.C.M. Luijendijk (voorzitter)

Dr. S. Bambang Oetomo (Rijksuniversiteit Groningen)

Prof. dr. H. Devlieger (Katholieke Universiteit Leuven, België)

Dr. T.H.M. Hasaart

Prof. dr. S. de Lange 
Aan mijn moeder

Voor mijn dochter 


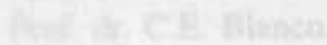

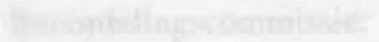

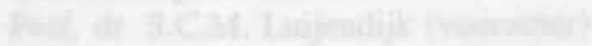

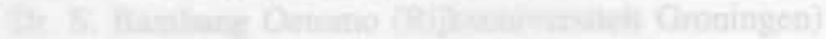

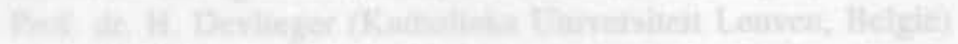

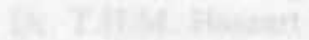

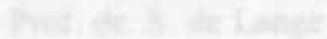

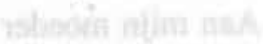

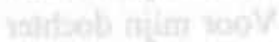




\section{CONTENTS}

List of Abbreviations $\quad 5$

1 Introduction and review of literature $\quad 7$

2 Effects of sustained lung inflations on lung function in premature newborn lambs

3 The effect of sustained lung inflations applied directly after cord clamping on lung function in premature newborn lambs

4 Cardiovascular changes during sustained lung inflations in premature newborn lambs

5 Quantitative and qualitative evaluation of lung morphology after sustained inflations in the premature lamb. The influence of sex, gestational age and clinical outcome

6 The effect of hypocapnia and mechanical pulmonary stress on lung tissue in newborn lambs

7 General discussion and conclusions

Summary

Samenvatting

Curriculum Vitae

Nawoord 


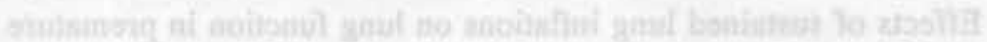

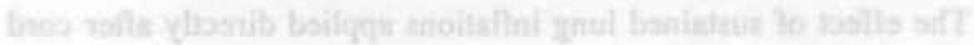

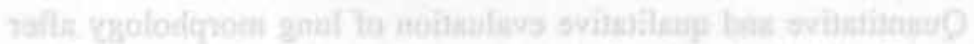

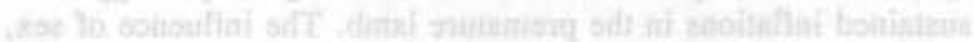




\section{List of Abbreviations}

$\mathrm{AaDO}_{2} \quad$ alveolar-arterial oxygen gradient

CV coefficient of variation (field-to-field variability)

CVP central venous pressure

ECMO extracorporeal membrane oxygenator

$\mathrm{FiO}_{2} \quad \mathrm{O}_{2}$ fraction of inspiratory gas

FRC functional residual capacity

HR heart rate

$\mathrm{I}: \mathrm{E} \quad$ inspiration : expiration

IPPV intermittent positive pressure ventilation

IVH intraventricular haemorrhage

MABP mean arterial blood pressure

MAP mean airway pressure

$\mathrm{OI} \quad$ oxygenation index

$\mathrm{PaCO}_{2}$ arterial $\mathrm{CO}_{2}$ tension

$\mathrm{PACO}_{2}$ alveolar $\mathrm{CO}_{2}$ tension

$\mathrm{PaO}_{2}$ arterial $\mathrm{O}_{2}$ tension

PEEP positive end-expiratory pressure

PIP peak inspiratory pressure

RDS respiratory distress syndrome

rll right lower lobe

rul right upper lobe

Vv par parenchyma as a percentage of the total measured sectional area 


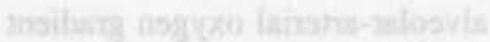

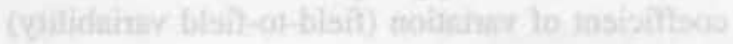

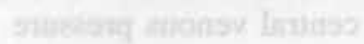

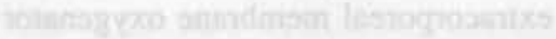

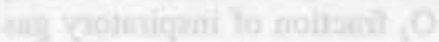

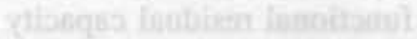

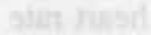

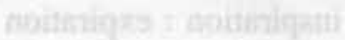

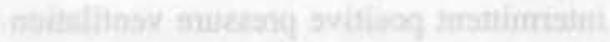

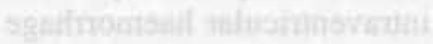

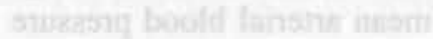

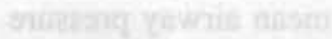

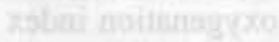

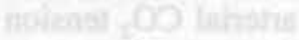

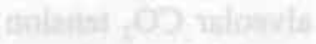

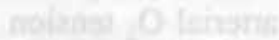

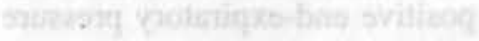

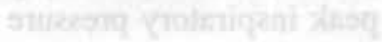

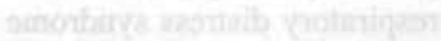
sobol zo wol thitua stiol xeqnu difin

OOlith 49 9V7) (OH:) 017 7989 9.15 II: $(\sqrt{99})$ PIVI $98 \mathrm{Al}$ 9RIM 10

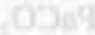
10789 , 1049 9मशㅁำ 919 2978 If ling Iing $\times 1$ 


\section{INTRODUCTION AND REVIEW OF LITERATURE}

\subsection{Introduction}

\subsubsection{The transition from fetus to newborn}

During fetal life the lungs are fluid filled and gas exchange is performed via the placenta. After birth gas exchange must be performed by the lungs. This depends exclusively on the prompt and successful establishment of pulmonary ventilation and circulation. This includes: initiation of ventilation and acute increase in pulmonary perfusion, clearance of fluid from the lungs, secretion of surfactant stores and finally establishment of a functional residual capacity (FRC). When the shift from liquid to air breathing occurs an air-liquid interface is formed with corresponding surface tension. This plays a crucial role in pulling the alveolar walls in, leading to alveolar collapse. Surfactant is needed to lower the surface tensions.

\subsubsection{First breath}

The mechanical events associated with birth and the first breath are not completely understood. Karlberg et al. (1) reported that during vaginal delivery in humans, the compliant rib cage was compressed by forces as high as $50 \mathrm{~cm} \mathrm{H}_{2} \mathrm{O}$, thereby displacing liquid from the lungs. After delivery the chest returned to its resting volume, drawing 7$42 \mathrm{ml}$ of air into the lungs (2). These events, although useful in preparing for subsequent breaths, are not essential because normal aeration occurs even after caesarean delivery. Karlberg (2) found that in the majority of infants studied, the initial inspiratory effort associated with the first breath resulted in a negative intrathoracic pressure of 10 $70 \mathrm{~cm} \mathrm{H}_{2} \mathrm{O}$, with initial inspiratory volumes of $12-67 \mathrm{ml}$. The major sources of resistance to inflation appeared to be surface forces caused by the air-liquid interface and the frictional forces resulting from the movement of the column of liquid in the airway (3). Some of the infants in Karlberg's study (2), and in a later study by Milner et al. (4), required much lower pressures to aerate their lungs, either because partial aeration occurred during vaginal delivery or because pharyngeal "frog breathing" (5) or pulmonary capillary erection (6) may have begun aeration prior to the first measured breath. These latter phenomena may also explain the fact that Mortola et al. (7) found similar volumes for the mean first breath: $39.6 \mathrm{ml}$ and $42.0 \mathrm{ml}$ in caesareian and vaginal deliveries respectively. Subsequent breaths followed a pattern similar to the first breath, although inspiratory pressure swings and inspiratory work were less large.

\subsubsection{Establishment of the functional residual capacity (FRC)}

The functional residual capacity is the resting state of the system at end-expiration. All forces are now balanced out. Forces tending towards collapse: elastic elements in the tissue of the chest wall, lung and diaphragm (elastic recoil force) and the surface ten- 
sion at the air-fluid interface in the alveoli. Forces opposing further collapse: elastic recoil of the chest wall in the opposing direction and the surface tension reducing properties of the surfactant film that normally lines the alveoli.

In the mature fetus the resting volume of the chest wall corresponds to that of the nonaerated lung, and therefore the pressure on the pleural surface is not subatmospheric. After birth, the lung fluid is removed. The mere substitution of air for liquid in part of the alveoli provides some recoil to the lung because of the surface tension of the airliquid interface. This recoil was not present before at the same lung volume. This recoil in the aerated lung tends to pull in the chest wall, which otherwise opposes it. The opposition increases progressively, due to an increase of end-expiratory volume of the chest wall during the first breaths. This probably happens due to a plasticlike phenomenon similar to that shown for the fetal tissue in the lung (3) and the development of the inspiratory muscle tone. These events initiate the opposing recoil of the lungs and chest wall and thus the negative pressure on the pleural surface.

Newborn infants exhibit virtually no chest wall recoil at high lung volumes; the resting volume of the chest wall is $20-30 \%$ of the vital capacity, and at maximum inflation chest recoil approximates $5 \mathrm{~cm} \mathrm{H}_{2} \mathrm{O}$ (8). Hence, in the infant the outward recoil of the chest wall is very small (9) and the inward recoil is slightly lower than that of the adult (10). Static balance of forces would indicate a very small FRC. Such a FRC seems almost incompatible with gas exchange and stability of the airways. From measurements of FRC (11) the FRC/TLC (TLC = total lung capacity) ratio appears to be $40 \%$. Mortola (7) found that the FRC rose by an average of $2.8 \mathrm{ml} / \mathrm{breath}$ or 41.9 $\mathrm{ml}$ over the first 60 minutes, a rate similar to the $10 \mathrm{ml} / \mathrm{kg}$ found by Karlberg (2) in vaginally delivered infants.

In the healthy newborn the FRC is often established at the end of the first breaths. Probably it is formed and maintained by:

- $\quad$ "Airtrapping": inhaled gas that can not be exhaled. Possible reasons for this are blocked airways, e.g. fluid and debris in airways (12),(13). Also airways of newborn babies are very compliant and tend to collapse during expiration, leading to airtrapping. Air trapped in the alveoli would keep the lungs open.

"Foamtrapping" (14) also could assist in the formation of a FRC by an airtrapping mechanism.

In 1978 Saunders et al. (15) and Milner et al. (16) were unable to find any evidence of hyperinflation as a major factor for establishment and maintenance of the FRC, but they did find a consistent difference between thoracic gas volume measured plethysmographically and the FRC measured using a helium dilution technique. This difference can be explained by areas in the lungs of relative hypoventilation and inaccessibility to tidal exchange (17).

- Distension of the pulmonary capillary bed could lead to mechanical changes in the lungs, giving stability at a higher lung volume (6),(18).

At birth the thorax is squeezed. This causes lung fluid to be expelled, consequently providing more potential space and a passive recoil of the chest 
wall, drawing in air (1). However, Saunders and Milner (19) did not observe "elastic recoil" reinflation of the lungs with air. They suggested that hypotonia of the respiratory muscles prior to the first inspiratory effort probably causes absence of the recoil.

A high expiratory pressure (for example during crying) could give a more even distribution of air and perhaps assist in clearing lung fluid. Karlberg (2) found that the initial expirations were prolonged and incomplete, perhaps because the upper airway was partially blocked, resulting in a continuous positive thoracic pressure, which presumably helped to open evenly the distal lung units. Kosch and Stark (20) reported in infants that expiration is terminated at substantial flow rates, indicating an active interruption of expiration. In the lamb adductor muscles of the larynx act as a brake during expiration in an awake state and nonrapid-eye-movement sleep (21). Also, Fisher et al. (22) have shown that glottic closure is a very important mechanism for establishing a lung volume in the immediate postnatal period. Olinsky et al. (23) suggested that long pulmonary time constant relative to expiratory time could also help to establish FRC.

The increase in muscle tone in the chest wall and diaphragm, producing a fall in the resting intrapleural pressure (24). Muller et al. (25) suggested that tonic activity in both the diaphragm and intercostals stiffens the chest wall and establishes a higher active end-expiratory volume.

A decreased FRC is produced by an increased lung recoil or a decreased chest wall recoil. At small volumes the static recoil of the respiratory system is determined by the static recoil of the chest wall. Elastic recoil of the thorax depends on tissue elastic elements but also on the bony development of the rib cage. In premature infants $(<32$ weeks) the compliance of the chest wall is 6.4 , decreasing to $4.2 \mathrm{ml} / \mathrm{cm} \mathrm{H}_{2} \mathrm{O} / \mathrm{kg}$ by term (26). The premature infant has a reduced elastic recoil and a high compliance of the chest wall. There is little opposing force to expansion and there is little counter force to lung collapse. The fact that there is little opposition to collapse at end-expiration explains why the premature infant has a relatively low FRC, even when respiratory distress syndrome (RDS) is not present. The major force contributing to lung elastic recoil in the newborn is that produced by the surface tension of the alveoli.

\subsubsection{Clearance of fluid from the lungs.}

In fetal life an electrochemical gradient across the pulmonary epithelium causes liquid to flow from pulmonary vasculature through the interstitium to the alveolar space. The fetal lamb lung contains $20-30 \mathrm{ml} / \mathrm{kg}$ alveolar fluid (27). After birth, breathing produces a decrease of pressure in the pulmonary capillary and an increase in pulmonary lymph flow; the lung liquid is removed by blood capillaries and lymphatics. The lung liquid is absorbed rapidly after birth, the process being complete in $<6$ hours (28). Interstitial spaces appear distended after birth and lung lymph flow increases 3- or 4fold within the first 30 minutes (29). Bland et al. (30) estimated that in rabbits 
born vaginally the perivascular cuffs contain about $75 \%$ of the total extravascular lung water 30 minutes postnatally. It seems that these sleeves of connective tissue surrounding large pulmonary blood vessels can accommodate residual fluid, apparently without serious compromise of lung function. Recent reports suggest that the removal of liquid from the lungs of fetal animals may begin even before birth: Walters et al. (31) showed that intravenous infusion of epinephrine and B-adrenergic agonists into late-term fetal lambs causes reabsorption of liquid from the potential air spaces. Bland et al. (32) demonstrated that events associated with labour reduce the extravascular lung water content of fetal rabbits. Later they concluded that clearance of lung liquid was more than two-thirds complete at the end of labour (33). They suggested that the decrease in lung water associated with labour was the result of a decrease in the volume of potential air spaces. Fluid drained after birth by the pulmonary lymphatics, averaged only $11 \%$ of the liquid present in the lungs at birth, most liquid must flow from the air spaces into the interstitium and the microcirculation of the lungs.

\subsubsection{Surfactant}

The efficient release of surfactant from mature type II cells is a prerequisite for the successful transition to air breathing. Pulmonary surfactant is a highly surface active lipid protein complex. Among the most important functions of surfactant is the lowering of the surface tension at the air-liquid interface in the alveoli. Surfactant is produced in lung type II cells and stored in lamellar bodies prior to being secreted into the alveolar lumen. Exactly what stimulates the release of these lamellar bodies is unclear, although mechanical and hormonal mechanism have been implicated (34),(35),(36),(37). The mechanisms for perinatal surfactant release have been the subject of several studies. Faridy et al. (38) found that 10-2 hours before birth there was a massive movement of intracellular surfactant into the alveolus, this prenatal release may be related to biochemical events, whereas the postnatal release might be related to lung expansion. During secretion from the cell the lamellar bodies lose their outer membranes while fusing with plasma membrane of the type II cell. As soon as the lamellar bodies are outside the cell, in the alveolar subphase, they are converted to tubular myelin. When the monolayer surface is expanded as during a large inspiration, surfactant from the subphase adsorbs in packets to bare surface which are then covered by rapid spreading. Regions with a high concentration of dipalmitoyl phosphatidylcholine (DPPC) are formed. On compression of this film, during expiration, areas of DPPC-poor film are squeezed out, leaving pure DPPC-film as the monolayer. This layer resists collapse during tidal breathing, while gradually surfactant disappears. The total surface area becomes smaller until the next large breath restarts the cycle (39). By reducing surface tension at the air-alveolar interface, it also tends to "keep the alveoli dry" by reducing the tendency to "suck fluid" into the alveolar spaces from the capillaries. One theory is that dipalmitoyl lecithin, one of the most surface active substances of the surfactant complex, could work as a waterproofing agent (40). Most theories are versions of the Starling hypothesis: opposing vascular and osmotic pressures produce a net infiltration of fluid into the interstitium, which is drained by the lym- 
phatics. Surface tension tends to cause alveolar collapse which lowers interstitial pressure by pulling the adjacent walls of the interstitial space away of each other. An increase in transudation and interstitial oedema results. Especially ventilation with large tidal volumes according to Faridy (34) increases surfactant turnover, possibly by breaking up the surface film or mechanically pumping surfactant out of the alveoli. Decreased compliance with interstitial edema may result. Positive end-expiratory pressure (PEEP) provides some protection (41) possibly by a decrease in the pumping effect due to an increased FRC, or augmented surfactant production by the continuous mild alveolar distension it induces or by mechanical stabilization of the surfactant film.

\subsection{Pathogenesis of the respiratory distress syndrome (RDS).}

In 1959 the relationship between RDS and surfactant was proposed by Avery and Mead (42). RDS is the most common respiratory disorder in the newborn, mainly in the premature infant. Prematurity is associated with the inability of the lungs to produce adequate amounts of surfactant. In the newborn infant, immediately after birth, the transition of a fluid filled organ to a gas filled organ can only be accomplished in the presence of an adequate amount of surfactant.

During the first breaths, the fetal fluid left in the lungs mixes with air in the airways and air bubbles are formed, filling the airways and alveoli. Surfactant, which is present in the pulmonary fluid, provides the stability of these air bubbles by forming a layer along the bubble wall. These air bubbles subsequently form the alveolar lining. Surfactant deficiency leads to formation of instable air bubbles with consequently rupture. In this way the air-liquid interface now plays a role in the conducting airways at end expiration and the alveoli are again refilled with pulmonary fluid. As a result the aeration of the lungs is delayed or impaired. Each single ventilatory cycle therefore requires the same efforts as normally demanded only for the first breaths (43).

Incomplete aeration of the lung results in shunting of blood through non-ventilated lung parts with as a consequence arterial hypoxemia and metabolic acidosis. Inadequate alveolar ventilation causes $\mathrm{CO}_{2}$ retention and respiratory acidosis. Non-homogenous aeration of the parenchyma induces shear forces in terminal conducting airways and alveoli, secondary to overexpansion of bronchioles and uneven expansion of terminal airspaces during the ventilatory cycle (44). Disruption of the epithelium causes necrosis and desquamation of the bronchiolar walls and later the alveolar walls. Hyaline membranes are the result of necrotic cell debris and fibrin and other proteins that leak into the alveolar space where the basal membrane is disrupted. Some of these proteins can interfere with the surface tension lowering effects of the surfactant (45).

All this leads to different levels of respiratory failure in the newborn infant. Clinically this is reflected by intercostal retractions, increased respiratory rate and "grunting".

In babies surviving the first days of the disease the number of mature type II cells increases and lung function improves. Other histological characteristics of repair are the interstitial proliferation of fibroblasts and histiocytes and the migration of these cells to 
the hyaline membranes which become fragmented and eventually digested by alveolar macrophages (46).

The management of these infants often includes mechanical ventilation with administration of supplementary oxygen. However, the increase in survival of sick infants has been accompanied by a high incidence of acute and chronic complications due to assisted ventilation, such as air leaks, bronchopulmonary dysplasia, cor pulmonale, infection and upper airway sequela. Pulmonary barotrauma results from overdistension of terminal and respiratory bronchioles and alveoli with subsequent rupture into the perivascular sheaths of adjacent vessels. This extra-alveolar air may further dissect to the mediastinum, fascial planes of the head and neck, pleural cavity, pericardium, retroperitoneal regions and over the pleural reflections of the great vessels.

Bronchopulmonary dysplasia (BPD) is a chronic emphysematous lung disease, associated with the use of mechanical ventilation and the prolonged use of high oxygen concentrations. This complication is present in 5 to 30 percent of the infants with respiratory failure due to surfactant deficiency (47).

\subsubsection{Possible prevention and treatment of RDS (Table 1.1).}

- $\quad$ Prevention of premature births.

- Increase surfactant synthesis: e.g. antepartum corticosteroids administration to the mother (48).

- $\quad$ Surfactant replacement therapy to the newborn infant (49).

- $\quad$ "Lung conditioning": improvement of lung distensibility by mechanisms independent of surfactant.

\subsection{Lung conditioning}

From here on we will focus on lung conditioning since it is the subject of this thesis. The term "lung conditioning" was first used in experiments of Kolobow et al. (50) to indicate distension of lungs of apnoeic exteriorized fetal premature lambs. This was done by applying a constant intrapulmonary pressure of $15 \mathrm{~cm} \mathrm{H}_{2} \mathrm{O}(51)$. Solca et al. (52) found an improved lung distensibility and prevention of RDS after delivery and ventilation of the premature lambs. Lung compliance was further increased when repeated inflations of $35 \mathrm{~cm} \mathrm{H}_{2} \mathrm{O}$ with a duration of 5 seconds were applied preceding a constant intrapulmonary pressure. This was called "accelerated conditioning" of the lungs (53). Groups in which lung conditioning was administered had a higher survival rate than the control group. The changes produced by conditioning of the fetal lungs were believed to be independent of the amount of surfactant since surface tensions were comparable between control and conditioned groups. The mechanism by which distension could possibly alter subsequent performance of the lungs were not identified. Other studies have emphasized the importance of structural changes distinct from surfactant, in the development of alveolar distensibility (54),(55),(56). 
Table 1.1 Pathogenesis of the respiratory distress syndrome (RDS) and possible management at the described moments in the course of the disease. TRH $=$ thyroid releasing hormone; $V / Q=$ ventilation-perfusion ratio; $C P A P=$ continuous positive airway pressure; IPPV = intermittent positive pressure ventilation.

\section{PATHOGENESIS RDS}

Prematurity

$\downarrow$ Surfactant synthesis, storage and release

$\downarrow$ Surfactant alveoli

$\uparrow$ Alveolar surface tension

Atelectasis

V/Q imbalance

hypoxia

Acidosis

Pulmonary vasoconstriction

Pulmonary hypoperfusion

Capillary endothelial damage

Plasma leak

Fibrogen in interstitium

Fibrin formation

\section{MANAGEMENT}

Prevention of premature births

Steroids, TRH antepartum

Surfactant administration

Lung Conditioning?

\section{CPAP}

IPPV

$\mathbf{T}$

O

O

L

A

$\mathrm{T}$

E 
Ikegami et al. (57) also reported an increase in compliance (2.5-fold) and pulmonary blood flow after one hour of "lung conditioning" in exteriorized fetal lambs, but the dramatic improvement in lung function reported by Solca et al. (53) was not verified. Furthermore these authors reported an increased leak of albumin from the vascular space to the lung interstitium and airways.

\subsubsection{Possible mechanisms for the improvement of lung function by lung condi- tioning.}

Although the mechanism for the improvement of compliance was not explained, it may be hypothesized that a prolonged inspiratory time as is used in lung conditioning would lead to a larger inflation volume. A larger inflation volume might improve lung function by one or more of the following mechanism:

A) a more even distribution of air within the lungs (58),(59) (it may overcome the inflation time constants of the peripheral lung units).

B) may aid to fluid clearance from the lungs.

C) recruitment and/or distension of more alveoli.

D) air inflation as a physical stimulus for surfactant release in alveoli (60),(61).

E) and in the end facilitation of the establishment of an adequate functional residual capacity (FRC) (62).

\section{Ad A: Time constant}

Lung conditioning may help to overcome the time constants of more peripheral lung units and cause a more even distribution of air within the lungs. The time constant of a lung unit is a measure of how quickly pressures in the proximal airways (or ventilator tubing) can be equilibrated in the alveoli. The time constant of a lung unit (T) is calculated by multiplying lung compliance $(\mathrm{C})$ by resistance $(\mathrm{R})$.

$$
\mathrm{T}=\mathrm{C} \times \mathrm{R}
$$

After three times the time constant a level of $95 \%$ of the pressure in the proximal airways is measured in the alveoli. In a newborn with hyaline membrane disease the compliance is decreased and resistance is unchanged, consequently the time constant is shortened. In an early stage of the disease the time constant may be as short as $0.05 \mathrm{sec}$ (63). However, Olinsky et al. (23), reported a time constant of more than one second in the premature lung. Also, the time constant during resuscitation of newborn infants seems to be longer than during spontaneous onset of respiration by the infant (58), indicating a need of a more prolonged inflation time during mechanical ventilation. Moreover, in pulmonary disease where greater variation of regional time constants exist inspired gas is preferentially distributed to those alveoli with short time constants. This tendency to uneven distribution is accentuated by increasing inspiratory flow rates. A pause at the end of such a inspiration allows for a redistribution of gas from alveoli with short time constants to those with longer time constants (64). 


\section{Ad B: Fluid clearance}

Malo reported a redistribution of intra-alveolar edema fluid to the interstitium by applying a high mean airway pressure (65).

\section{Ad C: Recruitment of alveoli}

The relationships between lung volume, oxygenation, and volume history have been studied by several investigators. It has been generally accepted that changes in the surface area of an alveolus during expansion and contraction of the lung, lead to hysteresis in wall tension, which in its turn results in pressure-volume (PV) curves (66). Gil et al. (67), showed that changes in lung volume are accompanied by complex changes in the geometry of the peripheral airspaces: Crumpling of the alveolar surface at low lung volumes. Pleating of septa in alveolar corners was observed at all inflation degrees. Recruitment-derecruitment, changes in shape through pleating and balloon-like distension prevail at volumes over $80 \%$ of total lung capacity (TLC).

At relatively low pressures $(\max \mathrm{P}=16 \mathrm{~mm} \mathrm{Hg}$ ) total alveolar volume is determined by the number of open alveoli, which in turn is a function of pressure (68). Hence, in low air-filled lungs changes in lung volume seem to occur in large part by recruitment and de-recruitment of alveoli. In airfilled lung volumes greater than $50 \%$ TLC, after an initial expansion to $100 \%$ TLC, alveoli behave elastically. Anthonisen (69) demonstrated a linear decrease in pulmonary shunt flow $(\mathrm{Qs} / \mathrm{Qt})$ with increases in lung volume (up to $70 \%$ total lung capacity), suggesting progressive recruitment of alveoli with a wide range of opening pressures. During deflation from total lung capacity, Qs/Qt was insensitive to change in lung volume, suggesting that in the normal lung, gas exchanging units once recruited were stable and markedly resistant to collapse.

However, in the degassed lung alveolar recruitment is important during the entire initial inflation. Alveoli are recruited, largest first, on initial inflation of a degassed lung with air, but then no de-recruitment is noted on deflation from TLC until relatively low volumes are reached (70).

In conclusion, under normal physiologic conditions when lung volume is above FRC, recruitment and de-recruitment of alveoli is probably not an important mechanism of volume change. Anthonisen (69) concluded that surface forces are largely responsible for PV hysteresis in the normal lung.

However, in any experimental or disease state where the ability of pulmonary surfactant materials to lower surface tension and stabilize alveoli are diminished, de-recruitment and recruitment of alveoli will likely play an important role. Neilson and Olsen (66) have suggested that in the sick lung, due to alveolar instability, recruitment and derecruitment become important contributors to PV hysteresis in the tidal range. Analogous to Anthonisen's study in the degassed lung (69), a progressive but not necessary linear recruitment of gas exchanging air space can be expected with increases in airway pressure. Prolongation of inspiratory time by lung conditioning may improve recruitment by opening airways or alveoli. 
Ad D: Air inflation

Lung expansion is reported to be a physical stimulus for surfactant release in the alveoli $(60),(61)$.

Ad E: Formation of an adequate functional residual capacity (FRC)

"Lung conditioning" might have improved lung function by increasing the volume of the functional residual capacity (FRC), which is small in neonates, especially in premature infants. The intraalveolar pressure $(\mathrm{P})$ needed to counteract the tendency of the alveoli to collapse is given by the Laplace relationship:

$$
P=2 \times \gamma / r
$$

$\gamma$ (surface tension) is determined by the presence or absence of surfactant. The ' $r$ ' is the radius of the alveolus. The bigger the radius i.e. the more the alveolus is already expanded, the less pressure will be required to maintain its size and to further expand the alveolus. The premature infant suffering from RDS must generate very high negative intrathoracic pressures to expand and stabilize its alveoli. This leads to an increasing work of breathing often resulting in respiratory failure. It could be hypothesized that when the establishment of an adequate FRC is facilitated, less pressure will be required to prevent alveolar collapse.

\subsection{Review of reported effects of prolongation of inspiratory time}

Reynolds (71), Herman (72), and Lachmann et al. (73),(74) used prolonged inspiratory times or reversed inspiration/expiration ratio's when ventilating newborns during the early phase of RDS. Since the time constant is short in RDS a prolongation of inspiration will cause a elevation of the tidal volume, leading to a better oxygenation without needing to use a high peak inspiratory pressure or high oxygen concentration. This concept can also be applied to the resuscitation procedure.

According to Milner and Saunders (4) the mean inflation volume of the first breath in a spontaneously breathing newborn is about $44.6 \mathrm{ml}$, from which $15.3 \mathrm{ml}$ remains in the lungs after expiration. This volume is delivered in $583(290-1400) \mathrm{msec}(62)$. It has been found that during resuscitation of mostly full-term babies using an endotracheal tube and applying an inflation pressure of $30 \mathrm{~cm} \mathrm{H}_{2} \mathrm{O}$ for 1 second resulted in a volume of $18.6 \mathrm{ml}$ (range $0-62.5$ ) (75). The FRC was usually not formed until the onset of the baby's own respiratory efforts. Inflation volume tracings showed that air continues to enter the lungs at the end of the inflation, suggesting that better aeration could be achieved by maintaining pressure for a longer period of time. In vaginally delivered full-term infants a significant correlation has been shown between first inspiratory volume and FRC at the end of the first breath $(p<0.004)$. No significant correlation was found between first inspiratory pressure and FRC. However a calculated index of inspiratory pressure and time was significantly correlated to FRC (62). 
Moreover, Vyas et al. (76) reported that when a pressure of $30 \mathrm{~cm} \mathrm{H}_{2} \mathrm{O}$ is applied, the volume reached by the spontaneously breathing baby can be matched by prolonging the inflation pressure for up to five seconds in the asphyxiated newborn infant (mean: $33.6 \mathrm{ml}$ ). Also all babies formed a FRC (mean: $15.9 \mathrm{ml}$ ) at the end of the first inflation. In short, when prolonged inflation is applied a FRC might be reached at a larger inflation volume. The pressure and energy necessary to build up a FRC and to counteract collapse are smaller. This is defined in the relationship of Laplace.

Augmented inspirations (Head's paradoxical reflex) can be provoked by lung inflation in human neonates (77). Mead and Collier (78) demonstrated this reflex to be important in increasing lung compliance and suggested that it may do so by reopening collapsed airways. Greenough and Morley (79) studied the possible stimulating effects of this reflex in ventilated premature infants suffering from RDS or bronchopulmonary dysplasia. In this study infants treated with theophylline had an increase in the frequency of elicitation of provoked augmented inspirations and also had more compliant lungs than matched controls.

When lungs are kept at low volumes the alveolar surface tension increases very slowly (80). Under normal in vivo conditions, a rising alveolar surface tension can probably be restored to very low values by a deep sigh, involving maximal inflations of the lungs followed by deflation to FRC. During long-term artificial ventilation, intermittent sighing is essential for preventing a gradual fall in lung compliance associated with alveolar collapse (78). Ferris and Pollard (81) suggested that sighs are necessary to prevent atelectasis. They found that inflations of $30 \mathrm{~cm} \mathrm{H} \mathrm{H}_{2} \mathrm{O}$ for two to three seconds increased total respiratory compliance in poliomyelitic patients in tank respirators. In anaesthetized man sighs restore lung compliance and improve blood gas exchange, presumably by reversing atelectasis (82).

\subsection{Possible negative effects of prolonged inspiration on cardiac output}

An increase in the normal negative intrathoracic pressure, as in inspiration, increases the pressure gradient along which blood flows to the heart. On the contrary, during inspiration produced by positive airway pressure, the pressure on the surface of the lungs and heart is elevated relative to atmospheric pressure. The increase in pleural pressure decreases venous return and accordingly decreases cardiac output. Thus, cardiac output correlates inversely with intrapleural pressure. Meaning that a decrease in lung compliance could possibly have a protective effect; pleural pressure is less elevated at the same airway pressure. Such a situation exists in the premature lamb.

In short, applying prolonged inspirations with relatively high pressures could depress cardiovascular function. 


\subsection{Possible negative effects of mechanical ventilation on alveolar $\mathrm{CO}_{2}$}

The lung is not a physiologically homogenous organ regarding ventilation (V) and perfusion (Q). Areas of high and low V/Q exist simultaneously. In the premature ventilated lamb there are large variations in pulmonary blood flow in different lung areas (83). Ventilation of underperfused areas and persistence of increased high pulmonary pressure after birth occurs in hyaline membrane disease. When there is no flow of desaturated blood through the pulmonary capillary bed, there is no delivery of $\mathrm{CO}_{2}$ to the lung via the mixed venous blood and no uptake and removal of $\mathrm{O}_{2}$. No perfusion results in alveolar $\mathrm{CO}_{2}$ and $\mathrm{O}_{2}$ tensions approximately to those in humidified inspired gas. Consequently: ventilation with room air or $100 \%$ oxygen results in the elimination of $\mathrm{CO}_{2}$ stores from the not perfused areas of the lung via the airway and a severe reduction in alveolar $\mathrm{CO}_{2}$ tension. This in turn leads to a decrease in hydrogen ion and bicarbonate concentration with the development of an extracelluar alkalosis and/or bicarbonate depletion which could induce a dysfunction of the cellular metabolism and lung tissue. If pulmonary lesion progresses, more blood shunts through the lungs without gas exchange. This further accentuates the preexisting regional hypoperfusion and contributes to further extremes in focal respiratory alkalosis within the lung parenchyma. Kolobow et al. (84),(85) have described edema formation, haemorrhage and pulmonary infarction within hours as a result from extreme alveolar alkalosis.

Hence, during neonatal resuscitation when $100 \% \mathrm{O}_{2}$ or a $\mathrm{CO}_{2}$ free gas mixture is used the chances of lung injury might be increased. By adding $\mathrm{CO}_{2}$ to the inspiratory gas mixture during lung conditioning we will attempt to assure an adequate alveolar $\mathrm{CO}_{2}$ tension and perhaps prevent alveolar epithelial damage.

\subsection{Hypothesis}

We hypothesized that the application of lung inflations with a prolonged inspiratory time in premature lungs would lead to an increased lung volume (FRC) and/or lung distension. Consequently lower inspiratory pressures and oxygen concentrations could be used, resulting in less morbidity and mortality. This would be reflected in the improvement of gas exchange and physiological pulmonary parameters, acute morbidity and lung pathology. 


\subsection{Animal models used to study respiratory distress syndrome (RDS) of the human neonate.}

\subsubsection{The premature lamb}

In our studies the premature lamb of 128-133 days gestational age was chosen as experimental animal. Full term pregnancy is reached at 147 days gestation. Date-mated "Dutch Texel" breed ewes were used, therefore the gestational age of the fetuses was exactly known.

The size of the premature lamb is approximately that of a full term infant, surgical techniques are easy and blood volume is large enough to tolerate frequent blood sampling. The lamb resembles the respiratory distress syndrome in the human within a wide range of gestational ages, ranging from 110 to 143 days. Stahlman et al. (86) described a syndrome of respiratory failure in prematurely delivered lambs similar by physiologic and anatomic criteria to the respiratory distress syndrome of the premature infant. They reported lambs with severe respiratory failure to have estimated gestational ages of $134 \pm 10$ days. Shaffer et al. (87) described immaturity of lung function in lambs at gestational ages of 138 to 143 days. According to Jobe et al. (88) most lambs delivered at gestational ages of 133-136 days will have a degree of respiratory failure very similar to that encountered clinically in premature infants. In his series around $20 \%$ of the lambs presented very severe respiratory failure. Reynolds et al. (89) described a respiratory distress syndrome in lambs between 125 and 129 days gestation that was comparable to that seen in prematurely delivered infants. According to Sandberg et al. (90) seven out of ten lambs with a gestational age of 129-131 days developed histologically verified hyaline membrane disease. However, Born et al. (91), reported that already by 110 days pulmonary distensibility increased substantially and therefore independent survival was possible in the premature lamb.

Biochemical estimates of fetal lung fluid from premature lambs indicated that very little surfactant is detectable before about 130 days of gestation (92),(93). Mescher et al. (93) reported that the amount of surfactant in the fetal lung fluid increases gradually until 135 days gestation, and then increases rapidly until term. Differentiated type II cells containing lamellar bodies appear at $22-26$ weeks (55\%-65\% of gestation) in humans, and at 120 days ( $80 \%$ of gestation) in fetal lambs (94). In the lamb at 120 days only about $10 \%$ of type II cells contain lamellar bodies. At 125-130 days the number of lamellar bodies increases rapidly to an average of 4 per type II cell and by term to 6 per cell (95),(96). At birth there is a 10- to 15-fold increase in alveolar surfactant associated with lung expansion and air breathing (97).

Besides surfactant secreting ability, lung structure plays an important role in lung function. In the fetal lamb type II pneumocytes do not appear in large numbers until after about 120 days of gestation (98), however, the extent of distal airway development is advanced relative to the human fetus. Between 80-120 days gestation the airways of 
the fetal sheep are mature enough to hold most of what will be the future air space volume.

In conclusion, the underdeveloped, surfactant deficient alveoli and immature airways in the lamb before $\sim 125$ days gestation limits the effectiveness of conventional gas ventilation techniques in supporting pulmonary gas exchange. Lambs delivered before this age rapidly deteriorate and die because of pneumothorax or the cascading effects of ventilation-perfusion mismatch, both of which impede oxygenation, $\mathrm{CO}_{2}$ removal and acid-base balance.

Lambs at 133-136 days of gestation are stable cardiovascularly. They have stable blood pressures with mean values of $\pm 55 \mathrm{~mm} \mathrm{Hg}$ and heart rates of \pm 175 beats per minute for at least the first $10 \mathrm{~h}$ of life (88), though lambs with respiratory failure will have lower systemic blood pressures.

\subsubsection{Other premature and adult animal models}

A number of animal models can mimic the problems caused by the immature lungs of premature infants. These are mainly premature newborn animals, but also some adult animals. Lachmann et al. (99) developed a lung lavage model, to cause surfactant deficiency in the adult animal. This can be done either by mechanical removal or impairment of surfactant. Adult animals were introduced because generally it is easier easier to operate upon them, and because lung structure is already mature. However, lung lavage does not only cause surfactant deficiency, but can also induce considerable airway damage leading to a chemical pneumonitis (100). Besides, the lung possesses a very complex structure, and the total structural entity determines the mechanical behaviour of the whole organ. The neonatal lung can not be considered as a small adult lung. Fetal and neonatal lungs are organs rich in nonfibrous interstitium with few capillaries and peripheral airways. They change their structure progressively towards a highly vascularized organ, poor in nonfibrous interstitial tissue, relatively rich in fibres and with a tremendously increased ratio of peripheral to central airways.

Besides the lamb, a number of other species of animals have been used when delivered prematurely and ventilated for the study of lung function. For example: prematurely delivered goats (101), pigs with "Barker syndrome" (102), rhesus monkeys (103),(104), baboons (105),(106) and rabbits (107). These species have syndromes of respiratory failure similar to that in premature lambs. In all studies these premature animals go rapidly into respiratory failure, unless they are treated with surfactant. Severe lesions of the broncho-alveolar epithelium were found in artificially ventilated premature animals (44).

The premature baboon as a model of RDS probably approaches the human premature newborn infant the most, but special breeding techniques and a long gestation make these models more expensive. Prematurely delivered rabbits can be successfully treated with surfactant and ventilated, however, vascular access for multiple blood sampling is impossible. While pulmonary mechanics can be measured, pulmonary gas exchange and cardiovascular status can not be evaluated. Another problem of the premature rabbit is that there is large variation in lung maturity, independent of the gestational age. 
The sheep model is easier to use than the monkey because of cost, availability and size of the premature animal. While premature goats and pigs are smaller than lambs, the larger litter size might be useful for certain types of studies. We used the premature lamb as experimental animal. All experimental protocols used for this thesis have been approved by the animal ethical committee of the Rijksuniversiteit Limburg. Composition of treatment and control groups and the endpoints of this study are depicted in Table 1.2 .

\subsection{Aims of the study}

The purpose of this investigation was to study whether applying lung conditioning prophylactically could improve lung function of premature lambs that are at high risk for RDS. We used the same technique as was introduced in the fetal lamb by Solca et al. (53). This technique was called "accelerated lung conditioning". We will call it lung conditioning or sustained inflations (SI).

We wanted to investigate:

1) the effects of time of application of lung conditioning on lung function (Chapter 2 and 3 )

2) to compare the effects of single versus multiple application of lung conditioning on lung function (Chapter 2)

3) the cardiovascular effects of lung conditioning (Chapter 4)

4) the effect of prevention of alveolar alkalosis on lung morphology (Chapter 6)

5) the effect of lung conditioning on lung morphology (Chapter 5) 
Table 1.2 Compostion of the treatment and control groups and endpoints in this study. $G=$ group.

Composition of the groups of premature lambs

Endpoints of this study

G Time postnatally of lung conditioning

1

within 15 minutes after birth birth and repeated each hour for three hours

3

once at four hours postnatally 4 control with disconnection $25(n=10)$

5

control without manipulations $25(n=11)$

$25(n=10)$

$35(n=8)$ $35(n=8)$

$25(n=7)$

Initial PIP

$25(n=8)$
Mortality

Lung compliance

Lung morphology

Physiological parameters

Morbidity
$30(n=8)$
postnatally
B control to A
$30(n=8)$
A within 30 seconds

control to A

Newborn lambs (two groups)

I

Alveolar normocapnia during hyperventilation $(n=6)$

Endpoint

II Alveolar hypocapnia during hyperventilation $(n=6)$ 


\section{References}

1. Karlberg P, Adams FH, Geubelle F, Wallgren G. Alteration of the infants's thorax during vaginal delivery. Acta Obstet Gynecol Scand 1962;41:223-229.

2. Karlberg P, Cherry RB, Escardo FE, Koch G. Respiratory studies in newborn infants. II. Pulmonary ventilation and mechanics of breathing in the first minutes of life, including the onset of ventilation. Acta Paediatr Scand 1962;51:121-136.

3. Agostoni E, Taglietti A, Ferrario Agostoni A, Setnikar I. Mechanical aspects of the first breath. J Appl Physiol 1958;13:344-348.

4. Milner AD, Saunders RA. Pressure and volume changes during the first breath of human neonates. Arch Dis Child 1977;52:918-924.

5. Bosma JF, Lind J, Genz N. Motions of the pharynx associated with initial aeration of the lungs of the newborn infant. Acta Paediatr Scand 1959;117:117-122.

6. Jaijkka S. Capillary erection and the structural appearance of foetal and neonatal lungs. Acta Peadiatr (Stockholm) 1958;47:484-500.

7. Mortola JP, Fisher JT, Smith JB, Fox GS, Weeks S, Willis D. Onset of respiration in infants delivered by cesarian section. J Appl Physiol 1982;52:716-724.

8. Richards CC, Backman L. Lung and chest wall compliance of apnoeic paralysed infants. J Clin Invest 1961;40:273-276.

9. Avery ME, Cook CD. Volume-pressure relationships of lungs and thorax in fetal, newborn and adult goats. J Appl Physiol 1961;16:1034-1038.

10. Fagan DG. Shape changes in static V-P loops for children's lungs related to growth. Thorax 1977;32:198-202.

11. Nelson NM, Prod'hom LS, Cherry RB, Lipsitz PJ, Smith CA. Pulmonary function in the newborn infant. V Trapped gas in the normal infant's lung. J Clin Invest 1963;42:1850-1857.

12. Thibeault DW, Wong MM, Auld PAM. Thoracic gas volume changes in premature infants. Pediatrics 1967;40:403-411.

13. Grossman G, Robertson B. Lung expansion and the function of the alveolar lining layer in the full term newborn rabbit. Acta Paediatr Scand 1975;64:7-16.

14. Scarpelli EM. Intrapulmonary foam at birth, an adaptational phenomenon. Pediatr Res 1978;12:1070-1076.

15. Saunders RA, Milner AD, Hopkin IE. A study of the role of air trapping in the establishment of the functional residual capacity by analysis of pressure/volume and flow/volume loops. Early Human Dev 1978;2(2):107-114.

16. Milner AD, Saunders RA, Hopkin IE. Is air trapping important in the maintenance of the functional residual capacity in the hours after birth? Early Human Dev 1978;2:97-105.

17. Boon AW, Ward-McQuaid JMC, Milner AD, Hopkin IE. Thoracic gas volume, helium functional residual capacity and air-trapping in the first six hours of life: the effect of oxygen administration. Early Human Dev 1981;5:157-166.

18. Avery ME, Frank NR, Gribetz, I. The inflationary force produced by pulmonary vascular distension in excised lungs. The possible relation of this force to that needed to inflate the lungs at birth. J Clin Invest 1959;38:456-462. 
19. Saunders RA, Milner AD. Pulmonary pressure/volume relationships during the last phase of delivery and the first postnatal breaths in the human subject. J Pediatr 1978;93:667-673.

20. Kosch PC, Stark AR. Determination and homeostasis of functional residual capacity (FRC) in infants. Physiologist 1979;22(4):71 (Abstract).

21. Harding R, Johnson P, McClelland ME. The expiratory role of the larynx during development and the influence of behavioral state. In: Central Nervous Control Mechanisms in Breathing, eds. C von Euler and H Lagercrantz. Oxford, UK: Pergamon, 1979, 357-358.

22. Fisher JT, Mortola JP, Smith JB, Fox GS, Weeks S. Respiration in newborns: development of the control of breathing. Am Rev Respir Dis 1982;125:650-657.

23. Olinsky A, Bryan $\mathrm{MH}$, Bryan AC. Influence of lung inflation on respiratory control in neonates. J Appl Physiol 1974;36:426-429.

24. Hull D. Recent advances in Paediatrics. 4th ed. 1972: 74-76.

25. Muller N, Volgyesi G, Becker L, Bryan MH, Bryan AC. Diaphragmatic muscle tone. J Appl Physiol 1979;47:279-284.

26. Gerhardt T, Bancalari E. Chest wall compliance in full term and premature infants. Acta Paediatr Scand 1980;69:359-364.

27. Humphreys PW, Normand ICS, Reynolds EOR, Strang LB. Pulmonary lymph flow and the uptake of liquid from the lungs of the lambs at the start of breathing. J Physiol London 1967;193:1-29.

28. Humphreys PW, Strang LB. Effects of gestation and prenatal asphyxia on pulmonary surface properties of the foetal rabbit. J Physiol London 1967;192:53-62.

29. Strang LB. Growth and development of the lung: fetal and postnatal. Annu Rev Physiol 1977;39:253-276.

30. Bland RD, McMillan DD, Bressack MA, Dong L. Clearance of liquid from lungs of newborn rabbit. J Appl Physiol 1980;49(2):171-177.

31. Walters DV, Olver RE. The role of catecholamines in lung liquid absorption at birth. Pediatr Res 1978;12:239-242.

32. Bland RD, McMillan DD, Bressack MA. Labor decreases lung water content of newborn rabbits. Am J Obstet Gynecol 1979;134:364-367.

33. Bland RD, Hansen TN, Haberkern CM et al. Lung fluid balance in lambs before and after birth. J Appl Physiol 1982;53:992-1004.

34. Faridy EE. Effect of distension on the release of surfactant in excised dogs' lungs. Respir Physiol 1976;27:99-114.

35. Oyarzun MJ, Clements JA. Ventilatory and cholinergic control of pulmonary surfactant in the rabbit. J Appl Physiol 1977;43:39-45.

36. Oyarzun MJ, Clements JA. Control of lung surfactant by ventilation, adrenergic mediators, and prostaglandins in the rabbit. Am Rev Respir Dis 1978;117:879891.

37. Hildebran JN, Goerke J, Clements JA. Surfactant release in excised rat lung is stimulated by air inflation. J Appl Physiol 1981;51(4):905-910. 
38. Faridy EE, Thliveris JA, Morris GS. Relationship between lung intra and extracellular DSPC in fetal and neonatal rats. Respir Physiol 1981;45:55-66.

39. Goerke J, Clements JA. Alveolar surface tension and lung surfactant. In: Handbook of Physiology; The respiratory system vol.3: Mechanics of breathing part I. eds. Fishman AP, Macklem PT, Mead J. Bethesda, Maryland 1986, 247-261.

40. Hills, B.A. Editorial. What is the true role of surfactant in the lung? Thorax 1981;36:1-4.

41. Wyszogrodski I, Kyei-aboagye K, Taesch Jr, Avery ME. Surfactant inactivation by hyperventilation: conservation by end-expiratory pressure. J Appl Physiol 1975;38(3):461-466.

42. Avery ME, Mead J. Surface properties in relation to atelectasis and hyaline membrane disease. Am J Dis Child 1959;97:517-523.

43. Scarpelli EM, Mautone AJ. The surfactant system and pulmonary mechanics. In: Pulmonary Surfactant, eds. Robertson B, van Golde LMG, Batenburg JJ, Elsevier Science Publishers, Amsterdam 1984, 119-170.

44. Nilsson RG, Grossman G, Robertson B. Lung surfactant and the pathogenesis of neonatal bronchiolar lesions induced by artificial ventilation. Pediatr Res $1978 ; 12: 249-255$.

45. Jobe A, Ikegami M, Jacobs H, Jones S, Conaway D. Permeability of premature lamb lungs to protein and the effect of surfactant on that permeability. J Appl Physiol 1983;55:169-176.

46. Taghizadeh A, Reynolds EOR. Pathogenesis of bronchopulmonary dysplasia following hyaline membrane disease. Am J Path 1976;82:241-264.

47. Tooley WH. Epidemiology of bronchopulmonary dysplasia. J Pediatr 1979;95:851-855.

48. Collaborative group on antenatal steroid therapy. Effects of antenatal dexamethason administration on the prevention of respiratory distress syndrome. Am J Obstet Gynecol 1981;141:276-286.

49. Fujiwara T, Konishi M, Chida S et al. Surfactant replacement therapy with a single postventilatory dose of a reconstituted bovine surfactant in preterm neonates with respiratory distress syndrome: final analysis of a multicenter, doubleblind, randomized trial and comparison with similar trials. Pediatrics 1990;86:753-764.

50. Kolobow T, Solca M, Pesenti A, Buckhold D, Pierce JD. The prevention of hyaline membrane disease (HMD) in the preterm fetal lamb through the static inflation of the lungs: the conditioning of the fetal lungs. Trans Am Soc Artif Intern Organs 1980;26:567-571.

51. Pesenti A, Kolobow T, Buckhold DK, Pierce JE, Huang H, Chen V. Prevention of hyaline membrane disease in premature lambs by apnoeic oxygenation and extracorporeal carbon dioxide removal. Intens Care Med 1982;8:11-17.

52. Solca M, Kolobow T, Huang H, Pesenti A, Buckhold D, Pierce JE. Management of the antenatal preterm fetal lung in the prevention of respiratory distress syndrome in lambs. Biol Neonate 1983;44:93-101. 
53. Solca M, Kolobow T, Huang HH, Chen V, Buckhold DK, Pierce JE. Respiratory distress syndrome in immature lambs. Prevention through antenatal accelerated conditioning of the lung. Am Rev Respir Dis 1984;129:979-984.

54. Mitzner WJ, Johnson WC, Scott R, London WT, Palmer AE. Effect of betamethasone on pressure-volume relationship of fetal rhesus monkey lung. J Appl Physiol 1979;47:377-382.

55. Wolfson MR, Tran N, Bhutani VK, Shaffer TH. A new experimental approach for the study of cardiopulmonary physiology during early development. J Appl Physiol 1988;65(3):1436-1443.

56. Jonson JWC, Mitzner W, London WT, Palmer AE, Scott R, Kearney K. Glucocorticoids and the rhesus fetal lung. Am J Obstet Gynecol 1978;130:905916.

57. Ikegami M, Jobe A, Berry D, Elkady T, Pettenazzo A, Seidner S. Effects of distension of the preterm fetal lamb lung on lung function with ventilation. Am Rev Respir Dis 1987;135:600-606.

58. Milner AD, Vyas $\mathrm{H}$. Medical progress. Lung expansion at birth. J Pediatr 1982;101(6):879-886.

59. Fuleihan SF, Wilson RS, Pontoppidan $\mathrm{H}$. Effect of mechanical ventilation with end-inspiratory pause on blood-gas exchange. Anesth Analg 1976;55(1):122-130.

60. Lawson EE, Birdwell RL, Huang PS, Taeusch HW. Augmentation of pulmonary surfactant secretion by lung expansion at birth. Pediatr Res 1979;13:611-614.

61. Jacobs $\mathrm{H}$, Jobe A, Ikegami M, Jones S. Accumulation of alveolar surfactant following delivery and ventilation of premature lambs. Exp Lung Res 1985;8:125-140.

62. Vyas H, Field D, Milner AD, Hopkin IE. Determinants of the first inspiratory volume and the functional residual capacity at birth. Pediatr Pulmonol 1986;2:189-193.

63. Reynolds, E.O.R. Effect of alterations in mechanical ventilator settings on pulmonary gas exchange in hyaline membrane disease. Arch Dis Child 1971;46:152159.

64. Giordano AJ, Diaz W, Kahn RC. Prolongation of the inspiratory phase in the treatment of unilateral lung disease. Anesth Analg 1988;67:593-595.

65. Malo J. How does positive end-expiratory pressure reduce intrapulmonary shunt in canine pulmonary edema. J Appl Physiol 1984;57:1002-1010.

66. Neilson D, Olson BB. The role of alveolar recruitment and derecruitment in pressure volume hysteresis in lungs. Respir Physiol 1978;32:63-77.

67. Gil J, Bachofen H, Gehr P, Weibel ER. Alveolar volume-surface area relation in air- and saline-filled lungs fixed by vascular perfusion. J Appl Physiol 1979;47:990-1001.

68. Gil J, Weibel ER. Morphological study of pressure-volume hysteresis in rat lungs fixed by vascular perfusion. Respir Physiol 1972;15:190-213.

69. Anthonisen NR. Effect of volume and volume history of the lungs on pulmonary shunt flow. Am J Physiol 1964;207:235-238. 
70. Radford EP Jr. Influence of physicochemical properties of the pulmonary surface on stability of alveolar air spaces and on static hysteresis of the lungs. In XXII International Congress of Physiological Sciences, Symposia and special lectures, Leiden; XXII Int. Cong. Physiol. Sci., Vol.1 1962.

71. Reynolds EOR. Effect of alterations in mechanical ventilator settings on pulmonary gas exchange in hyaline membrane disease. Arch Dis Child 1971;46:152-159.

72. Herman S, Reynolds EOR. Methods for improving oxygenation in infants mechanically ventilated for severe hyaline membrane disease. Arch Dis Child 1973;48:612-617.

73. Lachmann B, Grossman G, Freyse J, Robertson B. Lung-thorax compliance in the artificially ventilated premature rabbit neonate in relation to variations in inspiration:expiration ratio. Pediatr Res 1981;15:833-838.

74. Lachmann B, Berggren P, Curstedt T, Grossman G, Robertson B. Combined effects of surfactant substitution and prolongation of the inspiration phase in artificially ventilated premature newborn rabbits. Pediatr Res 1982;16:921-927.

75. Boon AW, Milner AD, Hopkin IE. Lung expansion, tidal volume and formation of functional residual capacity during resuscitation of asphyxiated neonates. J Pediatr 1979;95:1031-1036.

76. Vyas $\mathrm{H}$, Milner AD, Hopkin IE, Boon AW. Physiological responses to prolonged and slow rise inflation. J Pediatr 1981;99:635-639.

77. Cross KW, Klaus K, Tooley WH, Weisser K. The response of the newborn baby to inflation of the lungs. J Physiol London 1960;151:551-565.

78. Mead J, Collier C. Relation of volume history of lungs to respiratory mechanics in anesthetized dogs. J Appl Physiol 1959;14(5):669-678.

79. Greenough A, Morley CJ. Provoked augmented inspirations in ventilated premature infants. In: The physical development of the fetus and newborn. 1985 Academic Press, London, p 263-266.

80. Schurch S. Surface tensions at low lung volumes: dependence on time and alveolar size. Respir Physiol 1982;48:339-355.

81. Ferris GF, Pollard DS. Effect of deep and quiet breathing on pulmonary compliance in man. J Clin Invest 1960;39:143-149.

82. Bendixen HH, Hedley Whyte J, Lavar MB. Impaired oxygenation in surgical patients during general anaesthesia with controlled ventilation. $\mathrm{N}$ Engl $\mathrm{J}$ Med 1963;269:991-994.

83. Berry D, Jobe A, Jacobs H, Ikegami M. Distribution of pulmonary blood flow in relation to atelectasis in premature ventilated lambs. Am Rev Respir Dis 1985;132:500-503.

84. Kolobow T, Spragg R, Pierce J. Massive pulmonary infarction during total cardiopulmonary bypass in unanesthetized spontaneously breathing lambs. Int J Art Organs 1981;4(2):76-81.

85. Kolobow T, Fumagalli R, Arosio P, Chen V, Buckhold D, Pierce J. Severe pulmonary capillary alkalosis during states of low pulmonary blood flow: a 
possible cause of lung damage. Life Support Systems. Proceedings IX Annual Meeting ESAO, Brussels, Belgium, 1982;169-171.

86. Stahlman M, LeQuire VS, Young WC et al. Pathophysiology of respiratory distress in newborn lambs. Am J Dis Child 1964;108:375-393.

87. Shaffer TH, Delivoria-Papadopoulos M, Arcinue E, Paez P, Dubois AB. Pulmonary function in premature lambs during the first few hours of life. Respir Physiol 1976;28:179-188.

88. Jobe AH, Ikegami M, Jacobs HC, Jones SJ. Surfactant pool sizes and severity of respiratory distress syndrome in prematurely delivered lambs. Am Rev Respir Dis 1983;127:751-755.

89. Reynolds EOR, Jacobson HN, Motoyama EK et al. The effect of immaturity and prenatal asphyxia on the lungs and pulmonary function of newborn lambs: The experimental production of respiratory distress. Pediatrics 1965;35:382-392.

90. Sandberg K, Edberg K, Benton W, Silberberg A, Sladek M, Sundell HW. Surfactant improves gas mixing and alveolar ventilation in preterm lambs. Pediatr Res 1991;30(2):181-189.

91. Born GVR, Dawes GS, Mott JC. The viability of premature lambs. J Physiol 1955;130:191-212.

92. Egberts J, Rethmeier HB. Pressure-volume curves of lamb lungs and the lecithinsphingomyelin ratios of lung fluid. Biol Neonate 1975;27:208-220.

93. Mescher EJ, Platzker ACG, Ballard PL, Kitterman JA, Clements JA, Tooley WH. Ontogeny of tracheal fluid, pulmonary surfactant, and plasma corticoids in the fetal lamb. J Appl Physiol 1975;39:1017-1021.

94. Burri PH. Development and the growth of the human lung. In: Handbook of Physiology, Section 3: The Respiratory System. Vol 1: Circulation and Nonrespiratory Functions. Eds. Fishman AP, Fisher AB, Geiger SR, Am Physiological Society, Bethesda, Maryland, 1985, p 1-46.

95. Kikkawa Y, Motoyama EK, Cook CD. Ultrastructure of lungs of lambs: The relation of osmiophilic inclusions and alveolar lining layer to fetal maturation and experimentally produced respiratory distress. Am J Pathol 1965;47:877-903.

96. Alcorn DG, Adamson TM, Maloney JE, Robinson PM. A morphologic and morphometric analysis of fetal lung development in the sheep. Anat Rec 1981;202:655-667.

97. Jacobs H, Jobe A, Ikegami M, Jones S. Accumulation of alveolar surfactant following delivery and ventilation of premature lambs. Exp Lung Res 1985;8:125-140.

98. Brumley GW, Chernick V, Hodson WA, Normand C, Fenner A, Avery ME. Correlations of mechanical stability, morphology, pulmonary surfactant, and phospholipid content in the developing lamb lung. J Clin Invest 1967;46:863-873.

99. Lachmann B, Robertson B, Vogel J. In vivo lavage as an experimental model of the respiratory distress syndrome. Acta Anaesth Scand 1980;24:231-236.

100. Hamilton PP, Onayemi A, Smyth JA, Gillan JE, Cutz E, Froese AB, Bryan AC. 
Comparison of conventional and high-frequency ventilation: oxygenation and lung pathology. J Appl Physiol 1983;55:131-138.

101. Egan EA, Nelson RM, Beale EF. Lung solute permeability and lung liquid absorption in premature ventilated fetal goats. Pediatr Res 1980;14:314-318.

102. Bradley $\mathrm{R}$, Wrathall $\mathrm{AE}$. Barker (neonatal respiratory distress) syndrome in the pig: the ultrastructural pathology of the lung. J Path 1977;122:145-151.

103. McAdams AJ, Coen R, Kleinman LI, Tsang R, Sutherland J. The experimental production of hyaline membranes in premature rhesus monkeys. Am J Path 1973;70:277-290.

104. Kessler DL, Truog WE, Murphy JH, Palmer S, Standaert TA, Woodrum DE, Hodson WA. Experimental hyaline membrane disease in the premature monkey. Effects of antenatal dexamethason. Am Rev Respir Dis 1982;126:62-69.

105. Meredith KS, DeLemos RA, Coalson JJ, King RJ, Gerstmann DR, Kumar R, Kuehl TJ, Winter DC, Taylor A, Clark RH, Null DM. Role of lung injury in the pathogenesis of hyaline membrane disease in premature baboons. J Appl Physiol 1989;66(5):2150-2158.

106. Coalson JJ, King RJ, Winter VT, Prihoda TJ, Anzueto AR, Peters JI, Johanson WG Jr. $\mathrm{O}_{2}$ - and pneumonia-induced lung injury: I. Pathological and morphometrics studies. J Appl Physiol 1989;67(1):346-356.

107. Schwieler G, Robertson B. Liquid ventilation in immature newborn rabbits. Biol Neonate 1976;29:343-353. 


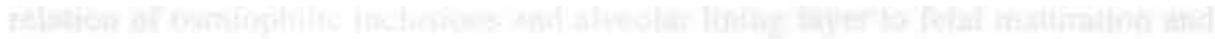

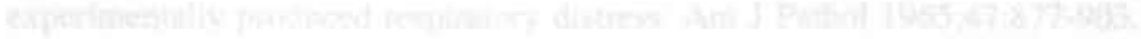




\title{
2 EFFECTS OF SUSTAINED INFLATIONS (SI) ON LUNG FUNC- TION IN PREMATURE NEWBORN LAMBS.
}

\author{
W.A.A. Klöpping-Ketelaars, W.J. Maertzdorf and C.E. Blanco \\ Submitted for publication
}

\subsection{Abstract}

We studied the possibility to improve lung distensibility by applying sustained inflations (SI) during the first hours of age in premature lambs (128-133 days of gestational age, $\mathrm{n}=70$ ). Initially all lambs were mechanically ventilated with $\mathrm{FiO}_{2}=1.0$ and a peak inspiratory pressure (PIP) to keep $\mathrm{PaCO}_{2}$ within $5.5-6.0 \mathrm{kPa}$. SI consisted of disconnecting the ventilator and manually inflating the lungs with a bag during five seconds at a PIP of $35 \mathrm{~cm} \mathrm{H}_{2} \mathrm{O}$ with a mixture of $5 \% \mathrm{CO}_{2}$ and $95 \% \mathrm{O}_{2}$. Each inflation was followed by positive end expiratory pressure (PEEP) of $5 \mathrm{~cm} \mathrm{H}_{2} \mathrm{O}$ for 5 seconds. This procedure was repeated a total of four times. SI was applied in three groups at different times: group 1) once within 15 minutes after birth, group 2) within 15 minutes after birth and repeated each hour for 3 hours, group 3 ) once at 4 hours of age. Two control groups were formed: group 4) as in group 1, except that during disconnection the lungs were inflated at the same pressure as for SI, but with a shorter inspiratory time, group 5) lambs were ventilated without any manipulation.

Eight hours postnatally arterial oxygen tension, mean airway pressure, arterial-alveolar oxygen gradient, oxygenation index, total static compliance, incidence of pneumothorax and mortality were not significantly different between the groups. In conclusion, SI as applied here, showed no significant changes in total static compliance or pulmonary gas exchange at 8 hours of age, nor at any other time during the experiment.

\subsection{Introduction}

Alveolar collapse due to surfactant deficiency causing respiratory distress syndrome (RDS) is the main respiratory problem in premature infants during the neonatal period. Surfactant lowers the surface tension generated at birth when the interface fluid-air is established. In infants with RDS, mechanical ventilation with high inspiratory pressures and high oxygen concentrations is needed to maintain an adequate gas exchange and 
lung function. Often, this conventional treatment for RDS causes complications in premature infants, namely barotrauma and bronchopulmonary dysplasia.

This problem has not yet been resolved, although the incidence of RDS decreased by the use of antenatal steroids and postnatal exogenous surfactant. In 1980 Kolobow et al. (1) reported an improvement in compliance of premature fetal lamb lungs after applying a constant intrapulmonary pressure (lung conditioning), while keeping the umbilical circulation intact. Solca et al. (2) reported that after applying repeated deep insufflations (accelerated conditioning) to fetal lambs, the improvement in static compliance was even faster and morbidity and mortality after birth were lower. The improved compliance was independent of mechanisms associated with surfactant, because the measured surface tension of the alveolar wash after lung conditioning did not change (2),(3). Lung conditioning might have improved lung function by increasing the volume of the functional residual capacity (FRC), which is small in neonates, especially in premature infants. Ikegami et al. (4) also found an increase in compliance after one hour of lung conditioning in exteriorized fetal premature lambs, but the dramatic improvement in lung function during mechanical ventilation as described by Kolobow et al. (1) and Solca et al. (2),(3) was not verified. We studied further this technique in the premature newborn lamb during the first hours of age. We hypothesized that sustained inflations immediately after birth could be used to facilitate the establishment of an adequate FRC, to increase lung distensibility and improve gas exchange. This might lead to the use of lower inspiratory pressures and lower oxygen concentrations and therefore could help reducing barotrauma and decrease the incidence or severity of bronchopulmonary dysplasia.

\subsection{Material and methods}

\subsubsection{Animal preparation}

42 "Texel" ewes were operated at a gestational age of 128-133 days (term=147 days of gestational age). Twenty-eight were twin and fourteen were single pregnancies. At this gestational age lambs are highly susceptible to RDS (5). General anaesthesia was induced with pentobarbital ( $1 \mathrm{~g}$ IV) and maintained with halothane (1\% in a $2: 1$ mixture of nitrous oxide and oxygen). A midline abdominal incision was made under sterile conditions just below the umbilical scar. The fetal head was identified through the uterine wall and gently manipulated to a more anterior position. An incision of approximately eight to ten centimetres was made in the uterus in an area free from cotyledons and large blood vessels. The head of the lamb and a forelimb were exteriorized. An incision in the anterio-lateral part of the fetal neck was made and the external jugular vein and carotid artery were cannulated with $5 \mathrm{~F}$ catheters, which were advanced for approximately $7 \mathrm{~cm}$. The position of the arterial catheter was pre-ductal. The cephalic vein in a forelimb was cannulated with a $5 \mathrm{~F}$ catheter, advanced approximately $3 \mathrm{~cm}$. The trachea was identified and an opening was made in an intercartilage space about 3 
$\mathrm{cm}$ below the thyroid cartilage; approximately $10 \mathrm{ml}$ of tracheal fluid was aspirated via a catheter. This fluid was analyzed for lecithin/sphingomyelin ratio according to a modification of the method described by Gluck et al. (6). An uncuffed endotracheal tube ( 4 or $4.5 \mathrm{~mm} \mathrm{ID)} \mathrm{was} \mathrm{positioned} \mathrm{proximal} \mathrm{of} \mathrm{the} \mathrm{head} \mathrm{bronchus} \mathrm{leading} \mathrm{to} \mathrm{the}$ right cranial lobe and secured with a suture around the trachea. The incisions were closed using a continuous suture. Blood samples were obtained from the arterial line to record the baseline condition of the fetus. The umbilical cord was clamped, ligated and the lamb delivered. Blood from the placenta was withdrawn in a heparinized $(10 \mathrm{U} / \mathrm{ml})$ syringe and it was later used to compensate for blood loss due to sampling during the experiment. In case of a twin or triple pregnancy, the next fetus was delivered as soon as possible using the same procedure.

\subsubsection{Experimental procedure}

The lamb was weighed and transported immediately to a radiant heater where the tracheal tube was connected to a continuous flow, time cycled, pressure controlled, positive pressure ventilator (Amsterdam infant ventilator, Hoekloos, The Netherlands). The period before ventilation usually took about $30-45$ seconds. Initially all the lambs were ventilated with a continuous $\mathrm{O}_{2}$ flow $(8 \mathrm{1} / \mathrm{min}), \mathrm{FiO}_{2}=1.0$, a PIP of 25 or $35 \mathrm{~cm} \mathrm{H} \mathrm{O}$ and a PEEP of $5 \mathrm{~cm} \mathrm{H}_{2} \mathrm{O}$, the respirator rate was 40 per minute and $\mathrm{I}: \mathrm{E}=1: 1$. The inspired gases were humidified and warmed. The first 15 minutes after birth PIP was kept the same, later PIP was adjusted to keep $\mathrm{PaCO}_{2}$ within the range of 5.5 to $6.0 \mathrm{kPa}$. In our initial experimental design we used a PIP of $25 \mathrm{~cm} \mathrm{H}_{2} \mathrm{O}$ during the first 15 minutes $(\mathrm{n}=46) . \mathrm{PaCO}_{2}$ during this period rose to $12.8 \pm 0.6 \mathrm{kPa}$, therefore we decided to start with a PIP of $35 \mathrm{~cm} \mathrm{H} \mathrm{H}_{2} \mathrm{O}$. By using $35 \mathrm{~cm} \mathrm{H}_{2} \mathrm{O}(\mathrm{n}=24)$ as initial PIP, $\mathrm{PaCO}_{2}$ decreased to $5.08 \pm 0.54 \mathrm{kPa} 15$ minutes postnatally. Because an initially higher PIP may have had influence on lung function, we analyzed separately the group of lambs ventilated with an initial PIP of 25 or $35 \mathrm{~cm} \mathrm{H}_{2} \mathrm{O}$. Rectal temperature was kept, after an initial fall, within a range of $38^{\circ}-39^{\circ} \mathrm{C}$ during the experiment. At this time, pentobarbital $4 \mathrm{mg} / \mathrm{kg}$ (Narcovet, $60 \mathrm{mg} / \mathrm{ml}$ ) was administered as an intravenous bolus in approximately 20 seconds. Ampicillinum $100 \mathrm{mg} / \mathrm{kg}$ was given. A constant infusion of $5 \%$ glucose and pentobarbital $(4 \mathrm{mg} / \mathrm{kg} / \mathrm{h})$ was administered at $6.7 \mathrm{ml} / \mathrm{h}$. Sodium bicarbonate solution was administered intravenously when base excess fell below -5.0 meq/l. After every five blood samples, $5 \mathrm{ml}$ of fetal blood was administered to replace blood loss. Haematocrit was measured each three samples. Thoracic drains were placed, when a pneumothorax occurred. Hypotension, when it occurred, was corrected by administering blood.

\subsubsection{Lung Conditioning}

Lung conditioning or sustained inflations consisted of disconnecting the ventilator and inflating the lungs during five seconds with a bag at a PIP of $35 \mathrm{~cm} \mathrm{H}_{2} \mathrm{O}$ with a mixture of $5 \% \mathrm{CO}_{2}$ and $95 \% \mathrm{O}_{2}$, to avoid alveolar hypocapnia. Each inflation was followed by PEEP of $5 \mathrm{~cm} \mathrm{H}_{2} \mathrm{O}$ for five seconds. This procedure was repeated a total of four times (Fig. 2.1A). 
Figure 2.1A shows the SI procedure in detail and B) shows the times at which SI were applied in group 1 to 3 and the control groups 4 and 5 .
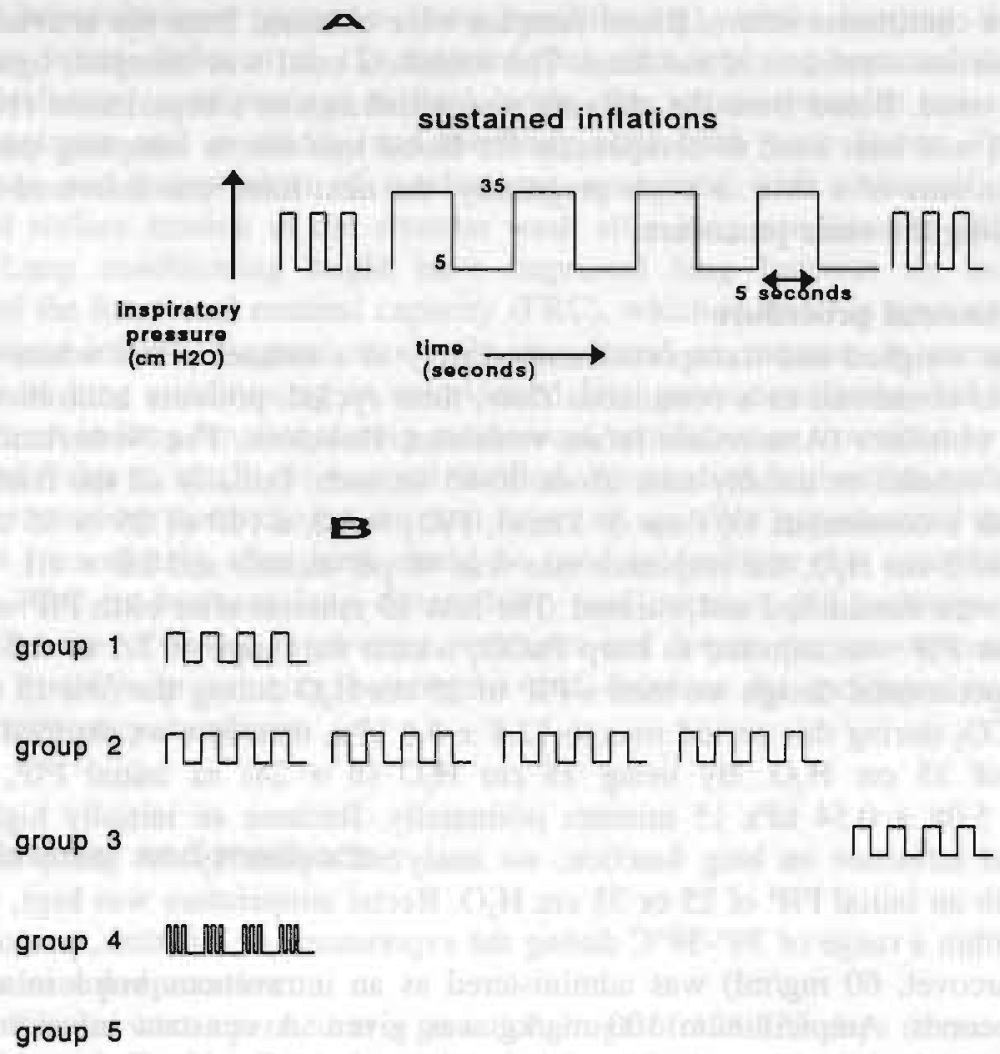

B

group 1 П几几ん

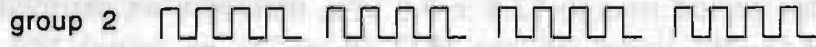

group 3

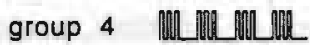

group 5

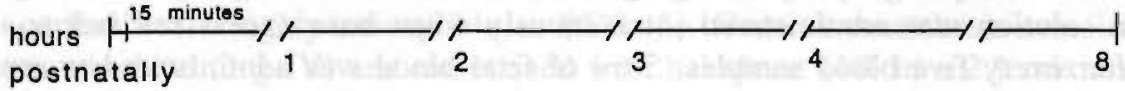


Lung conditioning was applied to three groups of lambs: G1) once within 15 minutes after birth, G2) within 15 minutes after birth and repeated each hour for three hours, G3) once at four hours of age. Two control groups were formed: G4) as in group 1, except that during disconnection the lungs were inflated at the same pressure as for the sustained inflations, but with shorter inspiratory time (approximately $0.8 \mathrm{sec}$ ), G5) lambs were ventilated without any manipulation (Fig. 2.1B).

\subsubsection{Data collection}

Arterial blood samples $(0.5 \mathrm{ml})$ were taken at $5,10,15,40$ and 60 minutes in the first hour after birth and each half hour thereafter. Arterial blood gas tensions, $\mathrm{pH}, \mathrm{HCO}^{-}$ and base deficit were analyzed with an ABL-3 blood gas analyzer (Radiometer, Copenhagen, Denmark) and corrected for body temperature. pH, $\mathrm{PaCO}_{2}, \mathrm{PaO}_{2}, \mathrm{PIP}$, mean airway pressure (MAP), oxygenation index (OI) and alveolar-arterial oxygen gradient $\left(\mathrm{AaDO}_{2}\right)$ were analyzed at each sample time and compared between groups. MAP was calculated as follows: MAP $=(\mathrm{Pi})(\mathrm{Ti} / \mathrm{Ttot})+(\mathrm{Pe})(\mathrm{Te} / \mathrm{Ttot})$, in this formula $\mathrm{Pi}=$ inspiratory pressure; $\mathrm{Ti}=$ inspiratory time; $\mathrm{Pe}=$ expiratory pressure; $\mathrm{Te}=$ expiratory time; Ttot $=$ inspiratory + expiratory time. $\mathrm{OI}=\mathrm{MAP} \times \mathrm{FiO}_{2} \times 100 / \mathrm{PaO}_{2} . \mathrm{AaDO}_{2}=$ atmospheric pressure $(760 \mathrm{~mm} \mathrm{Hg})$ - water vapour pressure $(47 \mathrm{~mm} \mathrm{Hg})-\mathrm{PaO}_{2}$ $\mathrm{PaCO}_{2}$.

After eight hours the lambs were sacrificed with an overdose of pentobarbital (100 $\mathrm{mg} / \mathrm{kg}$ body weight). Total static compliance was measured as follows: known volumes of air were injected stepwise and the resulting rise in tracheal pressure was recorded up to $30 \mathrm{~cm} \mathrm{H}_{2} \mathrm{O}$. Total static compliance was computed as the injected air volume per wet body weight necessary to reach a tracheal pressure of $20 \mathrm{~cm} \mathrm{H} \mathrm{H}_{2} \mathrm{O}$. The procedure was repeated twice. Between measurements the lungs were ventilated with the same parameters as at the time of sacrifice.

\subsubsection{Statistics}

All data are presented as mean \pm SEM. Differences between the five given groups were evaluated using the nonparametric Kruskal-Wallis test. Incidence of pneumothorax, mortality and sex distribution between groups was tested with the $X^{2}$-test. The Student's $\mathrm{t}$-test was used to evaluate the difference between larger groups as sex $(\mathrm{n}>30)$. The difference between the two samples before and after SI was tested with the nonparametric matched pairs Wilcoxon test. Statistical significance was $p$ (two-tailed) < 0.05 .

\subsection{Results}

The results and conclusions regarding possible differences between treatment and control groups were not different in lambs initially ventilated with a PIP of 25 or $35 \mathrm{~cm}$ $\mathrm{H}_{2} \mathrm{O}$, therefore all data were pooled together for analysis. The 5 groups of lambs had similar gestational age, birth weight, and sex distribution (Table 2.1). There was no 
significant difference between the initial blood gas samples before the umbilical cord was ligated. Lecithin/sphingomyelin ratio's were below 0.7 in all lambs, indicating an immature surfactant secretion system, as was expected in sheep at this gestational age (7).

Eight hours postnatally $\mathrm{PaO} 2$ was for $\mathrm{G} 1: 29.8 \pm 3.8, \mathrm{G} 2: 34.1 \pm 5.3, \mathrm{G} 3: 40.3 \pm 7.5$, G4: $28.6 \pm 4.5$ and G5: $26.7 \pm 8.1 \mathrm{kPa}$. (Table 2.2) At that time MAP needed to maintain $\mathrm{PaCO}_{2}$ within the above mentioned range was in G1: $15.6 \pm 1.0, \mathrm{G} 2: 14.4 \pm$ 1.0, G3: $13.8 \pm 1.2, \mathrm{G} 4: 16.0 \pm 1.3$ and in G5: $15.8 \pm 1.3 \mathrm{~cm} \mathrm{H} \mathrm{H}_{2} \mathrm{O}$. The $\mathrm{AaDO}_{2}$ was in G1: $446 \pm 28, G 2: 412 \pm 39, G 3: 369 \pm 60, G 4: 452 \pm 32$ and in G5: $466 \pm 60 \mathrm{~mm} \mathrm{Hg}$. Average total static compliance was in each group $0.7 \mathrm{ml} / \mathrm{cm} \mathrm{H} \mathrm{H}_{2} \mathrm{O} / \mathrm{kg}$. None of these parameters were significantly different between the five groups. There was not a significant difference in clinical course, incidence of pneumothorax or mortality rate between the groups (Table 2.2). $\mathrm{MAP}, \mathrm{AaDO}_{2}, \mathrm{OI}, \mathrm{PaO}_{2}, \mathrm{PaCO}_{2}$ and $\mathrm{pH}$ were not significantly different in the five groups at any time during the experiment (Figures 2.2 to 2.7) Analysis of the differences between the groups when using as covariant gestational age, sex, or mortality did not yield other results than the above mentioned.

When all lambs were divided according to sex, regardless whether SI were applied, there was a significantly $(p<0.045)$ lower OI in females than males during the third, fourth and fifth hour postnatally. (Fig 2.8) We compared, for females only, the groups in which $n \geq 6$ : G1 $(n=7), G 2(n=9), G 3(n=6)$ and $G 4(n=7)$. There were significant better $\mathrm{PaO}_{2}$ and $\mathrm{AaDO}_{2}$ values in group 2 compared to group 4, starting $41 / 2$ hours after birth and continuing for one hour $(p<0.05)$. (Fig. 2.9) MAP was not different during this time and OI was significantly lower for the treatment group at $4 \frac{1}{2}$ hours postnatally $(p<0.05)$.

Furthermore the lambs were arbitrarily divided in two groups: 1) lambs with a good clinical outcome and 2) with a bad clinical outcome. A bad clinical outcome was defined by one or more of the following conditions: 1) dead before the end of the experiment 2) occurrence of pneumothorax 3) PIP at 1.5 hours after birth greater than $30 \mathrm{~cm} \mathrm{H}_{2} \mathrm{O}$. These criteria yielded 29 lambs with bad clinical outcome and 41 lambs with good clinical outcome. Clinical outcome was significantly influenced by gestational age (Pearson's $r=0.376, p=0.0007$ ) and not by sex. There was a significant difference between bad and good clinical outcome lambs for $\mathrm{PaO}_{2}(p<0.027), \mathrm{AaDO}_{2}(p<$ $0.010)$, MAP $(p<0.0001)$ and OI $(p<0.0005)$ at all times, except for MAP during the first 15 minutes postnatally (figure 2.10 shows MAP). The number of lambs with bad versus good clinical outcome was respectively $9 / 10,6 / 12,4 / 4,7 / 11$ and $3 / 4$ in group 1 to 5 . This ratio was not significantly different in the five groups. Then the five groups formed only by the good clinical outcome lambs were compared for MAP (Fig. 2.11). Even under these circumstances there were no significant differences in MAP, pH, arterial blood gas tensions, $\mathrm{AaDO}_{2}$ and $\mathrm{OI}$. 
Table 2.1 Birth weight (BW), gestational age (GA), sex, and fetal blood gas tensions and pH in the five groups of lambs before cord clamping. Data are given as mean \pm SEM.

\begin{tabular}{|c|c|c|c|c|c|}
\hline $\begin{array}{l}\text { group } \\
\text { (n) }\end{array}$ & $\begin{array}{c}1 \\
(19)\end{array}$ & $\begin{array}{c}2 \\
(18)\end{array}$ & $\begin{array}{c}3 \\
(8)\end{array}$ & $\begin{array}{c}4 \\
(18)\end{array}$ & $\begin{array}{c}5 \\
(7)\end{array}$ \\
\hline $\mathrm{BW}(\mathrm{kg})$ & $3.47 \pm 0.54$ & $3.52 \pm 0.74$ & $3.45 \pm 0.40$ & $3.57 \pm 0.49$ & $3.39 \pm 0.53$ \\
\hline GA (days) & $130.6 \pm 1.3$ & $130.8 \pm 1.3$ & $130.6 \pm 1.7$ & $130.8 \pm 1.0$ & $130.6 \pm 1.8$ \\
\hline $\mathrm{m} / \mathrm{f}$ & $11 / 7^{*}$ & $9 / 9$ & $2 / 6$ & $10 / 7^{*}$ & $2 / 4^{*}$ \\
\hline $\mathrm{pH}$ & $7.29 \pm 0.13$ & $7.27 \pm 0.12$ & $7.29 \pm 0.04$ & $7.30 \pm 0.06$ & $7.31 \pm 0.03$ \\
\hline $\mathrm{PaCO}_{2}(\mathrm{kPa})$ & $5.79 \pm 1.02$ & $6.11 \pm 1.44$ & $5.71 \pm 0.95$ & $5.75 \pm 1.10$ & $7.18 \pm 0.95$ \\
\hline $\mathrm{PaO}_{2}(\mathrm{kPa})$ & $2.84 \pm 1.00$ & $2.84 \pm 0.75$ & $4.24 \pm 1.25$ & $2.82 \pm 0.94$ & $3.12 \pm 0.51$ \\
\hline
\end{tabular}

Table 2.2 Results at 8 hours after birth for the five given groups. Data are presented as mean \pm SEM.

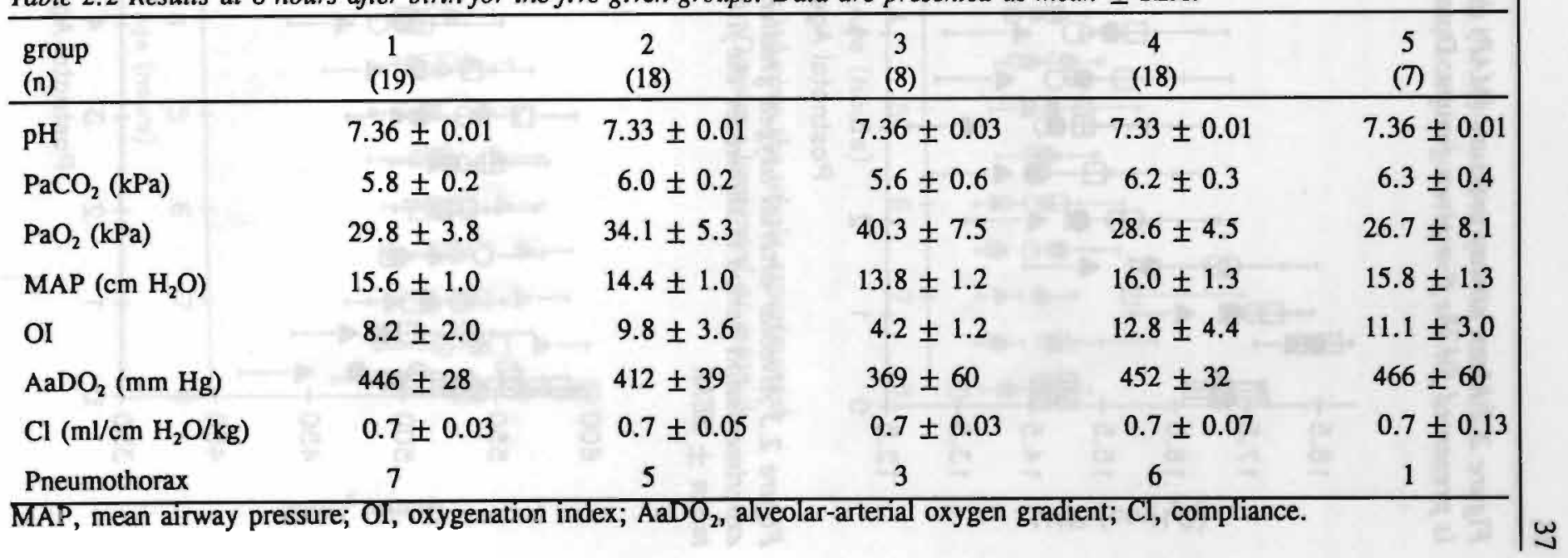


Figure 2.2 Mean airway pressure (MAP) during the whole experimentation period is presented for the five given groups. Data are given as mean $\pm S E M$.

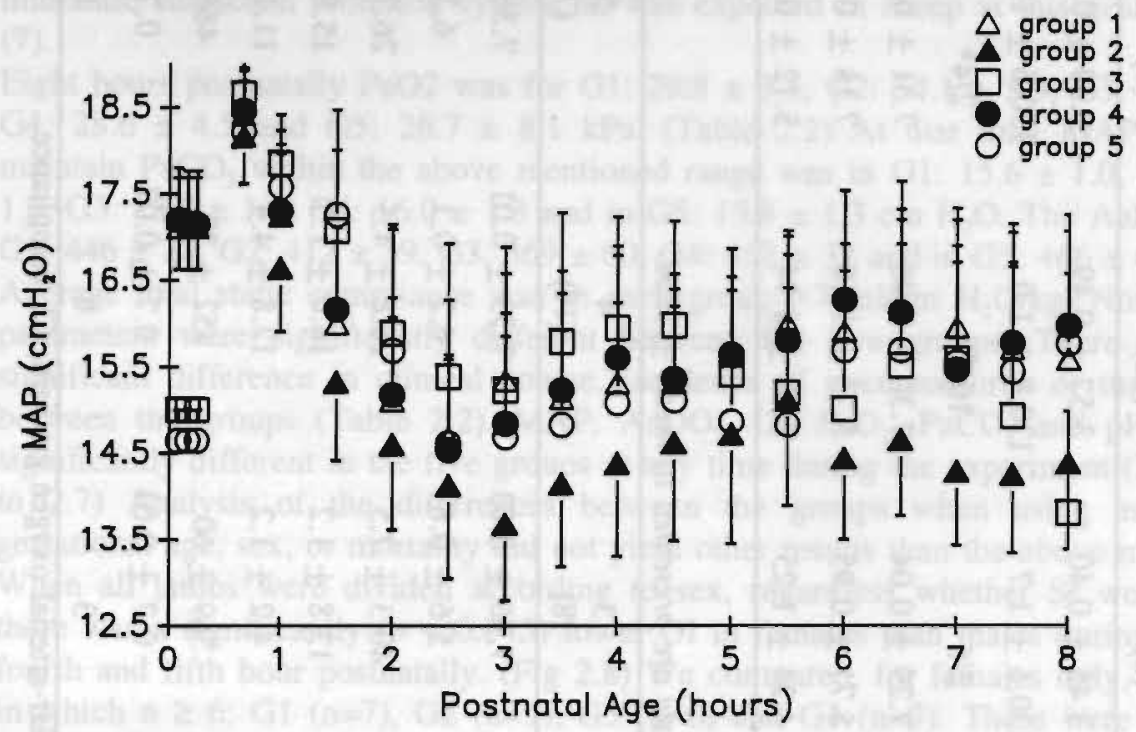

Figure 2.3 Alveolar-arterial oxygen gradient $\left(\mathrm{AaDO}_{2}\right)$ during the whole experimentation period is shown for the five given groups. Data are presented as mean $\pm S E M$.

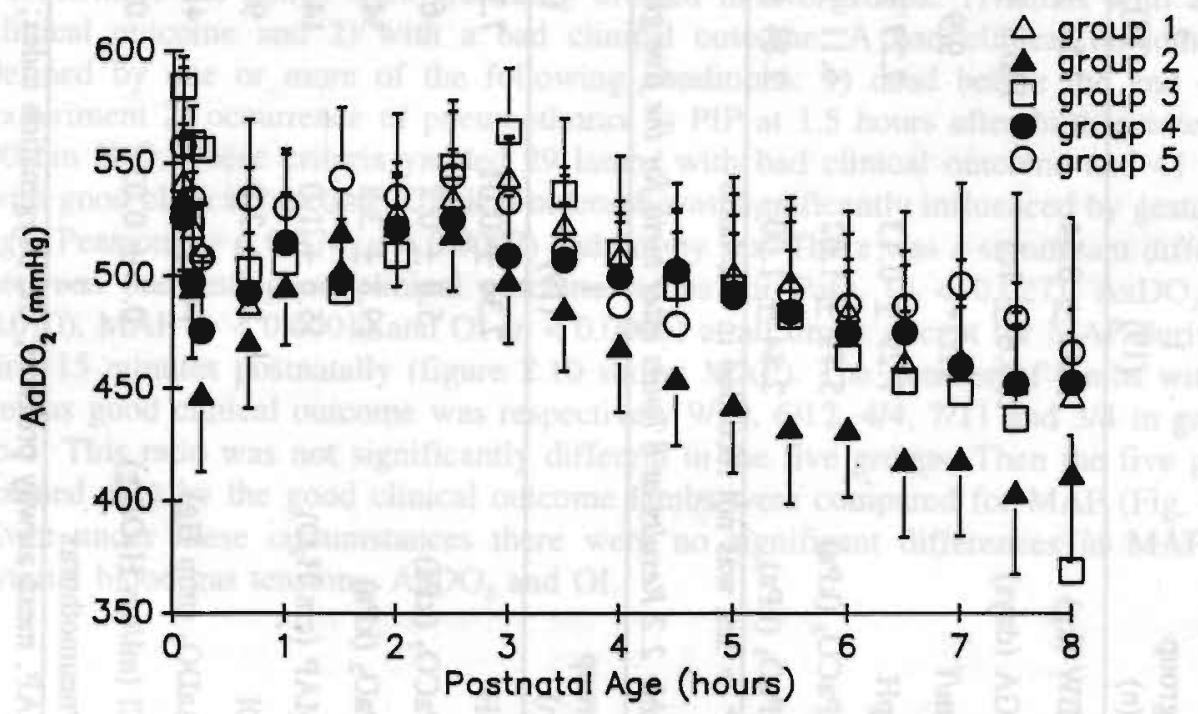


Figure 2.4 Oxygenation index (OI) during the whole experimental period is shown for the five groups given. Data are presented as mean $\pm S E M$.

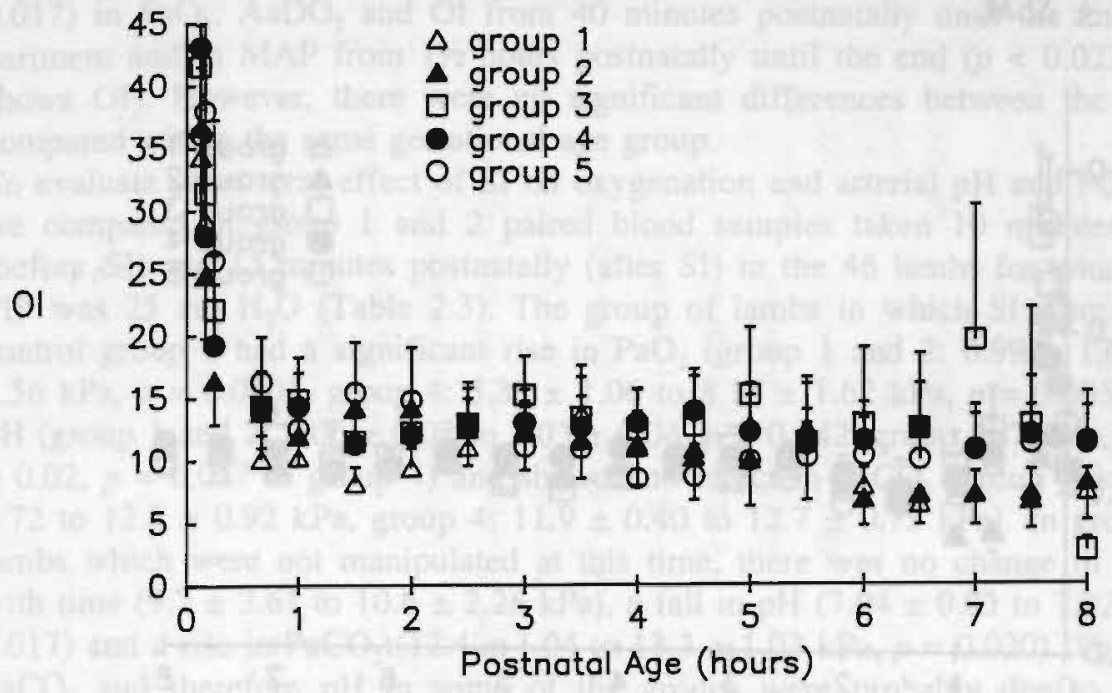

Figure 2.5 Arterial oxygen tension $\left(\mathrm{PaO}_{2}\right)$ during the whole experimental period is shown for the five groups given. Data are presented as mean \pm SEM.

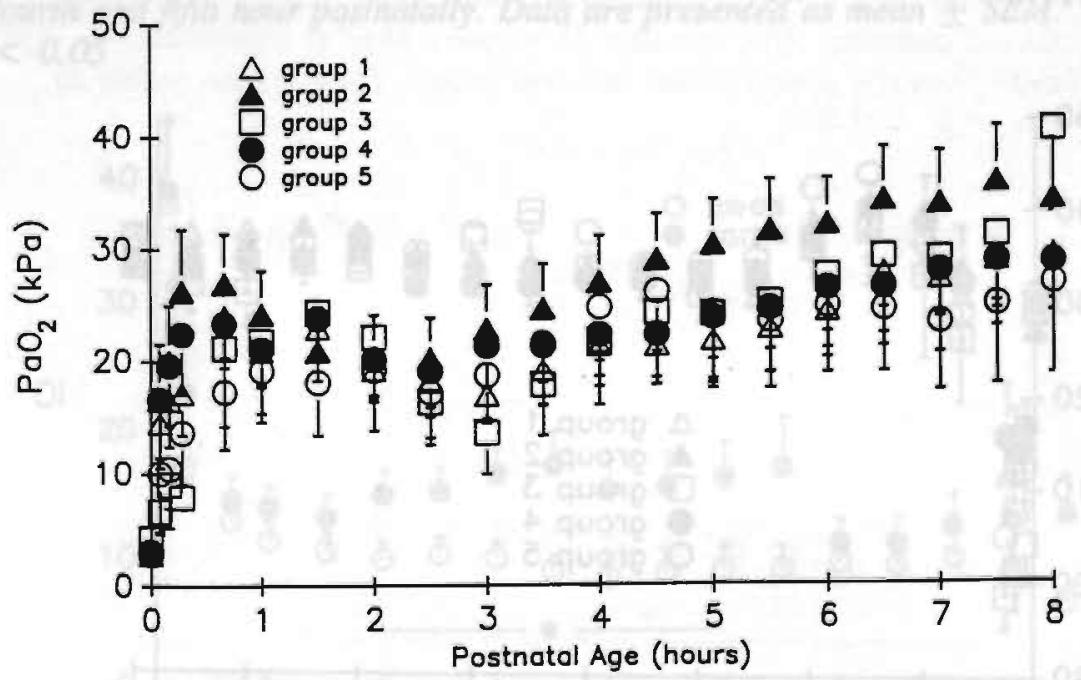


Figure 2.6 Arterial carbon dioxide tension $\left(\mathrm{PaCO}_{2}\right)$ during the whole experimental period is shown for the five groups given. Data are presented as mean \pm SEM.

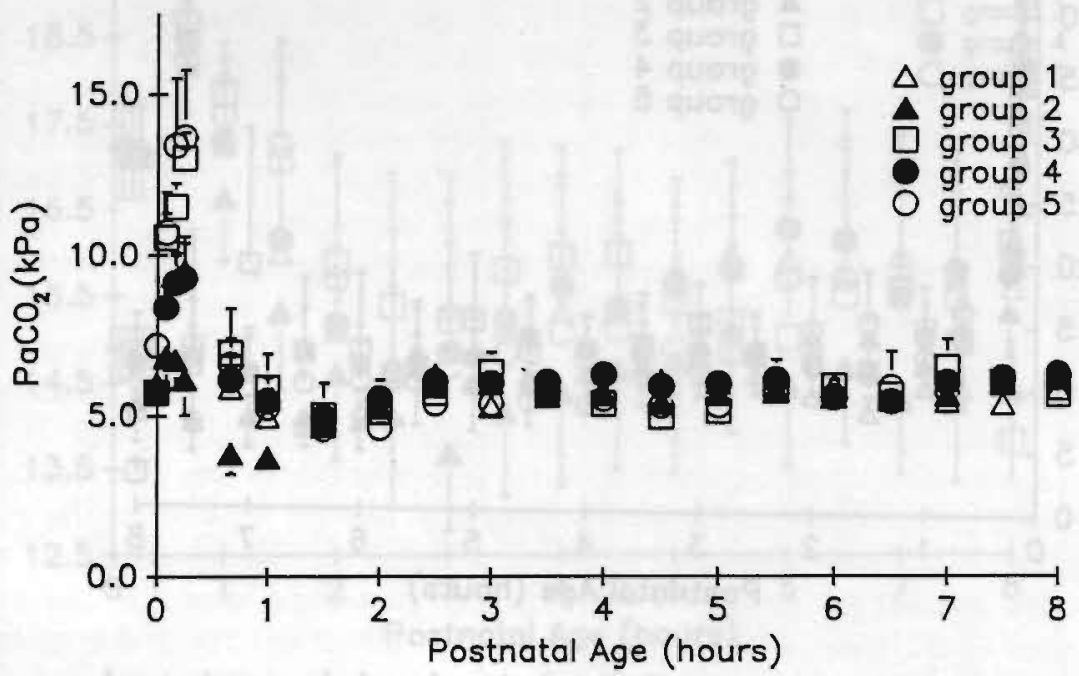

Figure 2.7 Arterial pH during the whole experimental period is shown for the five groups given. Data are presented as mean $\pm S E M$.

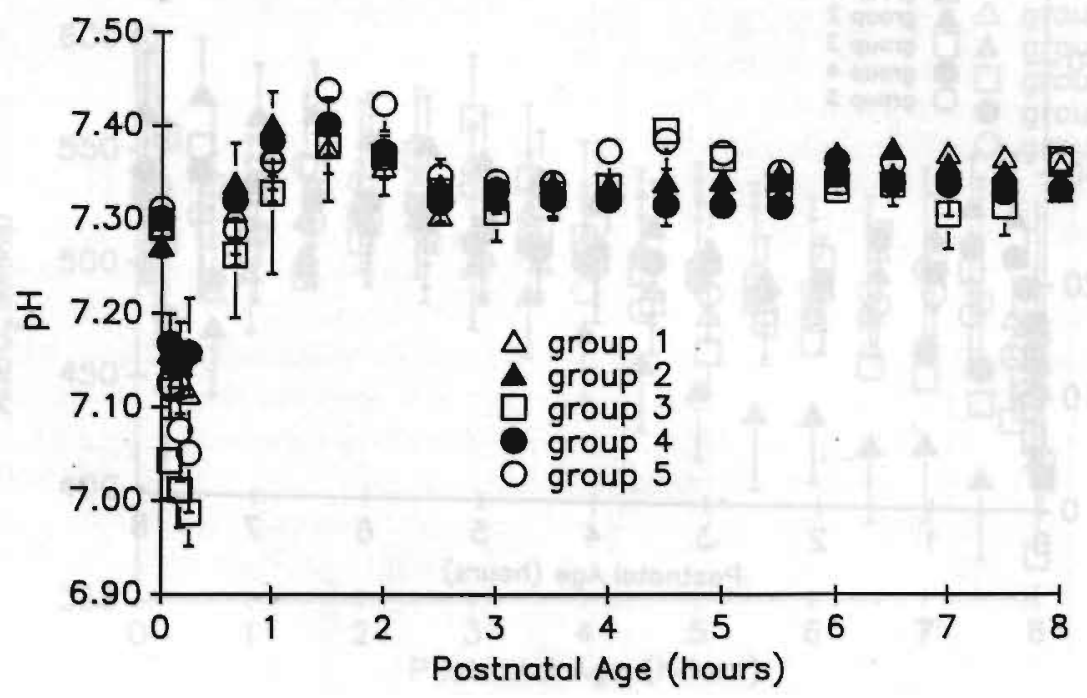


Furthermore, all lambs were divided by gestational age in two groups: 128 to 130 days and lambs with 131 to 133 days of gestation. There was a significant difference $(p<$ $0.017)$ in $\mathrm{PaO}_{2}, \mathrm{AaDO}_{2}$ and $\mathrm{OI}$ from 40 minutes postnatally until the end of the experiment and in MAP from $1 \frac{1 / 2}{2}$ hours postnatally until the end $(p<0.023)$ (Fig. 2.12 shows OI). However, there were no significant differences between the five groups compared within the same gestational age group.

To evaluate short term effect of SI on oxygenation and arterial $\mathrm{pH}$ and $\mathrm{PCO}_{2}$ tensions, we compared in group 1 and 2 paired blood samples taken 10 minutes postnatally (before SI) and 15 minutes postnatally (after SI) in the 46 lambs for which the initial PIP was $25 \mathrm{~cm} \mathrm{H}_{2} \mathrm{O}$ (Table 2.3). The group of lambs in which SI were applied and control group 4 had a significant rise in $\mathrm{PaO}_{2}$ (group 1 and 2: $6.99 \pm 1.63$ to $12.7 \pm$ $2.56 \mathrm{kPa}, p=0.0001$, group 4: $5.38 \pm 1.06$ to $8.16 \pm 1.62 \mathrm{kPa}, p=0.005)$ and fall in $\mathrm{pH}$ (group 1 and 2: $7.06 \pm 0.02$ to $7.03 \pm 0.04, p=0.042$, group 4: $7.03 \pm 0.01$ to 7.01 $\pm 0.02, p=0.047$ in group 4) and showed no effect in $\mathrm{PaCO}_{2}$ (group 1 and 2: $11.6 \pm$ 0.72 to $12.5 \pm 0.92 \mathrm{kPa}$, group $4: 11.9 \pm 0.40$ to $12.7 \pm 0.73 \mathrm{kPa}$ ). In group 3 and 5 , lambs which were not manipulated at this time, there was no change in oxygenation with time $(9.7 \pm 2.61$ to $10.6 \pm 2.26 \mathrm{kPa})$, a fall in $\mathrm{pH}(7.04 \pm 0.03$ to $7.02 \pm 0.03, p=$ $0.017)$ and a rise in $\mathrm{PaCO}_{2}(12.4 \pm 1.04$ to $13.3 \pm 1.03 \mathrm{kPa}, p=0.020)$. The changes in $\mathrm{PaCO}_{2}$ and therefore $\mathrm{pH}$ in some of the groups were probably due to the initially inadequate PIP $\left(25 \mathrm{~cm} \mathrm{H}_{2} \mathrm{O}\right)$.

Figure 2.8 Oxygenation index (OI) during the whole experimental period is shown for ewes and rams. Ewes had a significant lower OI during the third, fourth and fifth hour postnatally. Data are presented as mean $\pm S E M .{ }^{*} p$ $<0.05$

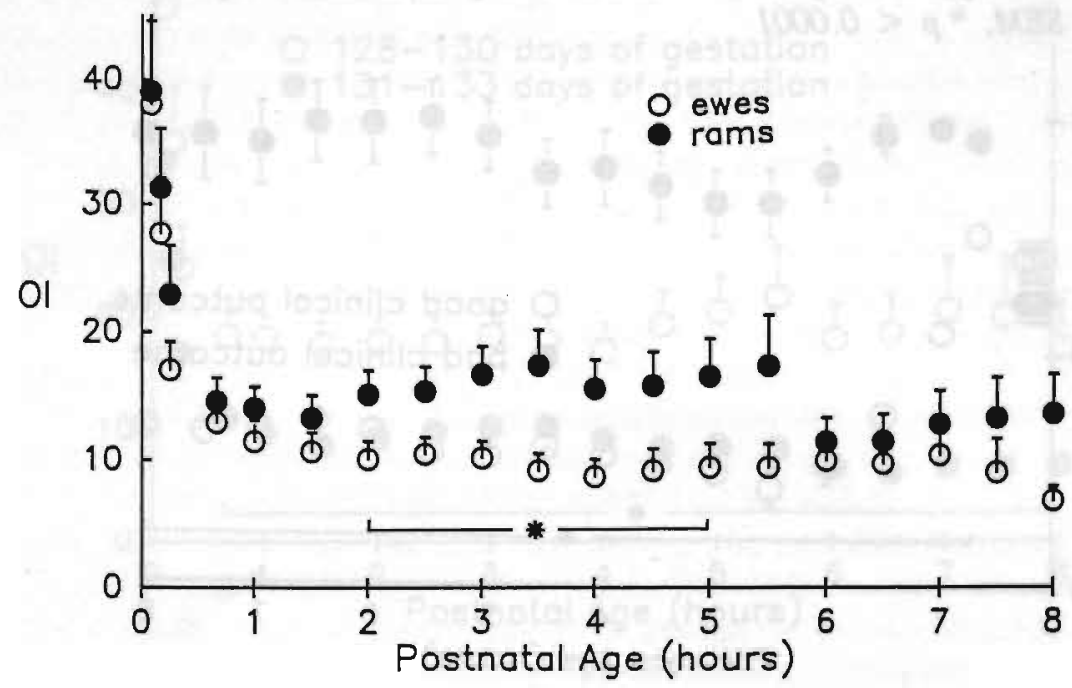


Figure 2.9 Arterial oxygen tension $\left(\mathrm{PaO}_{2}\right)$ during the whole experimental period is shown for ewes from group 1,2, 3 and 4. Group 2 lambs, in which SI were administered four times, had significantly higher oxygen tensions during one hour compared to control group 4. Data are presented as mean \pm SEM. ${ }^{*} p<0.05$

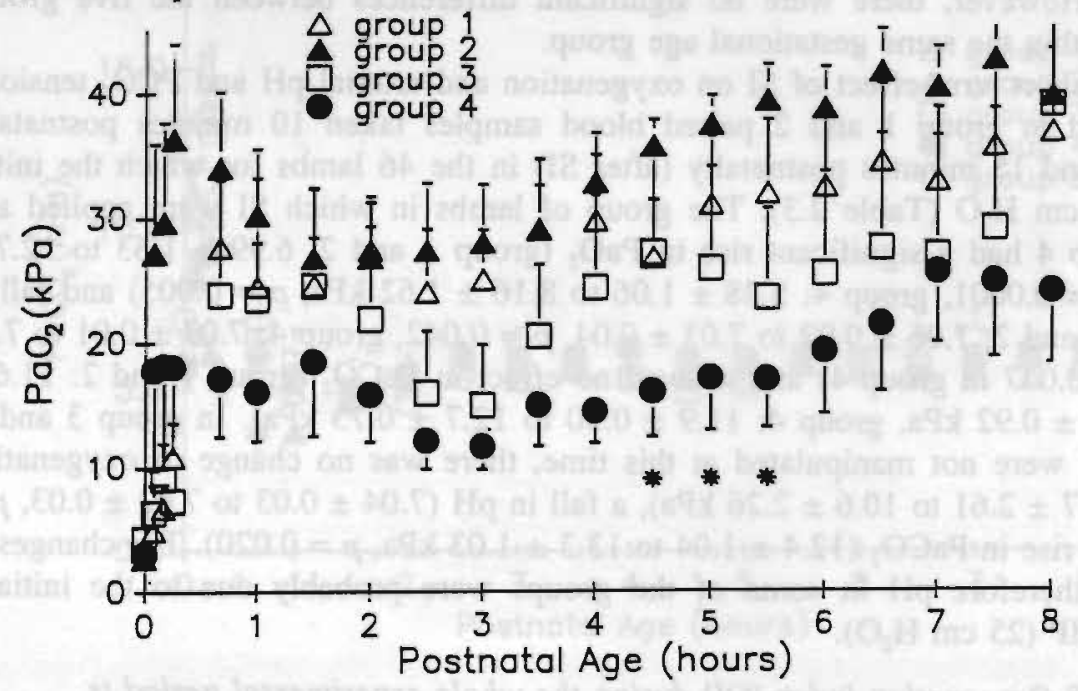

Figure 2.10 Mean airway pressure (MAP) during the whole experimental period is shown for lambs with a good clinical outcome compared to lambs with bad clinical outcome. After the first 15 minutes MAP is significantly lower in lambs from the good clinical outcome group. Data are presented as mean \pm SEM. ${ }^{*} p<0.0001$

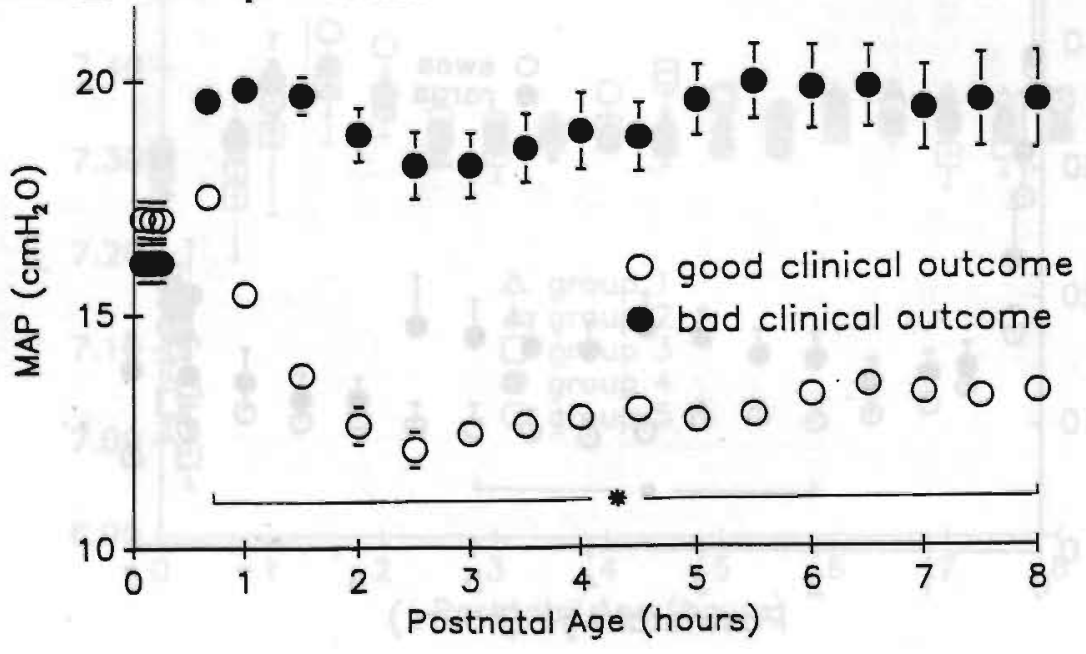


Figure 2.11 Mean airway pressure (MAP) during the whole experimental period is compared between the five groups given, formed only by lambs with a good clinical outcome. Data are presented as mean $\pm S E M$.

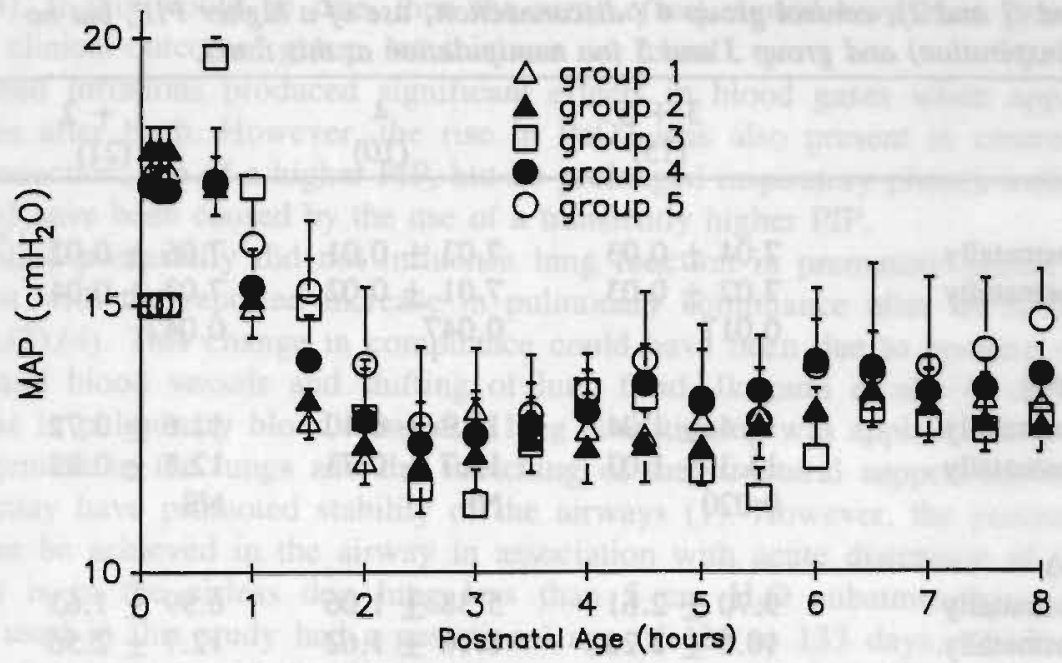

Figure 2.12 Oxygenation index (OI) during the whole experimental period is shown for lambs from 128 to 130 days of gestation and lambs from 131 up to 133 days of gestation. OI was significantly different from 40 minutes postnatally until the end of the experiments. Data are presented as mean \pm SEM. ${ }^{*} p<0.05$.

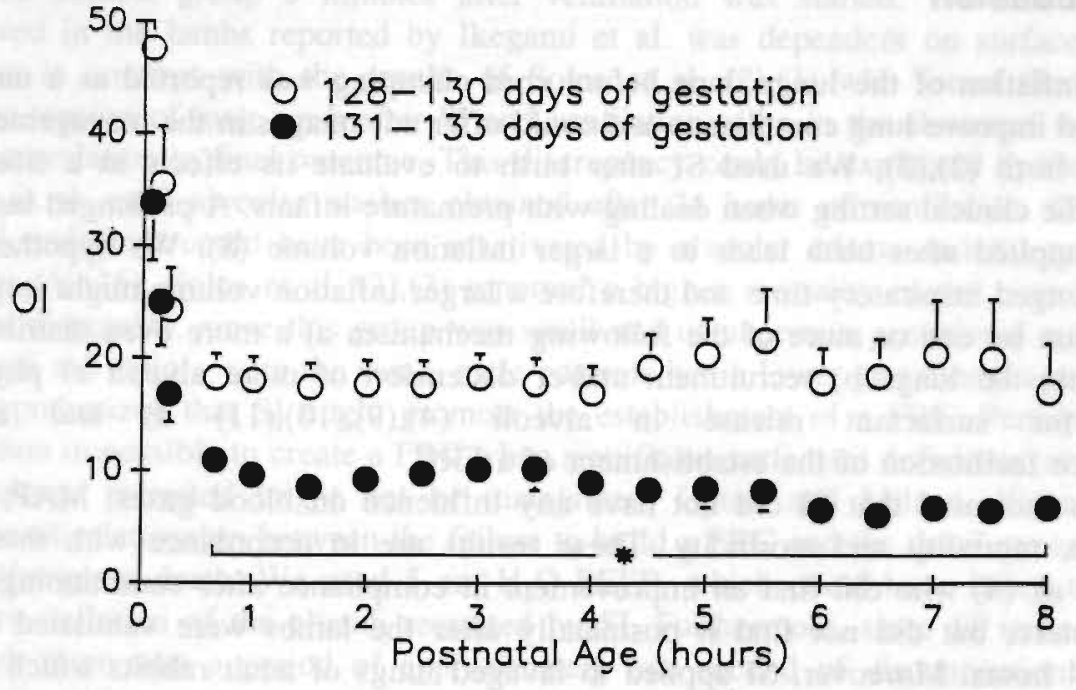


Table 2.3 Analysis of the difference between samples taken 10 and 15 minutes postnatally. Comparison between $\mathrm{PaO}_{2}, \mathrm{pH}$ and $\mathrm{PaCO}_{2}$ (mean \pm SEM) for the groups in which SI were applied (1 and 2), control group 4 (disconnection, use of a higher PIP, but no prolonged inspiration) and group 3 and 5 (no manipulation at this time).

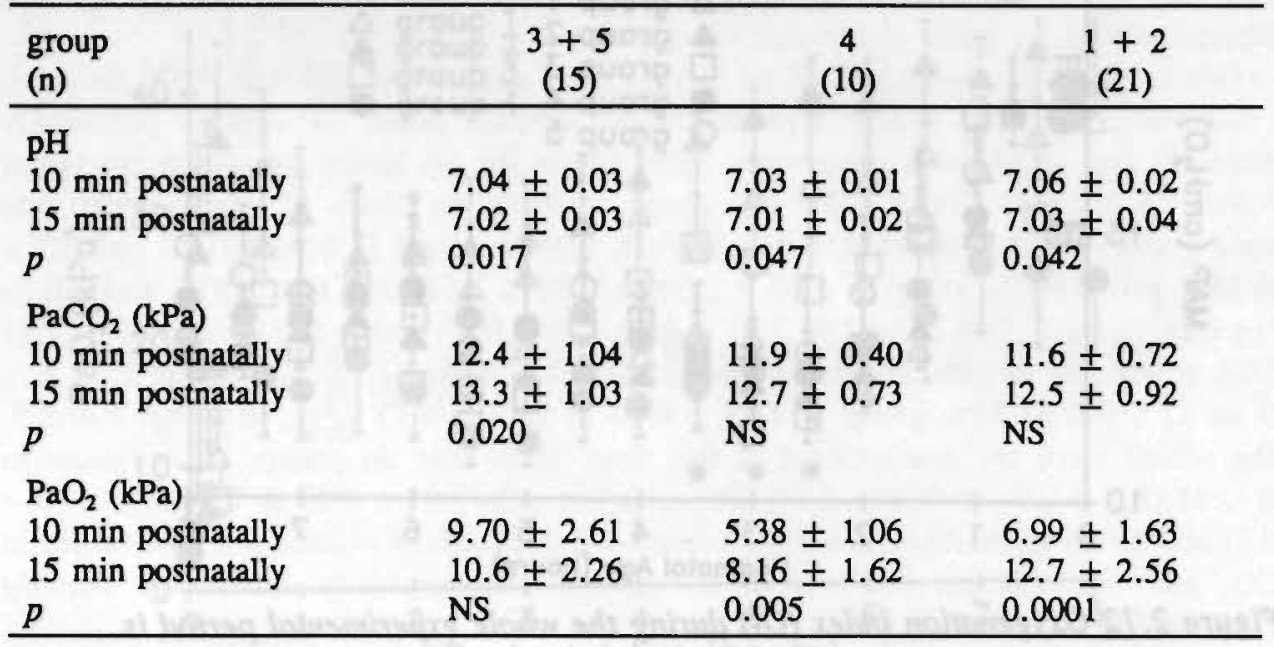

\subsection{Discussion}

Sustained inflation of the lungs done before cord clamping was reported as a method which could improve lung compliance and could offer advantages in the management of RDS after birth (2),(3). We used SI after birth to evaluate its effects in a situation similar to the clinical setting when dealing with premature infants. A prolonged inspiratory time applied after birth leads to a larger inflation volume (8). We hypothesized that a prolonged inspiratory time and therefore a larger inflation volume might improve lung function by one or more of the following mechanism a) a more even distribution of air within the lungs b) recruitment and/or distension of more alveoli c) physical stimulus for surfactant release in alveoli (4),(9),(10),(11) d) and as a consequence facilitation of the establishment of a FRC.

Our results indicated that SI did not have any influence on blood gases, MAP, lung compliance, mortality and morbidity. These results are in accordance with those of Ikegami et al. (4) who did find an improvement in compliance after conditioning fetal sheep in utero, but did not find it postnatally after the lambs were ventilated for a period of 4 hours. Moreover, SI applied to lavaged lungs of adult rabbits which were conventionally mechanically ventilated did not produce an increase either in lung volume or oxygenation (12). Other investigators reported a variable response to sus- 
tained inflations (3),(13). We have found a transitory significant difference in effect of SI during three hours when comparing females of group 1,2,3 and 4 . This could be explained by the fact that females are reported to have a more mature lung function (4),(14). If this would be true, then the same effect should have been present in the "good clinical outcome" group, but this was not found.

Sustained inflations produced significant effects in blood gases when applied at 15 minutes after birth. However, the rise in $\mathrm{PaO} 2$ was also present in control group 4 (disconnection, use of a higher PIP, but no prolonged inspiratory phase), indicating that it could have been caused by the use of a transiently higher PIP.

SI applied postnatally did not influence lung function in premature lambs, this is in contrast with the reported increase in pulmonary compliance after SI in fetal sheep (1),(2),(3),(4). This change in compliance could have been due to opening of the airways and blood vessels and shifting of lung fluid. Ikegami et al. (4) did report an increase in pulmonary blood flow after lung conditioning was applied. Turgid vascular engorgement in the lungs and the stretching of the structural support network of the lungs may have promoted stability of the airways (1). However, the pressure change that can be achieved in the airway in association with acute distension of pulmonary vessels is in the airless dog lung less than $5 \mathrm{~cm} \mathrm{H}_{2} \mathrm{O}$ subatmospheric (15). The lambs used in this study had a gestational age of 128 to 133 days, which was comparable in gestation with the fetal lambs used by Solca et al. (2),(3) and Ikegami et al. (4). We have used SI as reported by Solca et al. (2) which were very effective in the fetal lamb. However, Solca et al. (3) reported that 4 out of 13 lambs with a gestational age of 128 to 130 days did not react to SI. Also, Ikegami et al. (4) found that lung compliance and blood gases were the same in the group lambs in which SI were applied and the control group 5 minutes after ventilation was started. The clinical course observed in the lambs reported by Ikegami et al. was dependent on surface tensions. This is in contrast with the results of Solca et al. (2),(3) who found the minimum surface tension of lung wash after SI and ventilation to be in the abnormal range without a correlation to final outcome. This discrepancy could be explained by the fact that Solca et al. used alveolar washes obtained after 24 hours of ventilation. During this period surfactant could have been inactivated by alveolar edema and the presence of protein (4),(16). Solca et al. (2),(3) reported a higher mortality in the control groups. This is disputable, since this group was small and of uncertain gestational age (3), and although $\mathrm{m} / \mathrm{f}$ ratio's were the same, male controls had a lower gestational age (2).

We hypothesized that SI might promote the establishment of a FRC. Perhaps it is by definition impossible to create a FRC when significant surfactant deficiency exists, since the volume recruited might not be maintained. Upton and Milner (17) reported a significant relationship between the failure to build a FRC and the development of RDS and subsequent death. We used $5 \mathrm{~cm} \mathrm{H}_{2} \mathrm{O}$ PEEP, which could have failed to prevent massive deflation of the alveoli recruited by SI. Furthermore, since SI were manually applied, there was a period of approximately one second of disconnection from the ventilator and as a consequence no PEEP was applied. This is probably not the primary reason for the lack of effect of SI, since Kolton et al. (12) showed that there was no 
improvement in lung function when $9 \mathrm{~cm} \mathrm{H}_{2} \mathrm{O}$ PEEP was used during the switch from SI to conventional ventilation. Solca et al. (2),(3) used in their study in fetal lambs a PEEP of $15 \mathrm{~cm} \mathrm{H}_{2} \mathrm{O}$ after repeated deep insufflation and this could have prevented derecruitment of alveoli.

In the atelectatic lung the potential beneficial effects of positive end-expiratory pressure are well known. Keszler et al. (18) concluded that the use of PEEP of 12 to $14 \mathrm{~cm}$ $\mathrm{H}_{2} \mathrm{O}$ prevented deterioration of pulmonary function during extracorporeal membrane oxygenation and resulted in more rapid lung recovery than the traditional lung management with low PEEP. However, we wanted to study the effect of SI at the level of PEEP that is generally used when treating premature infants suffering from RDS. The application of higher PEEP has multiple effects (19),(20),(21),(22) mainly secondary to changes in haemodynamics. Cardiac output is reduced, largely due to a reduction in venous return. There is a risk of alveolar overdistension and rupture resulting in barotrauma (19). Niemann et al. (23) demonstrated that PEEP $(10 \mathrm{~cm}$ $\mathrm{H}_{2} \mathrm{O}$ ) increased the rate of lung water accumulation in lungs with high alveolar surface tension.

In conclusion, sustained inflations applied after birth in premature newborn lambs, as used here, showed no significant changes in lung compliance or pulmonary gas exchange up to 8 hours of age. There was no significant difference in the incidence of pneumothorax or in mortality rate. This lack of effect could have been the consequence of the use of low PEEP which did not avoid alveolar deflation. Therefore, we can not support its use in the present form for the management of premature infants in an attempt to modify the course of RDS. 


\section{References}

1. Kolobow T, Solca M, Pesenti A, Buckhold D, Pierce JD. The prevention of hyaline membrane disease (HMD) in the preterm fetal lamb through the static inflation of the lungs: the conditioning of the fetal lungs. Trans Am Soc Artif Intern Organs 1980;26:567-571.

2. Solca M, Kolobow T, Huang HH, Chen V, Buckhold DK, Pierce JE. Respiratory Distress Syndrome in immature lambs. Prevention through antenatal accelerated conditioning of the lung. Am Rev Respir Dis 1984;129:979-984.

3. Solca M, Kolobow T, Huang HH, Pesenti A, Buckhold DK, Pierce JE. Management of the antenatal preterm fetal lung in the prevention of respiratory distress syndrome in lambs. Biol Neonate 1983;44:93-101.

4. Ikegami M, Jobe A, Berry D, Elkady T, Pettenazzo A, Seidner S. Effects of distension of the preterm fetal lamb lung on lung function with ventilation. Am Rev Respir Dis 1987;135:600-606.

5. Sandberg K, Edberg K, Benton W, Silberberg A, Sladek M, Sundell HW. Surfactant improves gas mixing and alveolar ventilation in preterm lambs. Pediatr Res 1991;30(2):181-189.

6. Gluck L, Motoyama EK, Smits HL, Kulovich MV. The biochemical development of surface activity in mammalian lung. Part I, Pediatr Res 1967;1:237-246.

7. Ikegami M, Jobe A. Phospholipid composition of fetal lung fluid and amniotic fluid during late gestation in sheep. Am J Obstet Gynecol 1981;141:227-229.

8. Vyas H, Milner AD, Hopkin IE, Boon AW. Physiological responses to prolonged and slow rise inflation. J Pediatr 1981;99:625-629.

9. Hildebran JN, Goerke J, Clements JA. Surfactant release in excised rat lung is stimulated by air inflation. J Appl Physiol 1981;51(4):905-910.

10. Lawson EE, Birdwell RL, Huang PS, Taeusch HW. Augmentation of pulmonary surfactant secretion by lung expansion at birth. Pediatr Res 1979;13:611-614.

11. Jacobs $\mathbf{H}$, Jobe $A$, Ikegami $\mathbf{M}$, Jones $\mathrm{S}$. Accumulation of alveolar surfactant following delivery and ventilation of premature lambs. Exp Lung Res 1985;8:125-1407.

12. Kolton M, Cattran CB, Kent G, Volgyesi G, Froese AB, Bryan AC. Oxygenation during high-frequency ventilation compared with conventional mechanical ventilation in two models of lung injury. Anesth Analg 1982;61:323-332.

13. Walsh MC, Waldemar CA. Sustained inflation during HFOV improves pulmonary mechanics and oxygenation. J Appl Physiol 1988;65(1):368-372.

14. Naeye RL, Burt LS, Wright DL, Blanc WA, Tatter D. Neonatal mortality, the male disadvantage. Pediatrics 1971;48:902-906.

15. Avery ME, Frank NR, Gribetz I. The inflatory force produced by pulmonary vascular distension in excised lungs. The possible relation of this force to that needed to inflate the lungs at birth. J Clin Invest 1959;38:456-462.

16. Ikegami $\mathbf{M}$, Jobe $\mathrm{A}$, Jacobs $\mathrm{H}$, Lam $\mathrm{R}$. A protein from airways of premature lambs that inhibits surfactant function. J Appl Physiol 1984;57:1134-1142. 
17. Upton CJ, Milner AD. Endotracheal resuscitation of neonates using a rebreathing bag. Arch Dis Child 1991;66:39-42.

18. Keszler M, Ryckman FC, McDonald JV et al. A Prospective, multicenter, randomized study of high versus low positive end-expiratory pressure during extracorporeal membrane oxygenation. J Pediatr 1992;120:107-113.

19. Baeza OR, Wagner RB, Lowery BD, Gott VL. Pulmonary hyperinflation. A form of barotrauma during mechanical ventilation. J Thoracic Cardiovasc Surgery 1975;70(5):790-805.

20. Jarnberg PO, De Villota D, Eklund J, Granberg PO. Effects of positive endexpiratory pressure on renal function. Acta Anaesth Scand 1978;22:508-514.

21. Kanarek DJ, Shannon DC. Adverse effect of positive end-expiratory pressure on pulmonary perfusion and arterial oxygenation. Am Rev Respir Dis 1975;112:457459.

22. Nelson RM, Egan EA, Eitzman DV. Increased hypoxemia in neonates secondary to the use of continuous positive airway pressure. J Pediatr 1977;91:87-91.

23. Nieman GF, Bredenberg CE, Paskanik AM. Positive end-expiratory pressure accelerates lung water accumulation in high surface tension edema. Surgery 1990;107:156-162. 
(3) THE EFFECT OF SUSTAINED INFLATIONS (SI) APPLIED DIRECTLY AFTER CORD CLAMPING ON LUNG FUNCTION IN PREMATURE NEWBORN LAMBS.

\author{
W.A.A. Klöpping-Ketelaars, W.J. Maertzdorf and C.E. Blanco \\ Submitted for publication
}

\title{
3.1 Abstract
}

We studied the possibility to improve lung volume and therefore clinical outcome in premature newborn lambs by increasing the inspiratory volumes during the first minute after birth. 16 lambs from 8 ewes were delivered by hysterotomy at day 130-131 of gestation. In eight lambs the lungs were inflated with a bag with a sustained inspiratory inflation (SI) of 5 seconds and expiratory time of five seconds during the first four inflations after cord clamping and then mechanically ventilated. Their siblings did not receive SI and served as control group. At eight hours postnatally, the SI group and the control group showed the following results (mean \pm SEM): mean airway pressure 14.8 $\pm 1.8 \mathrm{~cm} \mathrm{H} \mathrm{H}_{2} \mathrm{O}$ versus $11.9 \pm 1.1 \mathrm{~cm} \mathrm{H}_{2} \mathrm{O}, \mathrm{PaO}_{2} 41.5 \pm 7.3 \mathrm{kPa}$ versus $31.3 \pm 7.7 \mathrm{kPa}$, Alveolar-arterial oxygen gradient $359 \pm 55 \mathrm{~mm} \mathrm{Hg}$ versus $437 \pm 58 \mathrm{~mm} \mathrm{Hg}$. Clinical course, incidence of pneumothorax, oxygenation index, total static compliance or mortality rate were not different. There was not a significant difference between the two groups at this time, nor at any other time during the experiments.

\subsection{Introduction}

Respiratory distress syndrome (RDS) is the main respiratory problem in premature infants during the neonatal period. Lung collapse due to surfactant deficiency is one of the main causes of RDS. Solca et al. (1) reported an improved lung distensibility and decrease in incidence of RDS in apnoeic exteriorized fetal premature lambs to which a constant intrapulmonary pressure of $15 \mathrm{~cm} \mathrm{H}_{2} \mathrm{O}$ was applied. Lung compliance was further improved when repeated inflations up to $35 \mathrm{~cm} \mathrm{H}_{2} \mathrm{O}$ with a duration of $5 \mathrm{sec}$ onds preceded this constant pressure (2). These inflations might have improved lung function by increasing the volume of the functional residual capacity (FRC). 
The factors concerning the tidal exchange and formation of a FRC within the first few minutes postnatally are not entirely clear. In vaginally delivered spontaneously breathing full-term infants a significant correlation has been found between first inspiratory volume, but not with inspiratory pressure and FRC at the end of the first breath (3). However, a calculated index of inspiratory pressure and time was significantly correlated to FRC (3).

An inflation pressure of $30 \mathrm{~cm} \mathrm{H} \mathrm{H}_{2} \mathrm{O}$ maintained for one second has been a recognized way of initiating lung aeration. Inflation volume tracings during resuscitation showed that air continued to enter the lungs at the end of the inflation, suggesting that better aeration could be achieved by maintaining pressure for a longer period of time (4). Vyas et al. (5) applied a pressure of $30 \mathrm{~cm} \mathrm{H} \mathrm{H}_{2} \mathrm{O}$ and found that the volume reached by term newborn spontaneously breathing babies (about $45 \mathrm{ml}(6)$ ) could be matched by maintaining the inflation pressure for up to five seconds. All babies also formed a FRC (mean: $15.9 \mathrm{ml}$ ) at the end of the first inflation.

In short, these reports suggest that when prolonged inflation is applied, FRC might be easier to establish. The increased inflation time presumably allows for more even distribution of air within the lungs and may aid fluid clearance from the lungs. When the FRC has been established, the pressure and energy necessary to counteract collapse of the lungs is smaller according to the relationship of Laplace.

We have studied the possibility to improve lung distensibility and to decrease morbidity and mortality by applying sustained inflations (SI) in premature lambs during their first minute of age.

\subsection{Material and methods}

\subsubsection{Animal preparation}

8 "Texel" ewes with a twin pregnancy were operated at a gestational age of 130-131 days (term=147 days of gestational age). At this gestational age most of the newborn lambs develop RDS (7). General anaesthesia was induced with pentobarbital (1 g IV) and maintained with halothane ( $1 \%$ in a $2: 1$ mixture of nitrous oxide and oxygen). A midline abdominal incision was made under sterile conditions just below the umbilical scar. A fetal head was identified through the uterine wall and gently manipulated to a more anterior position. An incision of approximately eight to ten centimetres was made in the uterus in an area free from cotyledons and large blood vessels. The head of the lamb and a forelimb were exteriorized. An incision in the anterio-lateral part of the fetal neck was made and the external jugular vein and carotid artery were cannulated with 5 F umbilical catheters, which were advanced approximately $7 \mathrm{~cm}$. The position of the arterial catheter was pre-ductal. The cephalic vein in a forelimb was cannulated with a 5 $F$ catheter, which was advanced for $3 \mathrm{~cm}$. The trachea was identified and an opening was made in an intercartilage space about $3 \mathrm{~cm}$ below the thyroid cartilage; an uncuffed endotracheal tube (4 or $4.5 \mathrm{~mm}$ ID) was placed proximal of the head bronchus leading 
to the right cranial lobe and secured with a suture around the trachea. The incisions were closed using a continuous suture. Blood samples were obtained from the arterial line to record the baseline condition of the fetus. Then the umbilical cord was clamped, ligated and the lamb exteriorized. Blood from the placenta was withdrawn in a heparinized $(10 \mathrm{U} / \mathrm{ml})$ syringe and it was later used to compensate for blood loss due to sampling during the experiment. The next fetus was delivered as soon as possible using the same procedure.

\subsubsection{Experimental procedure}

The lambs were weighed and transported immediately to a radiant heater. Since twins may have different postnatal courses, the first born from the sequential ewes was allocated to control or treatment group. The treatment group received sustained inspiratory inflations (SI) as soon as possible after cord clamping. Sustained inflations consisted of inflating the lungs during five seconds with a bag at a peak inspiratory pressure (PIP) of $35 \mathrm{~cm} \mathrm{H}_{2} \mathrm{O}$ with a mixture of $5 \% \mathrm{CO}_{2}$ and $95 \% \mathrm{O}_{2}$, to avoid alveolar hypocapnia. Each inflation was followed by positive end expiratory pressure (PEEP) of $5 \mathrm{~cm} \mathrm{H}_{2} \mathrm{O}$ for five seconds. This procedure was repeated a total of 4 times (Fig. 3.1). Afterwards the lambs were connected to the ventilator.

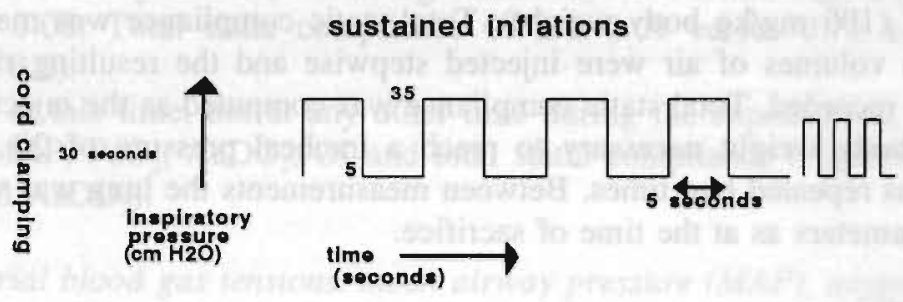

Figure 3.1 Sustained inflations as applied within 30 seconds after umbilical cord ligation in the treatment group.

The lambs allocated to the control group were connected immediately to a continuous flow, time cycled, pressure controlled, positive pressure ventilator (Amsterdam infant ventilator, Hoekloos, The Netherlands). Rectal temperature was kept, after an initial fall, within a range of $38^{\circ}-39^{\circ} \mathrm{C}$ during the experiment. At this time, pentobarbital $4 \mathrm{mg} / \mathrm{kg}$ (Narcovet, $60 \mathrm{mg} / \mathrm{ml}$ ) was administered as an intravenous bolus in approximately 20 seconds. Ampicillinum $100 \mathrm{mg} / \mathrm{kg}$ was given. A constant infusion of $5 \%$ glucose and pentobarbital $(4 \mathrm{mg} / \mathrm{kg} / \mathrm{h} /)$ was administered at $6.7 \mathrm{ml} / \mathrm{h}$. Sodium bicarbonate solution was administered intravenously when base excess fell below -5.0 meq/l. After every five blood samples, $5 \mathrm{ml}$ of fetal blood was administered to replace blood loss. Haematocrit was measured each three samples. When a pneumothorax occurred, a 10 Cherriere Trocar thoracic drain was placed in the thorax. Hypotension, when it occurred, was managed by administering blood. 


\subsubsection{Ventilation}

Initially all the lambs were ventilated with a continuous flow $\mathrm{O}_{2}(8 \mathrm{l} / \mathrm{min}), \mathrm{FiO}_{2}=1.0$, a PIP of $30 \mathrm{~cm} \mathrm{H}_{2} \mathrm{O}$ and a PEEP of $5 \mathrm{~cm} \mathrm{H}_{2} \mathrm{O}$, frequency 40 per minute and I:E = 1:1. The inspired gases were humidified and warmed. The first 15 minutes after birth the PIP was kept the same, then PIP was adjusted to keep $\mathrm{PaCO}_{2}$ within the range of 5.5 to $6.0 \mathrm{kPa}$. The total ventilation time was 8 hours.

\subsubsection{Data collection}

Arterial blood samples $(0.5 \mathrm{ml})$ were taken at $7,12,17$ and 40 minutes during the first hour postnatally and then at 30 minutes intervals. $\mathrm{PaO}_{2}, \mathrm{PaCO}_{2}, \mathrm{pH}, \mathrm{HCO} 3$ and base deficit blood samples were analyzed with an ABL-3 blood gas analyzer (Radiometer, Copenhagen, Denmark) and corrected for body temperature. $\mathrm{pH}, \mathrm{PaCO}_{2}, \mathrm{PaO}_{2}, \mathrm{PIP}$, mean airway pressure (MAP), oxygenation index (OI) and alveolar-arterial oxygen gradient $\left(\mathrm{AaDO}_{2}\right)$ were analyzed at each sample time and compared between groups. MAP was calculated as follows: MAP $=(\mathrm{Pi}) \times(\mathrm{Ti} / \mathrm{Ttot})+(\mathrm{Pe}) \times(\mathrm{Te} / \mathrm{Ttot})$, in this formula $\mathrm{Pi}=$ inspiratory pressure; $\mathrm{Ti}=$ inspiratory time; $\mathrm{Pe}=$ expiratory pressure; $\mathrm{Te}=$ expiratory time; Ttot $=$ inspiratory + expiratory time. $\mathrm{OI}=\mathrm{MAP} \times \mathrm{FiO}_{2} \times 100 / \mathrm{PaO}_{2}$; $\mathrm{AaDO}_{2}=$ atmospheric pressure $(760 \mathrm{~mm} \mathrm{Hg})$ - water vapour pressure $(47 \mathrm{~mm} \mathrm{Hg})$ $\mathrm{PaO}_{2}-\mathrm{PaCO}_{2}$. After eight hours the lambs were sacrificed with an overdose of pentobarbital $(100 \mathrm{mg} / \mathrm{kg}$ body weight). Total static compliance was measured as follows: known volumes of air were injected stepwise and the resulting rise in tracheal pressure was recorded. Total static compliance was computed as the injected air volume per $\mathrm{kg}$ wet body weight necessary to reach a tracheal pressure of $20 \mathrm{~cm} \mathrm{H}_{2} \mathrm{O}$. The procedure was repeated two times. Between measurements the lung was ventilated with the same parameters as at the time of sacrifice.

\subsubsection{Statistics}

All data are presented as mean \pm SEM. Differences between the two groups were evaluated using the nonparametric Mann-Whitney test. Incidence of pneumothorax, mortality and sex distribution between groups was tested with the $\mathrm{X}^{2}$-test. Differences between siblings were tested with the nonparametric Wilcoxon paired samples test. Statistical significance was considered when $p$ (two-tailed) $<0.05$.

\subsection{Results}

There was no difference between the two groups of lambs in gestational age, birth weight, sex distribution and initial blood gas samples before the umbilical cord was ligated (Table 3.1). SI were administered at $28 \pm 2.6$ seconds after birth and ventilation in the control group was started $25 \pm 1.2$ seconds postnatally. 
Table 3.1 Birth weight, sex and fetal blood gases before cord clamping. Data are given as mean $\pm S E M$.

\begin{tabular}{lcc}
\hline $\begin{array}{l}\text { group } \\
(\mathrm{n})\end{array}$ & $\begin{array}{c}\text { control } \\
(8)\end{array}$ & $\begin{array}{c}\text { sustained inflations } \\
(8)\end{array}$ \\
\hline birth weight $(\mathrm{kg})$ & $3.17 \pm 0.36$ & $3.32 \pm 0.22$ \\
$\mathrm{f} / \mathrm{m}$ & $3 / 5$ & $4 / 4$ \\
$\mathrm{pH}$ & $7.31 \pm 0.01$ & $7.31 \pm 0.01$ \\
$\mathrm{PaCO}_{2}(\mathrm{kPa})$ & $5.87 \pm 0.30$ & $5.99 \pm 0.30$ \\
$\mathrm{PaO}_{2}(\mathrm{kPa})$ & $2.91 \pm 0.16$ & $2.60 \pm 0.17$ \\
\hline
\end{tabular}

At eight hours postnatally, the variables considered for the treatment and control group were: MAP $14.8 \pm 1.8 \mathrm{~cm} \mathrm{H}_{2} \mathrm{O}$ versus $11.9 \pm 1.1 \mathrm{~cm} \mathrm{H}_{2} \mathrm{O} ; \mathrm{PaO}_{2} 41.5 \pm 7.3 \mathrm{kPa}$ versus $31.3 \pm 7.7 \mathrm{kPa} ; \mathrm{AaDO}_{2} 359 \pm 55 \mathrm{~mm} \mathrm{Hg}$ versus $437 \pm 58 \mathrm{~mm} \mathrm{Hg}$; OI $5.73 \pm 2.41$ versus $6.70 \pm 3.08$; Total static compliance $0.71 \pm 0.09$ versus $0.71 \pm 0.11 \mathrm{ml} / \mathrm{cm}$ $\mathrm{H}_{2} \mathrm{O} / \mathrm{kg}$ (Table 3.2).

There was not at this time, nor at any other time during the experiments, a significant difference in $\mathrm{MAP}, \mathrm{PaO}_{2}, \mathrm{AaDO}_{2}$, OI and total static compliance (Figures 3.2 and 3.3 show MAP and $\mathrm{AaDO}_{2}$ ).

Table 3.2 Arterial blood gas tensions, mean airway pressure (MAP), oxygenation index (OI), arterial-alveolar oxygen gradient $\left(\mathrm{AaDO}_{2}\right)$, total static lung compliance $(\mathrm{Cl})$ and incidence of pneumothorax are shown for the control and treatment group eight hours after birth. Data are presented as mean $\pm S E M$.

\begin{tabular}{|c|c|c|}
\hline group & control & sustained inflations \\
\hline 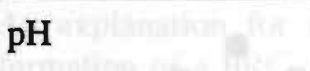 & $7.34 \pm 0.03$ & $7.33 \pm 0.01$ \\
\hline $\mathrm{PaCO}_{2}(\mathrm{kPa})$ & $5.58 \pm 0.38$ & $5.77 \pm 0.12$ \\
\hline $\mathrm{PaO}_{2}(\mathrm{kPa})$ & $31.3 \pm 7.66$ & $41.5 \pm 7.33$ \\
\hline MAP $\left(\mathrm{cm} \mathrm{H}_{2} \mathrm{O}\right)$ & $11.9 \pm 1.14$ & $14.8 \pm 1.79$ \\
\hline OI & $6.70 \pm 3.08$ & $5.73 \pm 2.41$ \\
\hline $\mathrm{AaDO}_{2}(\mathrm{~mm} \mathrm{Hg})$ & $437 \pm 57.9$ & $359 \pm 54.6$ \\
\hline $\mathrm{Cl}\left(\mathrm{ml} / \mathrm{cm} \mathrm{H} \mathrm{H}_{2} \mathrm{O} / \mathrm{kg}\right)$ & $0.71 \pm 0.11$ & $0.71 \pm 0.09$ \\
\hline pneumothorax & 2 & 3 \\
\hline
\end{tabular}


Figure 3.2 Mean airway pressure (MAP) in the treatment and control group during the eight hours of experimental period. Data are given as mean \pm SEM.

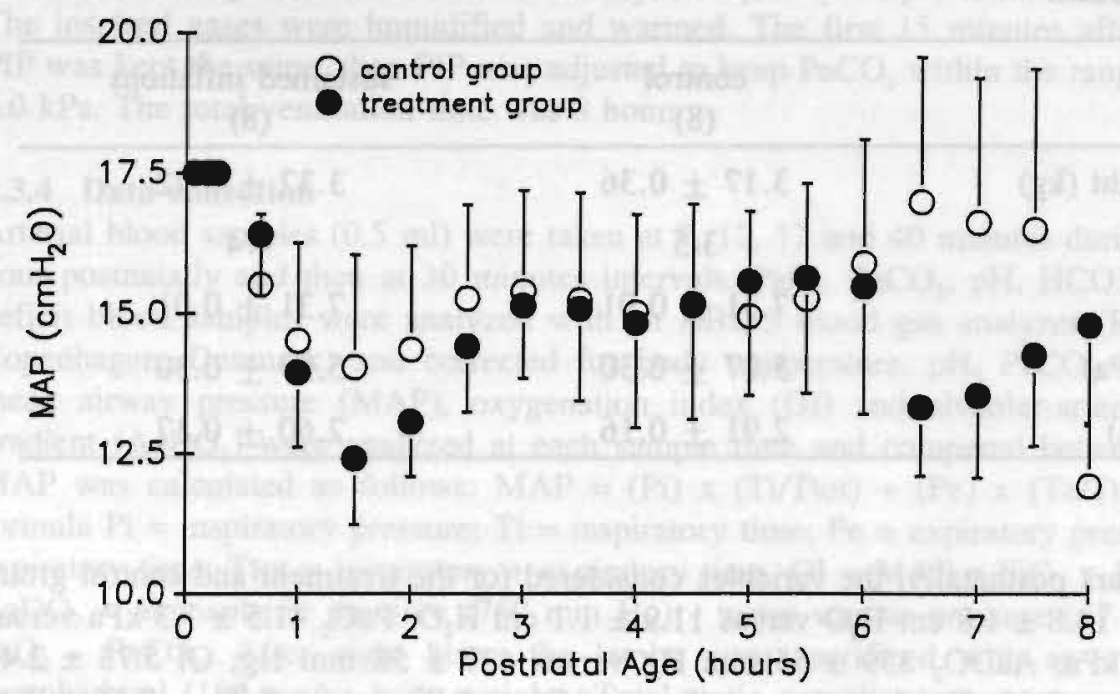

Figure 3.3 Arterial-alveolar oxygen gradient $\left(\mathrm{AaDO}_{2}\right)$ in the treatment and control group during the eight hours of experimental period. Data are presented as mean $\pm S E M$.

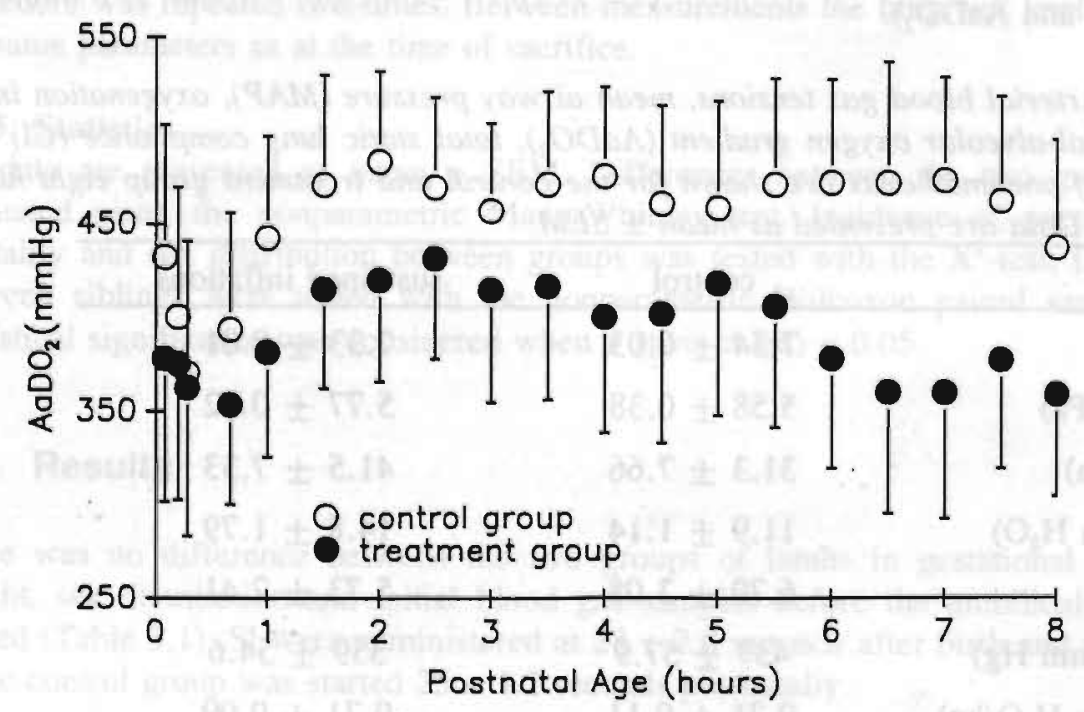


There was not a significant difference in clinical course, incidence of pneumothorax or mortality rate between groups. Moreover, even when siblings were tested in pairs, there was no difference in clinical course between control and treatment lambs.

Since first versus second born twins may have different postnatal courses, the first born from the sequential ewes was allocated to control or treatment group. Intrauterine $\mathrm{pH}$ was positively correlated between siblings (Pearson's $r=0.8076, p=0.015$ ). When comparing the eight first born lambs with the second born twin, disregarding the fact whether they were treatment or control lambs, we did not find significant differences in baseline condition and in postnatal course.

\subsection{Discussion}

The present study was designed to test whether SI applied during the first seconds of life might have an influence on the development or severity of RDS, lung function, and morbidity and mortality in premature lambs. Prolongation of the first inflations after birth did not influence lung function after 8 hours of life or significantly change blood gases during the experiments. There was no significant difference in outcome between the lambs receiving SI and their siblings, who served as a control group. By comparing siblings we had optimal control over intrauterine conditions.

In this study allocation of the first born of sequential ewes to control and treatment groups was proven to be superfluous, since there was no significant difference in postnatal course between first versus second born. The fetal $\mathrm{pH}$, taken just before cord clamping, was not different between siblings. This means that a prolonged intrauterine stay had no influence on $\mathrm{pH}$ in the second born twin.

SI did not improve lung function; these results are in accordance with Ikegami et al. (8), who did find an improvement in compliance after applying sustained inflations to fetal sheep in utero, but reported no difference in lung compliance after delivery and 4 hours of ventilation. Also, Hoskyns et al. (9) did not find an association between initial tidal exchange in the first three breaths after birth and the development of RDS in premature infants.

An explanation for the failure of SI to improve lung function could be inadequate formation of a FRC or, if formed, loss of the recruited volume. Vyas et al. (3) reported a significant correlation between inspiratory volume and FRC at the end of the first breath in vaginally delivered full-term infants. In our study, lambs were born by a caesarean section without preceding labour and squeeze by the birth canal. This could interfere with the formation of a FRC. Faxelius et al. (10) reported lower compliance and tidal volumes in infants during the first 30 minutes of life if they were born by caesarean section. Vyas et al. (11) confirmed that half of the babies delivered by caesarean section did not form a FRC.

Moreover, in our study we used premature newborn lambs. Hoskyns et al. (9) reported adequate tidal ventilation in five of 21 premature babies after ventilation with an inflation pressure of about $30 \mathrm{~cm} \mathrm{H} \mathrm{H}_{2} \mathrm{O}$ and inspiratory time of $1 \mathrm{sec}$. This rose to $33 \%$ by 
the third inflation. This was significantly less than in term infants $(77 \%)$. Upton and Milner (12) reported a mean pressure of $49 \mathrm{~cm} \mathrm{H}_{2} \mathrm{O}$ to be needed to produce visible movements of the chest wall in premature infants, this pressure was not related to gestational age or FRC (3). Therefore we choose prolonging inspiratory time rather than inspiratory pressure to improve early tidal exchange.

It is possible that the volume recruited during the inspiratory phase of SI might not have been sufficiently maintained during expiration. We did use a PEEP of $5 \mathrm{~cm} \mathrm{H}_{2} \mathrm{O}$ between the first inflations and later during mechanical ventilation. A PEEP of $5 \mathrm{~cm}$ $\mathrm{H}_{2} \mathrm{O}$ could have failed to prevent massive deflation of the recruited alveoli. Furthermore, since SI were manually applied, there was a period of approximately one second of disconnection from ventilation and as a consequence there was no PEEP. Solca et al. (1),(2) used in their study in the fetal lamb an intrapulmonary pressure of $15 \mathrm{~cm} \mathrm{H}_{2} \mathrm{O}$ after repeated deep insufflation and that possibly prevented derecruitment of alveoli during expiration. However, Milner and Saunders (6) reported that although the first expiration is usually accompanied by high, positive intrathoracic pressure, this is not essential for the formation of a gaseous residual volume. In the study of Vyas et al. (11) there was no relationship between the formation of a FRC and the expiratory pressure. We did not use higher PEEP values, because we wanted to study the effect of SI in a form that could be used for clinical purposes. PEEP of about $5 \mathrm{~cm} \mathrm{H}_{2} \mathrm{O}$ are generally used for management of premature infants, since a higher PEEP can have adverse effects on the cardiovascular system (13).

In our study there was no difference in clinical outcome between lambs in which sustained inflations were applied directly after cord clamping and the control group. It could be speculated that the PEEP offered in this work was not sufficient to maintain the alveolar recruitment achieved by sustained inflations. This could support the idea of using higher PEEP in lungs with tendency to collapse. This management must be balanced against the possible adverse effects of PEEP on the cardiovascular system. 


\section{References}

1. Solca M, Kolobow T, Huang H, Pesenti A, Buckhold D, Pierce JE. Management of the antenatal preterm fetal lung in the prevention of respiratory distress syndrome in lambs. Biol Neonate 1983;44:93-101.

2. Solca M, Kolobow T, Huang HH, Chen V, Buckhold DK, Pierce JE. Respiratory Distress Syndrome in immature lambs. Prevention through antenatal accelerated conditioning of the lung. Am Rev Respir Dis 1984;129:979-984.

3. Vyas H, Field D, Milner AD, Hopkin IE. Determinants of the first inspiratory volume and the functional residual capacity at birth. Pediatr Pulmonol 1986;2:189-193.

4. Boon AW, Milner AD, Hopkin IE. Lung expansion, tidal volume and formation of functional residual capacity during resuscitation of asphyxiated neonates. J Pediatr 1979;95:1031-1036.

5. Vyas H, Milner AD, Hopkin IE, Boon AW. Physiological responses to prolonged and slow rise inflation. J Pediatr 1981;99:635-639.

6. Milner AD, Saunders RA. Pressure and volume changes during the first breath of human neonates. Arch Dis Child 1977;52:918-924.

7. Sandberg K, Edberg K, Benton W, Silberberg A, Sladek M, Sundell HW. Surfactant improves gas mixing and alveolar ventilation in preterm lambs. Pediatr Res 1991;30(2):181-189.

8. Ikegami M, Jobe A, Berry D, Elkady T, Pettenazzo A, Seidner S. Effects of distension of the preterm fetal lamb lung on lung function with ventilation. Am Rev Respir Dis 1987;135:600-606.

9. Hoskyns EW, Milner AD, Boon AW, Vyas H, Hopkin IE. Endotracheal resuscitation of preterm infants at birth. Arch Dis Child 1987;62:663-666.

10. Faxelius G, Hägnevik K, Lagercrantz H, Lundell B, Irestedt L. Catecholamine surge and lung function after delivery. Arch Dis Child 1983;52:262-266.

11. Vyas H, Milner AD, Hopkin IE. Comparison of intrathoracic pressure and volume changes during spontaneous onset of respiration in babies born by caesarean section and by vaginal delivery. J Pediatr 1981;99:787-791.

12. Upton CJ, Milner AD. Endotracheal resuscitation of neonates using a rebreathing bag. Arch Dis Chid 1991;66:39-42.

13. Shaffer TH, Koen PA, Moskowitz GD, Ferguson JD, Delivoria-Papadopoulos M. positive end expiratory pressure: effects on lung mechanics of premature lambs. Biol Neonate 1978;34:1-10. 


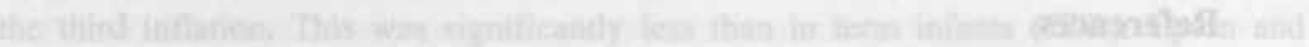

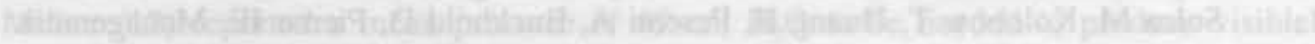

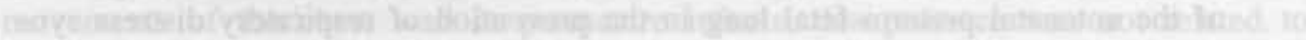
werang

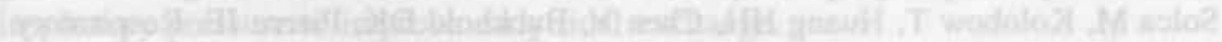

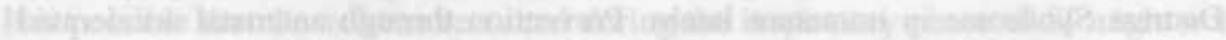

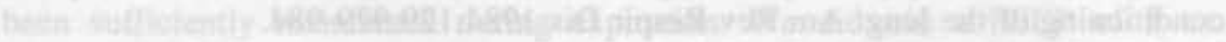

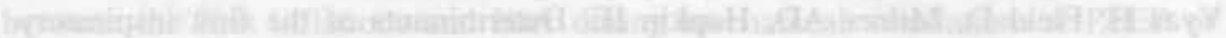

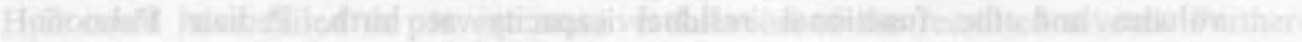

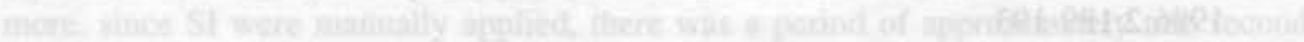

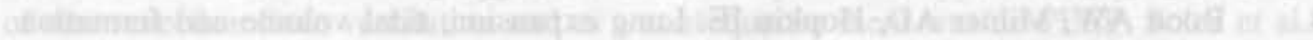

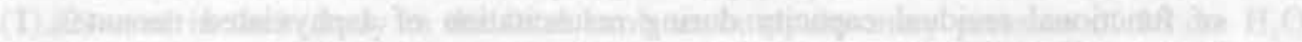

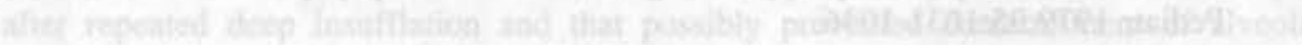

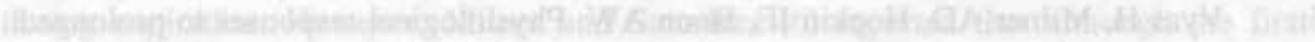

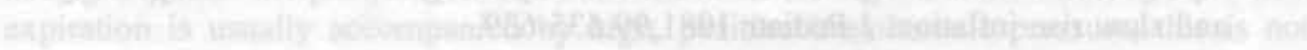

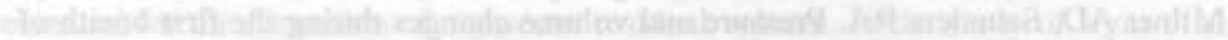

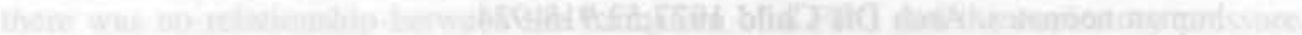

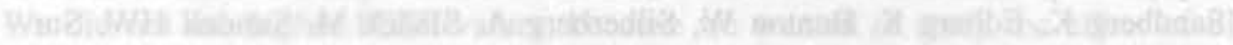

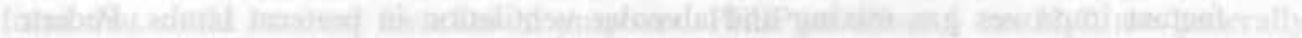

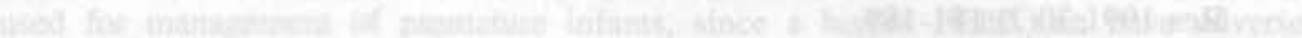

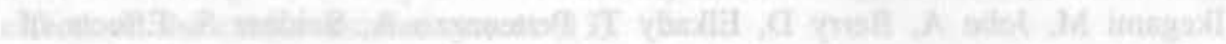

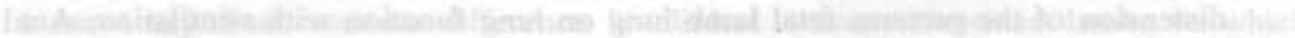

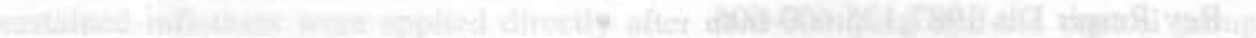

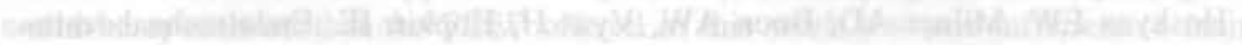

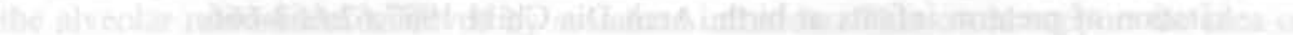

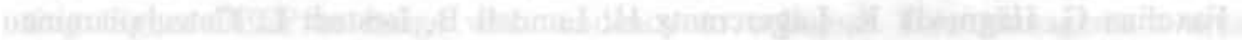

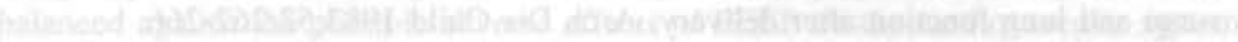

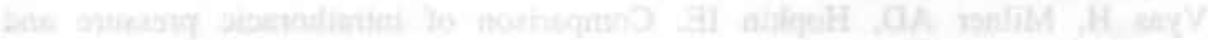

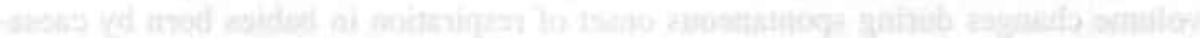

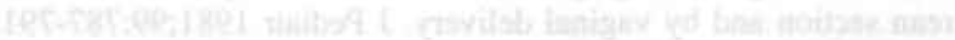

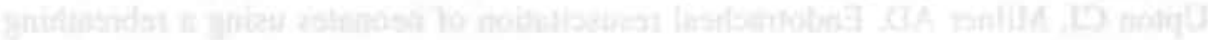

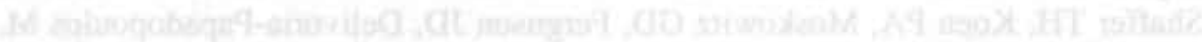

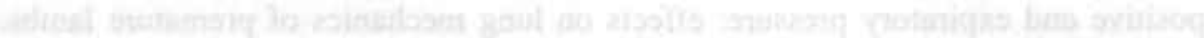




\title{
4) CARDIOVASCULAR CHANGES DURING SUSTAINED LUNG INFLATIONS (SI) IN PREMATURE NEWBORN LAMBS.
}

\author{
W.A.A. Klöpping-Ketelaars, W.J. Maertzdorf and C.E. Blanco \\ Accepted for publication in Acta Paediatrica.
}

\subsection{Abstract}

We studied the effect of sustained inspiratory inflations (SI) on the cardiovascular system by measuring mean central venous pressure (MCVP), mean arterial blood pressure (MABP) and heart rate (HR) before and during sustained lung inflations in premature lambs (128-133 days of gestation). SI consisted of 4 inflations of five seconds at a peak inspiratory pressure of $35 \mathrm{~cm} \mathrm{H}_{2} \mathrm{O}$ with a mixture of $5 \% \mathrm{CO}_{2}$ and $95 \% \mathrm{O}_{2}$. Each inflation was followed by a positive end expiratory pressure of $5 \mathrm{~cm} \mathrm{H}_{2} \mathrm{O}$ for five seconds. Percentage change from baseline in MABP and HR was respectively $-3.88 \%$ and $-2.55 \%$ during the first inflation. The changes in MCVP fluctuated with each inflation (an averaged $9.61 \%, p<0.01$ versus baseline) and deflation (averaged $-3.87 \%, p<$ 0.05 versus baseline). These changes were dependent on: 1) time after birth, and 2) the pressure used for SI. The observed cardiovascular changes produced by the procedure are considered of clinical relevance when managing premature infants with high risk for intraventricular haemorrhage.

\subsection{Introduction}

Respiratory distress syndrome (RDS) due to surfactant deficiency is the main respiratory disease in the neonatal period. Mechanical ventilation with high inspiratory and/or expiratory pressures and high oxygen concentrations is needed to counteract lung collapse and to maintain an adequate gas exchange. This management often causes complications as barotrauma and bronchopulmonary dysplasia. In 1984 Solca et al. (1) reported an improved lung compliance in premature fetal lambs after sustained inflations (SI) by mechanisms independently from surfactant. This procedure, known as "accelerated lung conditioning", consisted of 4 inflations of $35 \mathrm{~cm} \mathrm{H}_{2} \mathrm{O}$ and 4 deflations of $5 \mathrm{~cm} \mathrm{H} \mathrm{H}_{2} \mathrm{O}$, each of 5 seconds duration. The authors did not report the effect of this procedure on the cardiovascular system. 
A strong association exists between RDS, and in particular the severity of RDS, prematurity and intraventricular haemorrhage (IVH) (2). In recent years it has been emphasized that disturbances in cerebral blood flow are particularly important factors in causing IVH (3),(4). A likely mechanism in the premature infant is an impaired autoregulation of cerebral blood flow, thus becoming pressure passive. This means that, whenever systemic blood pressure changes, alterations in cerebral blood flow occur (5). Mechanical ventilation produces intrathoracic pressure swings, which produce fluctuations in blood pressure (6), therefore SI could increase the risk of IVH.

This report is part of a study evaluating the effect of SI on gas exchange, morbidity and mortality. The aim of the present study was to observe the influence of positive intrathoracic pressure on cardiovascular variables in premature newborn lambs.

\subsection{Material and methods}

\subsubsection{Animal preparation}

45 premature lambs born from 28 "Dutch Texel" ewes were operated at a gestational age of 128-133 days (term $=147$ days of gestational age). 10 lambs were from a single pregnancy and 35 were twins. General anaesthesia was induced with pentobarbital ( $1 \mathrm{~g}$ IV) intravenously and maintained with halothane (1\% in a $2: 1$ mixture of nitrous oxide and oxygen). Under sterile conditions a midline abdominal incision was made just below the umbilical scar. The fetal head was identified through the uterine wall and gently manipulated to a more anterior position. An incision of approximately eight to ten centimetres was made in the uterus in an area free from cotyledons and large blood vessels. The head of the lamb and a forelimb were exteriorized. An incision in the anterio-lateral part of the fetal neck was made and the external jugular vein and carotid artery were cannulated with $5 \mathrm{~F}$ catheters, which were advanced approximately $7 \mathrm{~cm}$. The position of the arterial catheter was pre-ductal. The cephalic vein in a forelimb was cannulated with a $5 \mathrm{~F}$ catheter, which was advanced approximately $3 \mathrm{~cm}$. An uncuffed endotracheal tube (4 or $4.5 \mathrm{~mm}$ ID) was positioned proximal of the head bronchus leading to the right cranial lobe and secured with a suture around the trachea. The incisions were closed using a continuous suture. Then the umbilical cord was clamped and ligated. Blood from the umbilical cord was withdrawn in a heparinized $(10 \mathrm{U} / \mathrm{ml})$ syringe and it was later used to compensate for blood loss due to sampling during the experiment. When it was a twin or triple pregnancy, the next fetus was delivered as soon as possible using the same procedure. The lamb was weighed and transported immediately to a radiant heater where it was connected to a ventilator.

The lambs were mechanically ventilated within approximately 40 seconds of cord clamping with a time cycled, pressure controlled ventilator (Amsterdam Infant Ventilator, Hoekloos, The Netherlands). At this time, pentobarbital $4 \mathrm{mg} / \mathrm{kg}$ (Narcovet, 60 $\mathrm{mg} / \mathrm{ml}$ ) was administered as an intravenous bolus in approximately 20 seconds and then a constant infusion of nutrient substrate $(5 \%$ glucose) together with pentobarbital (4 
$\mathrm{mg} / \mathrm{kg} / \mathrm{h}$ ) was administered at $6.7 \mathrm{ml} / \mathrm{h}$. Initially all the lambs were ventilated with $\mathrm{FiO}_{2}$ $=1.0$, flow rate of $8 \mathrm{l} / \mathrm{min}$, peak inspiratory pressure (PIP) of $30 \mathrm{~cm} \mathrm{H}_{2} \mathrm{O}$ and a positive end expiratory pressure (PEEP) of $5 \mathrm{~cm} \mathrm{H} \mathrm{H}_{2} \mathrm{O}$, a ventilator rate of 40 per minute and I:E $=1: 1$. Arterial blood samples for blood gas monitoring were taken at 30 minutes intervals and analyzed with an ABL-3 (Radiometer, Copenhagen, Denmark) blood gas analyzer and corrected for body temperature. After five blood samples, $5 \mathrm{ml}$ of umbilical cord blood was administered to replace blood loss.

\subsubsection{Sustained inflations}

Sustained inflations consisted of disconnecting the ventilator and inflating the lungs with a bag during five seconds at a PIP of $35 \mathrm{~cm} \mathrm{H}_{2} \mathrm{O}$ with a gas mixture of $5 \% \mathrm{CO}_{2}$ and $95 \% \mathrm{O}_{2}$. Each inflation was followed by a PEEP $5 \mathrm{~cm} \mathrm{H}_{2} \mathrm{O}$ for five seconds. This procedure was repeated a total of four times (Fig. 4.1). Total time needed for each procedure was 40 seconds. In 18 lambs SI were administered at four predetermined times: within 15 minutes and at approximately 1,2 and 3 hours postnatally. In 19 lambs only once at 15 minutes postnatally and in 8 lambs only once at approximately 4 hours postnatally. This makes a total of 99 observations divided in 37 observations at 15 minutes postnatally (Time 1), 18 observations each at 1,2 and 3 hours postnatally (Time 2,3 and 4) and 8 observations 4 hours postnatally (Time 5).

\subsubsection{Data collection}

Mean central venous pressure (MCVP), mean arterial pressure (MABP) and heart rate (HR) were recorded continuously from the jugular vein and carotid artery catheters (Spectramed DTX transducers, Bilthoven, the Netherlands) respectively. Tracheal pressure was measured proximal at the side of the tracheal tube. The signals were recorded continuously with an eight-channel Schwarzer polygraph. Calibration to atmospheric pressure occurred every hour. MCVP, MABP and HR were expressed as percentage change compared to baseline. Baseline values were recorded approximately 30 seconds before sustained inflations were applied. MCVP and MABP were evaluated during the last second of the first inflation of the SI period. For the purpose of describing dynamic changes of the cardiovascular parameters, we analyzed the changes of those parameters during the last second of each inflation and deflation during the SI procedure. HR was averaged during the 5 seconds of each in- and deflation and compared to 5 seconds of baseline. We have applied the sustained inflations at different times postnatally, respectively at $0: 15,1: 15,2: 15,3: 15$ and $4: 15$ hours after birth. At those times the baseline PIP needed to keep $\mathrm{PaCO}_{2}$ between 5.5 and $6.0 \mathrm{kPa}$ varied, since lung function was different in each individual lamb. Therefore we took into consideration the difference between baseline PIP and the inspiratory pressure used for $\mathrm{SI}$ and introduced this parameter as $\Delta \mathrm{P}$. 


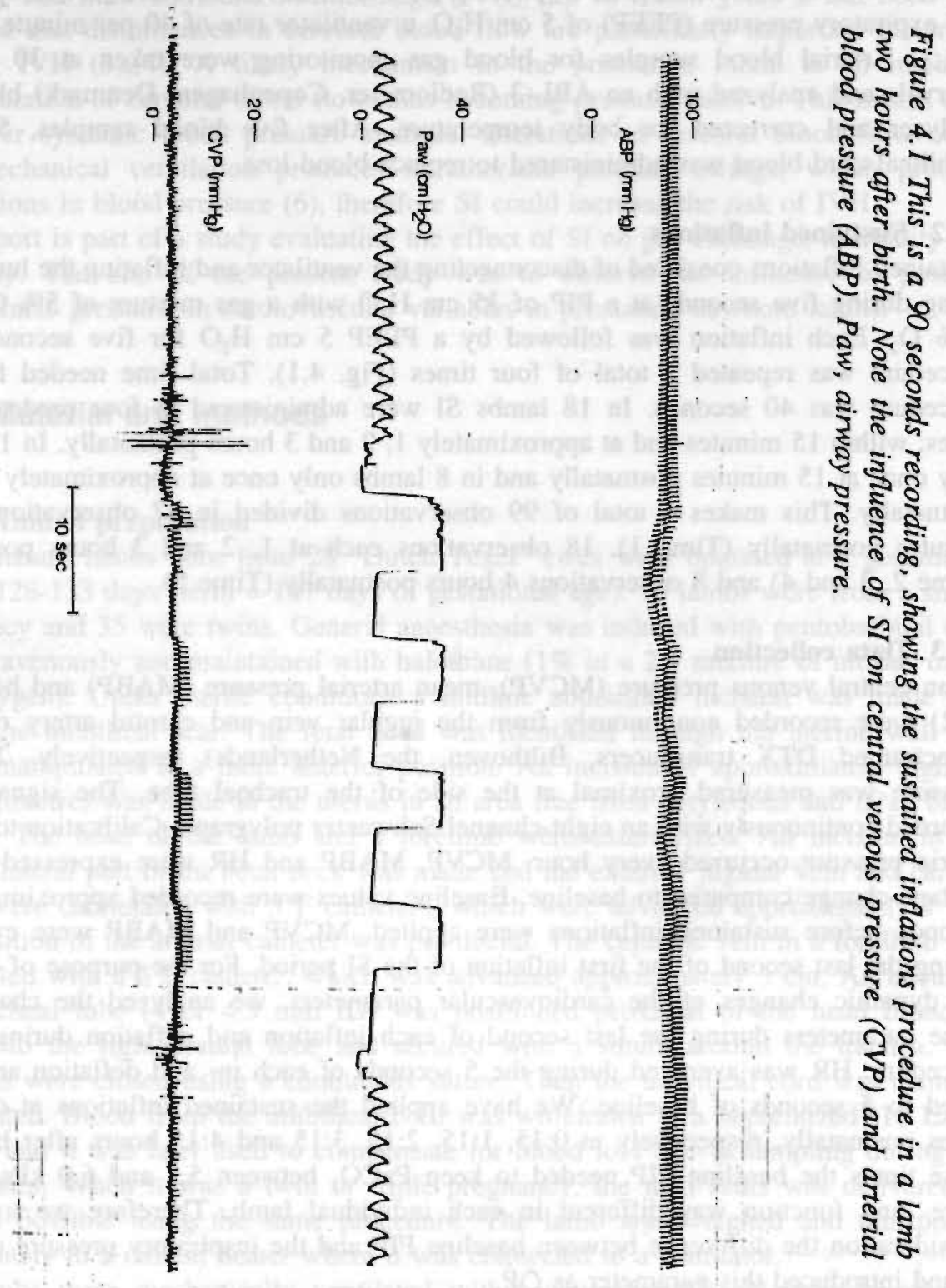




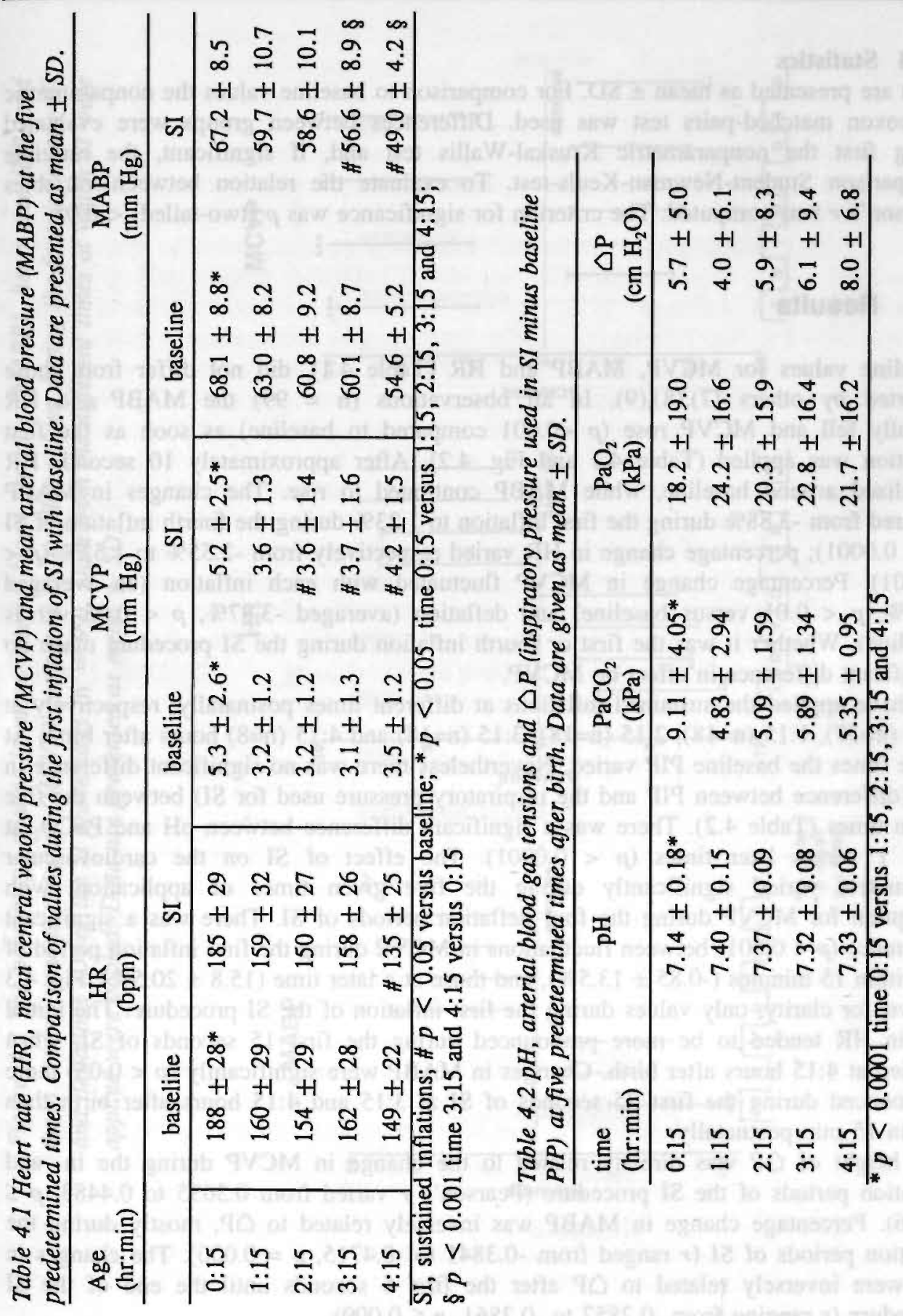




\subsubsection{Statistics}

Data are presented as mean $\pm S D$. For comparison to baseline values the nonparametric Wilcoxon matched-pairs test was used. Differences between groups were evaluated using first the nonparametric Kruskal-Wallis test and, if significant, the multiple comparison Student-Newman-Keuls-test. To evaluate the relation between variables Pearson's $r$ was computed. The criterion for significance was $p$ (two-tailed) $<0.05$.

\subsection{Results}

Baseline values for MCVP, MABP and HR (Table 4.1), did not differ from those reported by others (7),(8),(9). In all observations $(n=99)$ the MABP and HR initially fell and MCVP rose ( $p<0.001$ compared to baseline) as soon as the first inflation was applied (Table 4.1 and Fig. 4.2). After approximately 10 seconds HR stabilized around baseline, while MABP continued to rise. The changes in MABP differed from $-3.88 \%$ during the first inflation to $1.23 \%$ during the fourth inflation of SI $(p<0.0001)$; percentage change in HR varied respectively from $-2.55 \%$ to $1.52 \%(p<$ 0.0001 ). Percentage change in MCVP fluctuated with each inflation (an averaged $9.61 \%, p<0.01$ versus baseline) and deflation (averaged $-3.87 \%, p<0.05$ versus baseline). Whether it was the first or fourth inflation during the SI procedure made no significant difference in effect on MCVP.

We have applied the sustained inflations at different times postnatally, respectively at $0: 15(n=37), 1: 15(n=18), 2: 15(n=18), 3: 15(n=18)$ and 4:15 $(n=8)$ hours after birth. At those times the baseline PIP varied. Nevertheless there was no significant difference in $\Delta \mathrm{P}$ (difference between PIP and the inspiratory pressure used for SI) between the five given times (Table 4.2). There was a significant difference between $\mathrm{pH}$ and $\mathrm{PaCO}_{2}$ at time 1 versus later times $(p<0.0001)$. The effect of SI on the cardiovascular parameters varied significantly during the five given times of application, with exception for MCVP during the four deflation periods of SI. There was a significant difference $(p<0.001)$ between fluctuations in MCVP during the first inflation period of SI within 15 minutes $(-0.85 \pm 13.5 \%)$, and those at a later time $(15.8 \pm 20.5 \%)$. Fig. 4.3 shows, for clarity, only values during the first inflation of the SI procedure. The initial fall in HR tended to be more pronounced during the first 15 seconds of SI, when applied at 4:15 hours after birth. Changes in MABP were significantly $(p<0.05)$ more pronounced during the first 25 seconds of SI at 3:15 and 4:15 hours after birth than within 15 min postnatally.

The height of $\triangle P$ was directly related to the change in MCVP during the in- and deflation periods of the SI procedure (Pearson's $r$ varied from 0.3035 to $0.4483, p \leq$ 0.006). Percentage change in MABP was inversely related to $\triangle P$, mostly during the inflation periods of SI ( $r$ ranged from -0.3841 to $-0.4715, p=0.000$ ). The changes in HR were inversely related to $\triangle \mathrm{P}$ after the first 5 seconds until the end of the SI procedure ( $r$ ranging from -0.2857 to $-0.3861, p \leq 0.009$ ). 

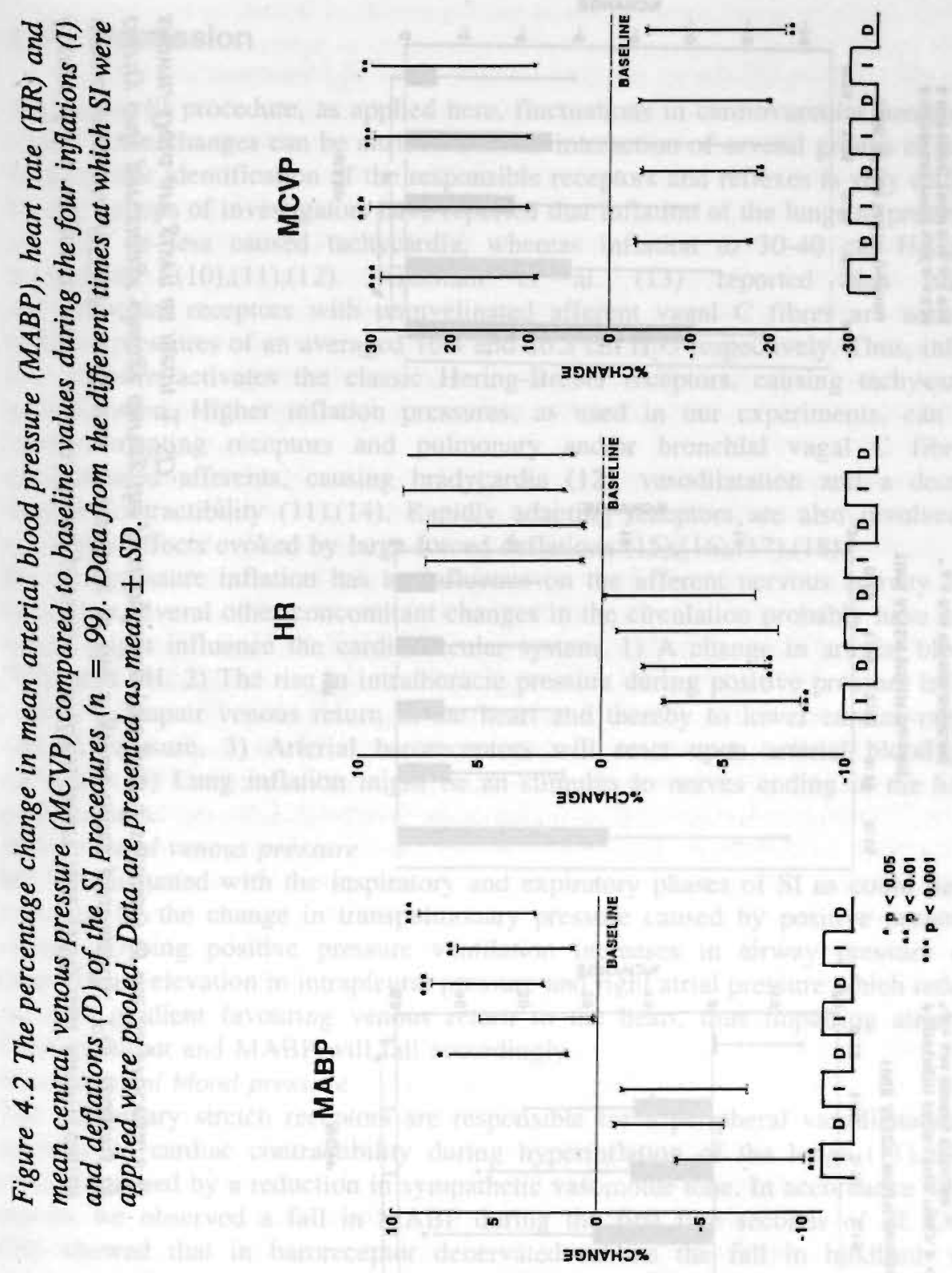

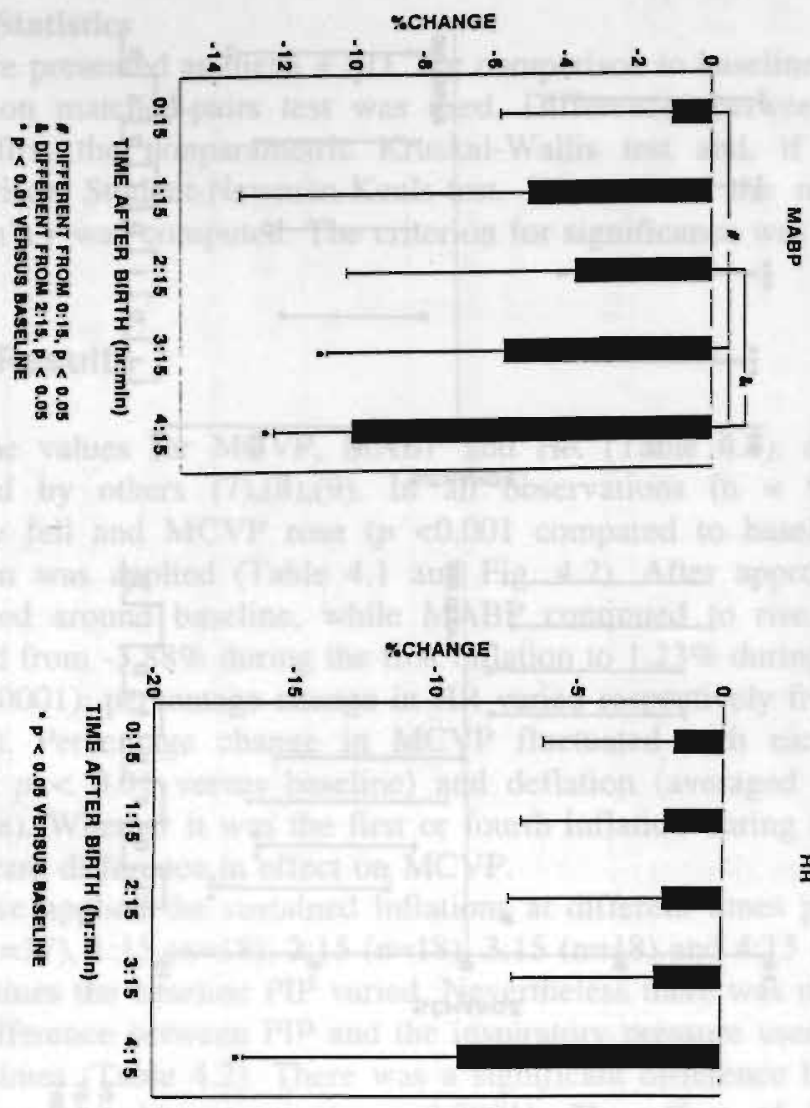

퐆

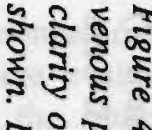

$\checkmark \stackrel{2}{2}$ 5

จ ชิ $\infty$ ) ริ ค 5 느 รี 8 อ อ 1 으녹 ๘ 00 ₹ ㄴํㅇ इ ริ \& 2 ธ. ₹ ฟิ ज ₹. นิร จุ o 07 รูป ถู่ 용

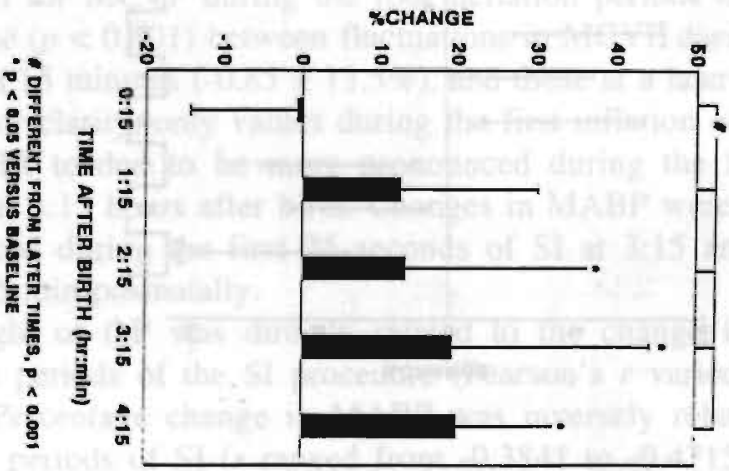
$=$ का $40^{2}$

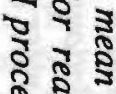
ริ ธิ त. थ 


\subsection{Discussion}

During the SI procedure, as applied here, fluctuations in cardiovascular parameters did occur. These changes can be attributed to the interaction of several groups of receptors. The separate identification of the responsible receptors and reflexes is very difficult.

Several groups of investigators have reported that inflation of the lungs to pressures of 9 $\mathrm{cm} \mathrm{H}_{2} \mathrm{O}$ or less caused tachycardia, whereas inflation to $30-40 \mathrm{~cm} \mathrm{H}_{2} \mathrm{O}$, caused bradycardia (10),(11),(12). Kaufman et al. (13) reported that pulmonary and bronchial receptors with unmyelinated afferent vagal $C$ fibres are activated by inflation pressures of an averaged 16.4 and $26.5 \mathrm{~cm} \mathrm{H}_{2} \mathrm{O}$ respectively. Thus, inflation at low pressure activates the classic Hering-Breuer receptors, causing tachycardia and vasodilatation. Higher inflation pressures, as used in our experiments, can activate rapidly adapting receptors and pulmonary and/or bronchial vagal $\mathrm{C}$ fibres with unmyelinated afferents, causing bradycardia (12), vasodilatation and a decrease in cardiac contractibility (11),(14). Rapidly adapting receptors are also involved in the excitatory effects evoked by large forced deflations (15),(16),(17),(18).

Positive pressure inflation has an influence on the afferent nervous activity from the lungs, but several other concomitant changes in the circulation probably have occurred, which might influence the cardiovascular system. 1) $\mathrm{A}$ change in arterial blood $\mathrm{PO}_{2}$, $\mathrm{PCO}_{2}$ and $\mathrm{pH}$. 2) The rise in intrathoracic pressure during positive pressure inflation is known to impair venous return to the heart and thereby to lower cardiac output and arterial pressure. 3) Arterial baroreceptors will react upon arterial blood pressure variations. 4) Lung inflation might be an stimulus to nerves ending in the heart and great vessels.

Mean central venous pressure

MCVP fluctuated with the inspiratory and expiratory phases of SI as could have been expected by the change in transpulmonary pressure caused by positive pressure ventilation. During positive pressure ventilation increases in airway pressure cause a proportional elevation in intrapleural pressure and right atrial pressure which reduces the pressure gradient favouring venous return to the heart, thus impairing atrial filling. Cardiac output and MABP will fall accordingly.

\section{Mean arterial blood pressure}

The pulmonary stretch receptors are responsible for a peripheral vasodilatation and a decrease in cardiac contractibility during hyperinflation of the lungs (11),(19). This effect is caused by a reduction in sympathetic vasomotor tone. In accordance with these reports we observed a fall in MABP during the first five seconds of SI. Ott et al. (20) showed that in baroreceptor denervated rabbits the fall in hindlimb vascular pressure could persist beyond 2 minutes during lung hyperinflation. The rise we have observed in MABP to levels above baseline values might have been due to a transient overshoot in the regulating mechanism of the arterial baroreceptors. The reduction in 
venous return can explain the variations observed in blood pressure related to in- and deflation.

\section{Heart rate}

We observed a fall in HR during the first 10 seconds of SI (disconnection and the first inflation and deflation period). This observation was in accordance with Kaufman et al. (13) who reported a decrease in heart rate at $3 \pm 0.3$ seconds after an inflation started. Glick et al. (11) reported that when pulmonary distension is maintained, variables would usually return to baseline levels in 20-60 seconds, but when the lungs were deflated variables returned to baseline within seconds. We observed a return to HR baseline values after 10 seconds; during the first deflation bradycardia persisted. An explanation might be that the response to deflation can be modified after a hyperinflation. Hainsworth (12) reported the same phenomenon after an inflation to $40 \mathrm{~cm} \mathrm{H}_{2} \mathrm{O}$ and attributed it to a loss of sensitivity of reflex activity after overstretching. The consequent rise to baseline values we have observed might again have been caused by systemic baroreceptor compensation.

The stimulus triggered by inflation and stretch may be modified by several factors, including anaesthetics, congestion of the lung, lung compliance and changes in alveolar $\mathrm{PCO}_{2}(21)$. We have added $5 \% \mathrm{CO}_{2}$ to the inspired gas during the SI procedure, the bradycardia and vasodilatation we have reported might have been attenuated by a direct depressive effect of inhaled $\mathrm{CO}_{2}$ on pulmonary stretch receptors (22).

We reported a significant difference in response of MCVP to SI at 15 minutes after birth compared to later times. This difference could be due to the greater amount of fluid still remaining in the lungs, shortly after birth (23),(24). The noncompliant lungs would attenuate transmission of positive pressure. Mirro et al. (25) showed that positive pressure ventilation in the neonate declines cardiac output, but that these effects are blunted when respiratory compliance is decreased. Less pressure is transmitted to other intrathoracic structures and the cardiovascular consequences are minimised. Lung stretch receptors are influenced by changes in the mechanical properties of the lungs, presumably because they are situated in the airway wall and are affected by the pull of the lung parenchyma on the airways. Sellick and Widdicombe (26) have published the inverted relationship between lung compliance and the sensitivity of the rapidly adapting receptors. If at 15 minutes after birth lung distensibility was less, lung stretch activity should have had more effect on MABP and HR. This is at variance with our results. One explanation might be that in our experiments hypercapnia was present 15 minutes after birth. Hypercapnia might have been counteracting vasodilatation by a vasoconstrictor response of the carotid chemoreflex (27). The more pronounced decrease in HR and MABP seen at 3 and 4 hours after birth could be due to deterioration of the lungs. However, we did not need a higher baseline PIP. $\triangle \mathrm{P}$ at these times was not significantly different from other times postnatally and could not have caused the greater fall in HR and MABP.

In our work $\triangle \mathrm{P}$ had an influence on the response of the cardiovascular parameters which is in accordance with reports by Daly et al. (19), Cassidy and Johnson (10) and 
Glick (11). The magnitude of the change in cardiovascular parameters to lung inflation was directly proportional to the magnitude of the pressures used to inflate the lungs.

Intracerebral haemorrhage is often seen in premature infants, mainly those of less than 32 weeks of gestational age (28). The basic lesion is bleeding in the subependymal germinal matrix. In the final 12-16 weeks of gestation this matrix becomes less prominent and disappears by term. The region is highly cellular, gelatinous and richly vascularized.

Fluctuations in blood pressure have been reported as having a role in the pathogenesis of IVH (2),(3),(29). In infants with severe IVH cerebral blood flow values had changed by a mean of $4.0 \%$ per $\mathrm{mm} \mathrm{Hg}$ change in mean arterial blood pressure (30). An increase in mean central venous pressure has also been associated with the occurrence of IVH (31),(32),(33). A systemic hypotension leading to a decrease in cerebral blood flow can encourage IVH by injuring the matrix capillaries, which then rupture upon reperfusion (34). Therefore, fluctuations in blood pressure should be avoided.

The question whether the fluctuations observed in our work would have resulted in an increase in incidence of IVH remains unanswered, since we used lambs too advanced in gestation. In the sheep, compared to the human infant, there is a discrepancy in lung maturation and the maturation of the germinal layer. The rate of change in the appearance of the germinal layer with gestation is proportionally less in the sheep fetus. At 58-85 days of gestation the germinal layer in the sheep fetus resembles that of an infant of 28-30 week gestation (35).

In conclusion: SI produce significant changes in the cardiovascular system. These changes are dependent on: 1) time after birth when SI is applied, and 2) the pressure used for SI. These observations are important when considering SI in the management of premature infants at risk for cerebral intraventricular haemorrhage. 


\section{References}

1. Solca M, Kolobow T, Huang HH, Chen V, Buckhold DK, Pierce JE. Respiratory Distress Syndrome in immature lambs. Prevention through antenatal accelerated conditioning of the lung. Am Rev Respir Dis 1984;129:979-984.

2. Perlman JM, McMenamin JB, Volpe JJ. Fluctuating cerebral blood flow velocity in respiratory distress syndrome: relation to the development of intraventricular hemorrhage. N Engl J Med 1983;309:204-209.

3. Perlman JM, Goodman S, Kreusser KL, Volpe JJ. Reduction in intraventricular hemorrhage by elimination of fluctuating cerebral blood flow velocity in preterm infants with respiratory distress syndrome. N Engl J Med 1985;312:1353-1357.

4. Lou HC, Lassen NA, Friis-Hansen B. Low cerebral blood flow in hypotensive perinatal distress. Acta Neurol Scand 1977;56:343-352.

5. Lou HC, Lassen NA, Friis-Hansen B. Impaired autoregulation of cerebral blood flow in the distressed newborn infant. J Pediatr 1979;94(1):118-121.

6. Dykes FD, Lazzra A, Ahmann P, Blumenstein B, Schwartz J, Brann AW. Intraventricular hemorrhage: a prospective evaluation of etiopathogenesis. Pediatrics 1980;66:42-49.

7. Jobe A, Jacobs H, Ikegami M, Jones S. Cardiovascular effects of surfactant suspensions given by tracheal instillation to premature lambs. Pediatr Res 1983;17:444-448.

8. Jobe A, Ikegami M, Jacobs $H$, Jones S. Surfactant pool sizes and severity of RDS in prematurely delivered lambs. Am Rev Respir Dis 1983;127:751-755.

9. Shaffer TH, Bhutani VK, Wolfson MR. Studies on developmental physiology in the preterm using liquid ventilation. In: The physiological development of the fetus and newborn. Academic Press, London 1985; p 337-341.

10. Cassidy SS, Johnson RL Jr. Pressure-Volume (P-V) characteristics of the reflex cardiovascular (CV) response to lung inflation in dogs. Physiologist 1979;22(4):18 (Abstract).

11. Glick G, Wechsler AS, Epstein SP. Reflex cardiovascular depression produced by stimulation of pulmonary stretch receptors in the dog. J Clin Invest 1969:48:467473.

12. Hainsworth R. Circulating responses from lung inflation in anesthetized dogs. Am J Physiol 1974;226:247-255.

13. Kaufman MP, Iwamoto GA, Ashton JH, Cassidy SS. Responses to inflation of vagal afferents with endings in the lung of dogs. Circ Res 1982;51:525-531.

14. Cassidy SS, Eshenbacher WL, Johnson RL Jr. Reflex cardiovascular depression during unilateral lung hyperinflation in the dog. J Clin Invest 1979;64:620-626.

15. Adrian ED. Afferent impulses in the vagus and their effect on respiration. J Physiol (London) 1933;79:323-358.

16. Knowlton GC, Larrabee MG. A unitary analysis of pulmonary volume receptors. Am J Physiol 1946;147:100-114.

17. Paintal A. Vagal sensory receptors and their reflex effects. Physiol Rev 1973;53:159-227. 
18. Widdicombe JG. Nervous receptors in the respiratory tree and lungs. In: Lung Biology in Health and Disease. Regulation of Breathing, ed. Hornbeim T. New York: Dekker, 1981, vol.17, p 429-472.

19. Daly $\mathrm{M}$ de B, Hazzledine JL, Ungar A. The reflex effects of alterations in lung volume on systemic vascular resistance in the dog. J Physiol London 1967; 188:331-351.

20. Ott NT, Sheperd JT. Vasodepressor reflux from lung inflation in the rabbit. Am J Physiol 1971;221:889-895.

21. Coleridge HM, Coleridge JCG. Afferents of the pulmonary vascular bed and their role. In: Integrative Functions of the Autonomic Nervous System. eds Brooks CM, Koizumu K, Sato A. Amsterdam: Elsevier, 1979; p 98-110.

22. Bradley GW, Noble MIM, Trenchard D. The direct effect on pulmonary stretch receptor discharge produced by changing lung carbon dioxide concentration in dogs on cardiopulmonary bypass and its action on breathing. J Physiol London 1976;261:359-373.

23. Bland RD, Hansen TN, Haberkern CM, Bressack MA, Hazinsky TA, Usha Raj J, Goldberg RB. Lung fluid balance in lambs before and after birth. J Applied Physiol 1982;53(4):992-1004.

24. Bland RD, McMillan DD, Bressack MA, Dong L. Clearance of liquid from lungs of newborn rabbit. J Appl Physiol 1980;49(2):171-177.

25. Mirro R, Busija D, Green R, Leffler C. Relationship between mean airway pressure, cardiac output, and organ blood flow with normal and decreased respiratory compliance. J Pediatr 1987;111:101-106.

26. Sellick $\mathrm{H}$, Widdicombe JG. Vagal deflation and inflation reflexes mediated by lung irritant receptors. Q J Exp Physiol 1979;55:153-163.

27. Koehler RC, McDonald BW, Krasney JA. Influence of $\mathrm{CO}_{2}$ on cardiovascular response to hypoxia in conscious dogs. Am J Physiol 1980;239:H545-H558.

28. Volpe JJ. Neurology of the newborn, 2nd edition, Philadelphia. PA: WB Saunders Co; 1987.

29. Bada HS, Korones SB, Perry EH, Arheart KL, Ray JD, Massroor Pourcyrous, Magill HL, Runyan W, Somes GW, Clark FC, Tullis KV. Mean arterial blood pressure changes in premature infants and those at risk for intraventricular hemorrhage. J Pediatr 1990;117:607-614.

30. Pryds O, Greisen G, Lou H, Friis-Hansen B. Heterogeneity of cerebral vasoreactivity in preterm infants supported by mechanical ventilation. $J$ Pediatr 1989;115:638-645.

31. Vert $\mathbf{P}$, Nomin $\mathrm{P}$, Sibout $\mathrm{M}$. Intracranial venous pressure in newborns: Variation in physiologic state and in neurologic and respiratory disorders. In: Intensive Care in the Newborn. Stern L, (ed): New York, Masson, 1975, p 185.

32. DeLemos RA, Tomasovic JJ. Effects of positive pressure ventilation on cerebral blood flow in the newborn infant. Clin Perinatol 1978;5:395-409.

33. Milligan DWA. Positive pressure ventilation and cranial volume in newborn infants. Arch Dis Child 1981;56:331-335. 
34. Fujimura M, Salisbury DM, Robinson RO, Howat P, Emerson PM, Keeling JW, Tizard JPM. Clinical events relating to intraventricular haemorrhage in the newborn. Arch Dis Child 1979;54:409-414.

35. Reynolds ML, Evans CAN, Reynolds EOR, Saunders NR, Durbin GM, Wigglesworth JS. Intracranial haemorrhage in the preterm sheep fetus. Early Human Develop 1979;3(2):163-186. 


\section{QUANTITATIVE AND QUALITATIVE EVALUATION OF LUNG MORPHOLOGY AFTER SUSTAINED INFLATIONS IN THE PREMATURE LAMB. THE INFLUENCE OF SEX, GESTATIONAL AGE AND CLINICAL OUTCOME.}

W.A.A. Klöpping-Ketelaars, M. Havenith, W.J. Maertzdorf and C.E. Blanco

\subsection{Abstract}

Lung collapse due to surfactant deficiency is one of the main causes of respiratory distress syndrome in the neonatal period. In 86 premature lambs (128-133 days of gestational age) the possibility to improve lung distensibility was studied by applying sustained inflations (SI) during the first hours of age. SI consisted of disconnecting the ventilator and manually inflating the lungs with a bag during five seconds at a peak inspiratory pressure of $35 \mathrm{~cm} \mathrm{H}_{2} \mathrm{O}$ with a mixture of $5 \% \mathrm{CO}_{2}$ and $95 \% \mathrm{O}_{2}$. Each inflation was followed by positive end expiratory pressure of $5 \mathrm{~cm} \mathrm{H}_{2} \mathrm{O}$ for 5 seconds. This procedure was repeated a total of four times. SI were applied in: group A) directly after cord clamping, group 1) once within 15 minutes after birth, group 2) within 15 minutes after birth and repeated each hour for 3 hours, group 3 ) once at 4 hours of age. Three control groups were formed: group B) sibling controls to group A, group 4) as in group 1 , except that during disconnection the lungs were inflated at the same pressure as for sustained inflations, but with a shorter inspiratory time, group 5) lambs were ventilated without any manipulation. After qualitative description of macroscopical lung damage, lung expansion was measured morphometrically in 48 of the premature newborn lambs. No significant differences in degree of macroscopical lung damage and parenchymalalveolar air space area ratio existed between the seven groups.

\subsection{Introduction}

Lung collapse due to surfactant deficiency is one of the main causes of respiratory distress syndrome (RDS) in the neonatal period. Solca et al (1) reported an improvement of lung compliance and prevention of RDS by applying sustained inflations (SI) in fetal lambs. We studied the possibility to improve lung distensibility by SI during the 
first hours of age in newborn premature lambs. The data on pulmonary function are described in chapter 3 and 4 . In the present study the results regarding macroscopical evaluation of lung damage and the quantitative measurement of lung expansion are reported and compared between treatment and control groups. Also, the morphometric and macroscopic results have been related to gestational age, sex and clinical outcome to estimate and compare the possible influence of these parameters on lung morphology.

\subsection{Material and methods}

\subsubsection{Animal preparation}

86 lambs at a gestational age of $128-133$ days (term $=147$ days of gestational age) were delivered by a caesarean section. After hysterotomy the fetal trachea was identified and an uncuffed endotracheal tube (4 or $4.5 \mathrm{~mm}$ ID) was positioned proximal of the head bronchi leading to the right cranial lobe and secured with a suture around the trachea. The umbilical cord was clamped, ligated and the lamb exteriorized.

\subsubsection{Experimental procedure}

If SI were not directly applied after cord clamping, the lambs were weighed and transported immediately to a radiant heater where the tracheal tube was connected to a continuous flow, time cycled, pressure controlled, positive pressure ventilator (Amsterdam infant ventilator, Hoekloos, The Netherlands). The period before ventilation usually took about $30-45$ seconds. Initially all the lambs were ventilated with a continuous flow $\mathrm{O}_{2}(8 \mathrm{l} / \mathrm{min}), \mathrm{FiO}_{2}=1.0$, a PIP of $30 \mathrm{~cm} \mathrm{H} \mathrm{H}_{2} \mathrm{O}$ and a PEEP of $5 \mathrm{~cm} \mathrm{H}_{2} \mathrm{O}$, the respirator rate was 40 per minute and $\mathrm{I}: \mathrm{E}=1: 1$. The inspired gases were humidified and warmed. Later PIP was adjusted to keep $\mathrm{PaCO}_{2}$ within the range of 5.5 to $6.0 \mathrm{kPa}$. All lambs were positioned on their left side to control for the possible effect of gravity on lung morphology. Lambs positioned on their side tended to have atelectatic dependent lungs with better aerated, non-dependent lungs (2).

\subsubsection{Sustained inflations}

Sustained inflations consisted of disconnecting the ventilator and inflating the lungs during five seconds with a bag at a PIP of $35 \mathrm{~cm} \mathrm{H}_{2} \mathrm{O}$ with a mixture of $5 \% \mathrm{CO}_{2}$ and $95 \% \mathrm{O}_{2}$, to avoid alveolar hypocapnia. Each inflation was followed by PEEP of $5 \mathrm{~cm}$ $\mathrm{H}_{2} \mathrm{O}$ for five seconds. This procedure was repeated a total of four times. SI were applied in: group A) directly after cord clamping, group 1) once within 15 minutes after birth, group 2) within 15 minutes after birth and repeated each hour for three hours, group 3) once at four hours of age. Three control groups were formed: group B) sibling controls to group A, group 4) as in group 1, except that during disconnection the lungs were inflated at the same pressure as for the sustained inflations, but with shorter inspiratory time, group 5) lambs were ventilated without any manipulation. 


\subsubsection{Data collection}

$\mathrm{PH}, \mathrm{PaCO}_{2}, \mathrm{PaO}_{2}, \mathrm{PIP}$, mean airway pressure (MAP), oxygenation index (OI) and alveolar-arterial oxygen gradient $\left(\mathrm{AaDO}_{2}\right)$ were determined every 30 minutes and compared between groups. MAP was calculated as follows: $\mathrm{MAP}=(\mathrm{Pi})(\mathrm{Ti} / \mathrm{Ttot})+(\mathrm{Pe})$ ( $\mathrm{Te} / \mathrm{Ttot}$ ), in this formula $\mathrm{Pi}=$ inspiratory pressure; $\mathrm{Ti}=$ inspiratory time; $\mathrm{Pe}=$ expiratory pressure; $\mathrm{Te}=$ expiratory time; $\mathrm{Ttot}=$ inspiratory + expiratory time. $\mathrm{OI}=$ MAP x FiO ${ }_{2} \times 100 / \mathrm{PaO}_{2} . \mathrm{AaDO}_{2}=$ atmospheric pressure $(760 \mathrm{~mm} \mathrm{Hg})$ - water vapour pressure $(47 \mathrm{~mm} \mathrm{Hg})-\mathrm{PaO}_{2}-\mathrm{PaCO}_{2}$. After eight hours the lambs were sacrificed with an overdose of pentobarbital ( $100 \mathrm{mg} / \mathrm{kg}$ body weight). Total static compliance was measured as follows: known volumes of air were injected stepwise and the resulting rise in tracheal pressure was recorded up to $30 \mathrm{~cm} \mathrm{H}_{2} \mathrm{O}$. Total respiratory compliance was computed as the injected air volume per wet body weight necessary to reach a tracheal pressure of $20 \mathrm{~cm} \mathrm{H}_{2} \mathrm{O}$. The procedure was repeated twice. Between measurements the lungs were ventilated with the same parameters as at the time of sacrifice.

\subsubsection{Macroscopical evaluation and morphometry}

The tracheal tube was clamped at end-inspiration, the abdomen was opened and the diaphragm inspected for any evidence of pneumothorax. After opening the thorax, the macroscopic appearance of the lungs of the lung was evaluated according to five grades described in a study by Kolobow et al. (3): no damage, light, moderate, severe and very severe damage.

After macroscopic inspection, the lungs and heart were excised with the tracheal clamp in situ. The lungs were fixed by intratracheal instillation of $4 \%$ buffered formaldehyde. After immersion in buffered formaldehyde, a fixative column was held $20 \mathrm{~cm}$ above the carina for one hour, which resulted in the lungs being expanded evenly. The immersion of the lungs in the fixative prevented distortion of the lungs from the weight of the fluid filled organ. To keep the head of pressure at $20 \mathrm{~cm} \mathrm{H}_{2} \mathrm{O}$, the fixative was slowly added in the column.

After 24 hours of immersion at room temperature, the lungs were sliced up into 10 blocks of $1.5 \mathrm{~cm}^{2}$ tissue selecting a central and peripheral area in each lobe. After dehydration, the blocks of tissue were embedded in paraffin, sliced into $5 \mu \mathrm{m}$ thick sections and stained with haematoxylin and eosin. In the eight lambs of group A and B only central sections of the right lower lung lobe (rll) were used. At least 6 animals per group were chosen at random in the five other groups. In 7 lambs from group 2 and 3 and 6 lambs from group 1,4 and 5 sections were taken centrally and peripherally of the right lower lung lobe. The proportion of parenchyma versus alveolar space ( $\mathrm{Vv}$ par) was evaluated using the image analyzer (CAS 200, Inc., Becton and Dickinson Image Cytometry Systems, the Netherlands) and its Quantitative Nuclear Antigen program. The program operates with two masks. One mask determines the total area of the measured parts of the section. The other mask defines a threshold, which differentiates the parenchyma, which is expressed as a percentage of the total measured sectional area. We also determined the field-to-field variability of the measurements (CV) for each lobe. The examining histologist was unaware of the treatment given. 
Twenty fields at $400 \mathrm{x}$ were studied in each section in each animal. These fields were selected at random by stepwise movements of the histological section under the microscope, rejecting every field in which bronchi, bronchioles, large vessels, or obvious artifacts would interfere with the subsequent measurements of alveolar spaces. The progressive mean and standard deviation were calculated in 5 slides. Statistical stability, defined as a stable progressive mean and standard deviation was reached in all after counting 20 fields.

\subsubsection{Statistics}

Field-to-field variability (CV) was computed as the square root of variance divided by the mean times $100 \%$. All data are presented as mean \pm SD. Differences between groups were evaluated with the nonparametric Kruskal-Wallis and Mann-Whitney tests. Relationships between parameters were evaluated by computing Pearson's correlation coefficient. The criterion for statistical significance was $p$ (two-tailed) $<0.05$.

\subsection{Results}

There were no significant differences in the macroscopical evaluation of the degree of lung damage between the seven groups (Table 6.1A en B). In the 48 lambs which were evaluated morphometrically there were no significant differences between the seven groups in parenchymal-alveolar air area ratio and field-to-field variability (Table 6.2). Analysis of the differences between the groups with as covariant gestational age, sex, birth weight or mortality did not yield other results than the above.

Results from the qualitative evaluation of lung damage were compared with those from the quantitative evaluation: $V v$ par centrally in the rll was directly related to degree of macroscopical lung damage $(r=0.4806, p=0.001)$. Central CV was inversely related ( $r=-0.5058, p=0.000$ ) to the degree of lung damage. Peripherally in the rll there was no relation between $\mathrm{Vv}$ par and qualitative evaluation, but peripheral $\mathrm{CV}$ was inversely related $(r=-0.4797, p=0.005)$.

Central Vv par was inversely related to central CV $(r=-0.6608, p=0.000)$ and to peripheral CV $(r=-0.4650, p=0.006)$. It was directly related with Vv par peripherally $(r=0.6472, p=0.000)$. Parenchymal-alveolar air area ratio centrally, but not peripherally, in the rll was related to $\mathrm{PaO}_{2}(r=-0.4175, p=0.003)$, MAP $(r=0.3724$, $p=0.009)$ and $\mathrm{AaDO}_{2}(r=0.4170, p=0.003)$ at 8 hours postnatally or at the last sample obtained before death. Field-to-field variability centrally in the rll was correlated with $\mathrm{PaO}_{2}(r=0.5334, p=0.000)$, MAP $(r=-0.5344, p=0.000)$ and $\mathrm{AaDO}_{2}(r=$ $-0.5146, p=0.000)$. CV peripherally was correlated with $\mathrm{PaO}_{2}(r=0.3787, p=0.033)$, MAP $(r=-0.4613, p=0.008)$ and OI $(r=-0.4331, p=0.013)$. Total static lung compliance was not related to Vv par or CV. 
Table 5.1A Macroscopical evaluation of all premature lambs $(n=86)$ used in this thesis.

\begin{tabular}{llllllll}
$\begin{array}{l}\text { macroscopical } \\
\text { lung damage: }\end{array}$ & G1 & G2 & G3 & G4 & G5 & GA & GB \\
\hline no & & 1 & & & & & \\
light & 4 & 6 & 3 & 4 & 2 & 4 & 3 \\
moderate & 8 & 3 & 1 & 7 & 2 & 1 & 2 \\
severe & 3 & 5 & 3 & 4 & 3 & 3 & 2 \\
very severe & 4 & 3 & 1 & 3 & & & 1 \\
\hline
\end{tabular}

Table 5.1B Macroscopical evaluation of the premature lambs, which also have been assessed quantitatively $(n=48)$.

\begin{tabular}{lccccccc}
$\begin{array}{l}\text { macroscopical } \\
\text { lung damage: }\end{array}$ & G1 & G2 & G3 & G4 & G5 & GA & GB \\
\hline no & 1 & 1 & & & & & \\
light & 1 & 2 & 3 & & 2 & 4 & 3 \\
moderate & 2 & & & 4 & 2 & 1 & 2 \\
severe & 1 & 1 & 3 & 1 & 2 & 3 & 2 \\
very severe & 2 & 3 & 1 & 1 & & & 1 \\
\hline
\end{tabular}


Table 5.2 Parenchymal-alveolar air area ratio $(V v$ par) and the field-to-field variability (CV) in the right lower lobes, central in the lobe (crll) or peripheral (prll) of the 7 given experimental groups $(n=48)$. Data are presented as mean $\pm S D$.

\begin{tabular}{lllll}
\hline $\begin{array}{l}\text { group } \\
(\mathrm{n})\end{array}$ & $\begin{array}{l}\text { Vv par } \\
\text { crll \% }\end{array}$ & CV crll \% & $\begin{array}{l}\text { Vv par } \\
\text { prll \% }\end{array}$ & CV prll \% \\
\hline $1(6)$ & $37.7 \pm 13.9$ & $21.4 \pm 6.23$ & $38.8 \pm 13.0$ & $23.2 \pm 11.4$ \\
$2(7)$ & $30.6 \pm 10.1$ & $25.5 \pm 9.72$ & $37.5 \pm 10.2$ & $24.8 \pm 9.70$ \\
$3(7)$ & $34.2 \pm 8.53$ & $25.2 \pm 5.98$ & $36.7 \pm 7.02$ & $26.9 \pm 13.3$ \\
$4(6)$ & $32.6 \pm 8.02$ & $26.1 \pm 8.14$ & $35.8 \pm 10.4$ & $21.4 \pm 4.12$ \\
$5(6)$ & $33.5 \pm 8.93$ & $24.3 \pm 7.72$ & $35.5 \pm 6.44$ & $23.1 \pm 4.71$ \\
& & & & \\
A (8) & $23.9 \pm 3.55$ & $35.8 \pm 11.8$ & & \\
B (8) & $28.7 \pm 7.18$ & $33.1 \pm 8.62$ & & \\
\hline
\end{tabular}

However, lung compliance was related to the qualitative evaluation of lung damage $(r=-0.5062, p=0.004)$. The degree of macroscopical lung damage was also related to $\mathrm{PaO}_{2}(r=-0.7565, p=0.000), \operatorname{MAP}(r=0.5967, p=0.000), \mathrm{AaDO}_{2}(r=0.7401, p=$ $0.000)$ and $\mathrm{OI}(r=0.3241, p=0.025)$.

To obtain I) lambs with a good clinical outcome and II) lambs with a bad clinical outcome all lambs were arbitrarily divided, regardless of treatment group. A bad clinical outcome was defined by one or more of the following conditions: 1) dead before the end of the experiment 2) occurrence of pneumothorax 3) PIP at 1.5 hours after birth greater than $30 \mathrm{~cm} \mathrm{H}_{2} \mathrm{O}$. These criteria yielded 21 lambs with bad clinical outcome and 27 lambs with good clinical outcome. Centrally in the right lower lobe morphometric lung expansion was significantly better in lambs with a good clinical outcome. The Vv par was $27.5 \pm 8.98 \%$ versus $36.0 \pm 7.30 \%$ in lambs with a bad clinical outcome $(p=$ $0.0003)$. CV was respectively $32.5 \pm 9.21 \%$ versus $21.8 \pm 5.96 \%(p=0.000)$. Peripheral Vv par was $35.3 \pm 10.4 \%$ in the good clinical outcome group versus $38.5 \pm 7.51 \%$ (NS). CV was respectively $28.4 \pm 10.7 \%$ versus $19.6 \pm 4.11 \%(p=0.0047)$. There was a significantly $(p=0.000)$ different qualitative evaluation of the degree of lung damage in lambs with a good clinical outcome $(2.63 \pm 0.88)$ versus a bad $(4.05 \pm 0.92)$.

Gestational age had a significant influence on clinical outcome: averaged gestational age was significantly higher in lambs with a good clinical outcome $(131.1 \pm 1.1$ days versus $129.8 \pm 1.4$ days, $p=0.0014$ ). There was no significant difference in qualitative evaluation, parenchymal-alveolar air area ratios or field-to-field variability between lambs with a gestational age of 128 to 130 days $(n=27)$ and lambs with a gestational 
age of 131 to 133 days $(n=21$ ), although gestational age was inversely related to the degree of lung damage $(r=-0.3408, p=0.018)$.

When all lambs were divided according to sex field-to-field variability peripherally in the right lower lobe was significantly higher $(p=0.036)$ in females $(27.6 \pm 11.1 \%)$ than males $(20.7 \pm 5.90 \%)$. Females also had less macroscopical lung damage $(2.91 \pm 1.11)$ than males $(3.65 \pm 1.11, p=0.0334)$.

\subsection{Discussion}

A quantitative image analyzer was used to obtain objective measurements of alveolar expansion at light microscopic level. Since the distensibility of air-filled lungs has a direct relationship to the size of air spaces (4) and fixation of the lungs occurred through instillation of a fixative into the airways under controlled standardized conditions (5), it was possible to measure structural size of the lungs (6). Therefore we were able to evaluate the relative values of parenchymal-alveolar air area ratio between the seven groups. The results of our study are in accordance with those of Alcorn et al. (7) (approximately 67\% air space around 130 days of gestational age) and Docimo et al. (8). The fact that there is no significant difference between the experimental groups in our study is not surprising since sustained inflations did not have any influence on physiological pulmonary parameters as blood gases and compliance. (Chapter 2 and 3) In all 86 lambs lung morphology was evaluated macroscopically. However, we stopped quantitative evaluation of lung morphology after having analyzed the results in the first 48 lambs, because we did not expect to gain more information from further analysis.

All image analyzers provide information on the two-dimensional image only (9). Thus, the values reported in this study are estimates of volume, i.e. of the volume of air space contained in the unit volume of lung. To obtain absolute values, we should have measured the total lung volume as reference space. In the present study, however, the animals were randomly allocated to the described groups after being selected according to gestational age. It can be assumed that averaged lung volume per group would not have been significantly different. When the lambs were divided according to gestational age and bad or good clinical outcome, with concomitantly larger body weights, absolute values of lung volume might have been different. According to Docimo et al. (8) right lung volume (VI) grew according to body weight $(\mathrm{BW})$ as $\mathrm{Vl}=0.02 \mathrm{~mL} \times \mathrm{BW}^{1.08}$ in the period of 112 days of gestation to term. This equation was used in the present study to create absolute values and our results were analyzed again without reaching other conclusions than the ones reported in the above paragraph.

Although none of the presently available methods of fixation can claim to reproduce the in vivo morphology with complete accuracy (10), standardized intratracheal fixation with afterwards semi-automated image analysis is an easy tool for objective and representative measurement of lung expansion. $\mathrm{Vv}$ par centrally in the right lower lobe 
correlated with qualitative evaluation of lung damage and blood gases. Peripheral $\mathrm{Vv}$ par did not have any relation with clinical course.

Field-to-field variability in both sections was inversely related to $\mathrm{Vv}$ par centrally and related to blood gases taken at the end of the experiment. Centrally in the rll in the good clinical outcome group Vv par was low with a high CV, contrasting with the high values for Vv par and low CV in the bad clinical outcome group. Rigaut et al. (11) reported a high parenchymal-alveolar area ratio and a low field-to-field variability in nonaerated liquid filled lungs. Lungs with patchy or irregular alveolar air expansion had intermediate values for parenchymal-alveolar area ratios and high field-to-field variability. Uniformly well-aerated alveoli had low parenchymal-alveolar area ratios and a low variability. Using these criteria our results seem to indicate that the lambs used in this study were very immature. Peripheral $V_{v}$ par values were unrelated to clinical course and not different when comparing good versus bad clinical outcome lambs. Perhaps in these immature lungs a large part of the peripheral airspaces remained uninflated (12). This would mean a high Vv par and a low CV. However, there was a significant difference in peripheral field-to-field variability between good versus bad clinical outcome lambs, indicating the possibility of aeration. Also, it could be that peripheral tissue is more sensitive to factors associated with the method of fixation, processing and handling of the specimens. A difference in results between peripheral and central sampling in the same lobe has also been reported by Zeltner et al. (13). They reported intralobar differences in the rat lung: air space surface density was significantly decreased in subpleural compared to central lung regions.

In the present study data from macroscopical qualitative and microscopical quantitative assessment of the lungs were correlated, but qualitative evaluation was better correlated with blood gases and total static lung compliance. This could be explained by the fact that qualitative evaluation took place immediately after the experiments and might have been influenced by the knowledge of the clinical course of the animal. Another explanation could be that the heterogeneity of the tissue of the whole specimen is more readily appreciated and accounted for in qualitative assessment.

Only sections from the right lower lobe were sampled in this study. Regional variations in the lungs have been reported (14),(15). Also, deflation stability has been found to develop earlier in the apical than in the caudal lobes in the sheep (16). This is in accord with the general cranio-caudal gradient in lung maturation that is reflected in the histological development and the appearance of alveolar surfactant in sheep (17). However, this difference disappeared in lambs of 133 to 136 days of gestation (20). Docimo et al. (8) did not find differences between apical and diaphragmatic tissue in fetal lamb and neither did Heldt et al. (18) in premature rabbits. Moreover, Kitterman et al. (19) did not detect consistent differences between upper and lower lobe concentrations of surfactant.

In the present study the lower lobes of the lungs were chosen, since in these parts stability has been reported to be correlated with gestational age (20) and therefore differences between the various groups of lambs would have been most obvious in the 
lower lobe. Still we can not be entirely certain that our selective sampling did not bias our results.

In conclusion, in the premature newborn lamb morphometric analysis of lung tissue sampled from centrally in the right lower lobe can be used to gain a representative value of lung expansion. Sustained inflations applied during the first hours after birth did not influence lung expansion. 


\section{References}

1. Solca M, Kolobow T, Huang HH, Chen V, Buckhold DK, Pierce JE. Respiratory Distress Syndrome in immature lambs. Prevention through antenatal accelerated conditioning of the lung. Am Rev Respir Dis 1984;129:979-984.

2. Jobe A, Ikegami M. The prematurely delivered lamb as a model for studies of neonatal adaptation. In: Animal models in fetal medicine. Ed. Nathanielsz PW, Perinatology Press 1984, p 22.

3. Kolobow T, Moretti MP, Fumagalli R, Mascheroni D, Prato P, Chen V, Joris M. Severe impairment in lung function induced by high peak airway pressure during mechanical ventilation. Am Rev Respir Dis 1987;135:312-315.

4. Haber PS, Colebatch HJH, NG CKY, Greaves IA. Alveolar size as a determinant of pulmonary distensibility in mammalian lungs. J Appl Physiol 1983;54(3):837845.

5. Weibel ER. Morphometric estimation of pulmonary diffusion capacity. I. Model and method. Resp Physiol 1970:11;54-75.

6. Gehr P, Bachofen M, Weibel ER. The normal human lung: Ultrastructure and morphometric estimation of diffusion capacity. Resp Physiol 1978:32:121-140.

7. Alcorn DG, Adamson TM, Maloney JE, Robinson PM. A morphologic and morphometric analysis of fetal lung development in the sheep. Anat Rec 1981;201:655-667.

8. Docimo SG, Crone RK, Davies P, Reid L, Retik AB, Mandell J. Pulmonary development in the fetal lamb: Morphometric study of the alveolar phase. Anat Rec 1991;229:495-498.

9. Weibel ER. Stereological Methods. I. Practical methods for biological morphometry. London, Academic Press, 1979, p 253-256.

10. Bachofen H, Ammann A, Wangensteen D, Weibel ER. Perfusion fixation of lungs for structure-function analysis: credits and limitations. J Appl Physiol 1982;53:528-533.

11. Rigaut J-P, Robertson B. Quantitative evaluation of neonatal lung expansion with automated image analysis. Pediatr Path 1986;6:11-24.

12. Scarpelli EM, Kumar A, Doyle C, Clutario B. Functional anatomy and volumepressure characteristics of immature lungs. Respir Physiol 1981;45:25-41.

13. Zeltner TB, M Bertacchini, A Messerli, PH Burri. Morphometric estimation of regional differences in the rat lung. Exp Lung Res 1990;16:145-158.

14. Gehr P, Weibel ER. Morphometric estimation of regional differences in the dog lung. J Appl Physiol 1974;37(5):648-653.

15. Kendall JZ, Rivera-Alcina ME, Plopper CG, Weir AJ, Randall GC, SaldanaGautier L. A morphometric study of lung maturation in the adrenocorticotrophininfused fetal lamb. Biol Neonate 1991;60:258-272.

16. Brumley GW, Chernick V, Hodson WA, Normand C, Fenner A, Avery ME. Correlation of mechanical stability, morphology, pulmonary surfactant and phospholipid content in the developing lamb lung. J Clin Invest 1967;46:863-873. 
17. DeLemos RA. Acceleration of appearance of pulmonary surfactant in the fetal lamb by administration of corticosteroids. Am Rev Respir Dis 1970:102:459-461.

18. Heldt GP, Merritt A, Golembeski D, Gilliard N, Bloor C, Spragg R. Distribution of Surfactant, lung compliance and aeration of preterm rabbit lungs after surfactant therapy and conventional and high-frequency oscillatory ventilation. Pediatr Res 1992;31:270-275.

19. Kitterman JA, Liggins GC, Campos GA, Clements JA, Forster CS, Lee C.H, Creasy RK. Prepartum maturation of the lung in fetal sheep: relation to cortisol. J Appl Physiol 1981;51(2):384-390.

20. Howatt WF, Avery ME, Humphreys PW, Normand ICS, Reid L, Strang LB. Factors affecting pulmonary surface properties in the foetal lamb. Clin Sci 1965;29:239-248. 

(5) THE EFFECT OF HYPOCAPNIA AND MECHANICAL PULMONARY STRESS ON LUNG TISSUE IN NEWBORN LAMBS.

\author{
W.A.A. Klöpping-Ketelaars, M. Havenith, W.J. Maertzdorf, I.M. Kuipers \\ and C.E. Blanco \\ Biology of the Neonate 1993;64:254-260.
}

\title{
6.1 Abstract
}

Positive pressure ventilation, using high inspiratory pressures, often causes lung damage. When associated with hypocapnia, it can produce severe focal alveolar alkalosis and can cause damage in areas of low blood flow.

A vein to vein extracorporeal membrane oxygenator (V-V ECMO) system was used to control blood gases independently from mechanical ventilation in 12 healthy newborn lambs. After connection to the ECMO system, ventilation was started with a peak inspiratory pressure (PIP) of $35 \mathrm{~cm} \mathrm{H}_{2} \mathrm{O}$ and a positive end expiratory pressure (PEEP) of $5 \mathrm{~cm} \mathrm{H}_{2} \mathrm{O}$, ventilator rate was 40 per minute with $\mathrm{I}: \mathrm{E}=1: 1.5$, and $\mathrm{FiO}_{2}=1.0$. In 6 of the 12 lambs sweep gases through the silicone membrane were regulated to assure arterial normocapnia. The other six were ventilated with the same settings and perfused with the same pump flow, but $\mathrm{PaCO}_{2}$ was allowed to fall to hypocapnic levels. The lambs were ventilated for 4 hours. Average $\mathrm{pH}$ and $\mathrm{PaCO}_{2}$ were $7.62 \pm 0.14$ respectively $2.11 \pm 0.54 \mathrm{kPa}$ in the hypocapnic group and $7.39 \pm 0.11$ respectively $4.79 \pm$ $0.51 \mathrm{kPa}$ in the normocapnic group. After sacrificing the lambs, the lungs were inspected macroscopically and microscopically by computer assisted morphometry to assess atelectasis and lung edema. Macroscopically there were no haemorrhages, barotrauma or widespread atelectasis of the lungs in either group. The thickness of interlobular lung septa in the right upper lobe was $32.5 \pm 18.0 \mu \mathrm{m}$ for the hypocapnic group and $29.7 \pm 12.5 \mu \mathrm{m}$ for the normocapnic group. The parenchymal-alveolar area ratio in the right upper lobe was $28.4 \pm 5.04 \%$ and $24.6 \pm 3.75 \%$ in the hypocapnic and normocapnic group, respectively. Hypocapnia and mechanical stress for four hours in initially healthy lungs did not produce alveolar epithelial damage. 


\subsection{Introduction}

Mechanical ventilation is often used to treat respiratory failure in the newborn period. It is a technique which has proved to be effective as a bridge therapy for various reversible pulmonary diseases of the newborn. However, it is not free of complications, since it can produce acute and chronic lung injury. Moreover, when its use is not well controlled, it can result in arterial hypocapnia. Arterial hypocapnia is still frequently used to manage persistent pulmonary hypertension in the neonate (PPHN) (1),(2), since it results in an alkaline $\mathrm{pH}$ and, consequently, pulmonary vasodilatation (3),(4).

Lung damage due to low $\mathrm{PACO}_{2}$ has been reported in studies of newborn lambs. The ventilation of unperfused alveoli with $100 \%$ oxygen induced a profound alveolar hypocapnia which led to edema formation, haemorrhage and pulmonary infarction within 1 to 18 hours (5),(6). Several studies showed that alveolar hypocapnia is the major factor for lamellar body depletion in type II pneumocytes and release of phospholipids into the alveoli (7),(8),(9),(10). Moreover, hypocapnia is reported to decrease lung compliance (11),(12). Supplementing inspired gas with $5 \% \quad \mathrm{CO}_{2}$ prevented lamellar body depletion (8), edema formation and infarction of the lungs (5),(13).

Our hypothesis was that by maintaining a normal $\mathrm{PACO}_{2}$ while applying high positive pressures we could protect the alveoli for injury. The endpoint of this study was to demonstrate possible differences in lung pathology between hypo- and normocapnic lambs. We used a combination of intermittent positive pressure ventilation (IPPV) and vein to vein extracorporeal membrane oxygenator (V-V ECMO), to produce mechanical stress and to assure alveolar normocapnia.

\subsection{Material and methods}

\subsubsection{Animal preparation}

12 healthy newborn lambs with an age ranging from 2 to 30 days and a weight from 2.5 to $9 \mathrm{~kg}$ were used. The lambs were anaesthetized with a bolus pentobarbital (20 $\mathrm{mg} / \mathrm{kg})$ i.v. and then continuously perfused with pentobarbital $(8 \mathrm{mg} / \mathrm{kg} / \mathrm{h})$ and glucose $5 \%(6 \mathrm{ml} / \mathrm{h})$. They were endotracheally intubated and ventilated with a continuous flow, time cycled, pressure controlled ventilator (Amsterdam infant ventilator, Hoekloos, the Netherlands). Before placing the ECMO catheters the lambs were heparinized with a bolus $(100 \mathrm{U} / \mathrm{kg})$ and afterwards heparin was continuously given in a dose of 100 $\mathrm{U} / \mathrm{kg} / \mathrm{h}$ in glucose $5 \%(2 \mathrm{ml} / \mathrm{h})$. Activated coagulation time values were kept within a range of 200-250 seconds.

For blood drainage to the ECMO a venous catheter $(12 \mathrm{~F})$ was placed in the right external jugular vein and advanced to the level of the right atrium $(10 \mathrm{~cm})$. For blood return from the ECMO to the lamb an additional catheter $(8 \mathrm{~F})$ was placed in the femoral vein and advanced for approximately $7 \mathrm{~cm}$. The femoral artery was cannulated 
with a $5 \mathrm{~F}$ catheter to measure arterial blood pressure, heart rate and for blood sampling. Bilateral thoracic drains were inserted prophylactically.

\subsubsection{Ventilation}

Before connection to the ECMO system the lambs were ventilated with a peak inspiratory pressure (PIP) of $12 \mathrm{~cm} \mathrm{H} \mathrm{H}_{2} \mathrm{O}$ and a positive end expiratory pressure (PEEP) of 2 $\mathrm{cm} \mathrm{H}_{2} \mathrm{O}$. Ventilator rate was 30 per minute and $\mathrm{I}: \mathrm{E}=1: 1.5$. After connection to the ECMO-system, PIP was increased to $35 \mathrm{~cm} \mathrm{H}_{2} \mathrm{O}$, PEEP to $5 \mathrm{~cm} \mathrm{H}_{2} \mathrm{O}$, and the ventilator rate to 40 per minute. A gas flow of 8 to $14 \mathrm{l} / \mathrm{min}$ with $\mathrm{FiO}_{2}=1.0$ was used during the experiment.

\subsubsection{ECMO}

Vein to vein ECMO (V-V ECMO) was used in order to load the venous system with $\mathrm{CO}_{2}$, to assure normal arterial $\mathrm{CO}_{2}$ tensions which represented alveolar $\mathrm{CO}_{2}$. A $0.8 \mathrm{~m}^{2}$ Scimed membrane oxygenator (Scimed Life Systems Inc., Minneapolis, USA) was used for this purpose. After connection of the lamb to the ECMO system the pump flow was progressively increased to $70-80 \mathrm{ml} / \mathrm{kg} / \mathrm{min}$. Sweep gases to the membrane, containing oxygen, air and carbon dioxide, were set at a total flow of $2.4 \mathrm{l} / \mathrm{min}$.

\subsubsection{Experimental procedure}

Six lambs were ventilated with high positive inspiratory pressures while arterial normocapnia was assured with the ECMO system. The other six lambs were ventilated with the same settings and perfused with the same pump flow, but arterial $\mathrm{PCO}_{2}$ was allowed to fall to hypocapnic levels. In this way 2 groups of animals were obtained.

Arterial blood sampling occurred 15 minutes after connection to the ECMO system and then each hour. Arterial blood gases and $\mathrm{pH}$ were determined in $0.5 \mathrm{ml}$ samples after $1.5 \mathrm{ml}$ blood had been withdrawn to clear out the catheter. After each blood sample the catheter was perfused with $1.5 \mathrm{ml}$ of heparinized $(10 \mathrm{U} / \mathrm{ml})$ saline solution. Blood samples were analyzed using an ABL-3 (Radiometer, Copenhagen, Denmark) blood gas analyzer and corrected for body temperature. Mean arterial blood pressure and heart rate were measured continuously from the femoral artery. Signals were amplified and displayed continuously on an eight-channel Schwarzer polygraph calibrated to the high range using a mercury manometer and zeroed to atmospheric pressure. After four hours of experiment the lambs were sacrificed with an overdose of pentobarbital.

\subsubsection{Histology and morphometry}

After thoracotomy, the lungs were inspected macroscopically. The right ventricle was opened and a catheter inserted in the pulmonary trunk. The pulmonary arterial system was perfused with buffered $10 \%$ formalin at a pressure of $30 \mathrm{~cm} \mathrm{H} \mathrm{H}_{2} \mathrm{O}$ for 30 minutes. The left atrium was opened to allow the perfusates to escape. During this time the lungs were kept inflated with a continuous pressure of $10 \mathrm{~cm} \mathrm{H}_{2} \mathrm{O}$. Afterwards the lungs were carefully removed and immersed in fixative. After 24 hours of fixation, a $5 \mathrm{~mm}$ thick section of tissue was cut from the vertical midplane of each lobe. After dehydration, the 
5 blocks of tissue were embedded in paraffin, sliced into $5 \mu$ thick sections and stained with haematoxylin and eosin. The slides were analyzed microscopically to assess pulmonary damage. The examining histologist was unaware of the treatment given.

To obtain more objective parameters the alveolar expansion and the thickness of interlobular septa were measured morphometrically. In each lamb at random 25 optical fields per right upper and lower lung lobe were chosen. The proportion of alveolar space was evaluated using an image analyzer (CAS 200, Inc., Becton and Dickinson Image Cytometry Systems, the Netherlands) and its Quantitative Nuclear Antigen program. The program operates with two masks. One mask determines the total area of the measured parts of the section. The other mask defines a threshold, which differentiates the parenchyma, which is expressed as a percentage of the total measured sectional area ( $V v$ par). This ratio served as an index for alveolar expansion. We also determined the coefficient of variation (CV) of the measurements in each lobe to indicate the field-tofield variability. To facilitate morphometric measurement of the thickness of the interlobular septa reticular fibres in the right upper lobes were also stained. The septa were measured blindly at $400 \mathrm{x}$, using a graphic tablet, optically projected into a standard microscope and coupled to a computer (Kontron, Digital, Munich, Germany) and mean values were calculated.

\subsubsection{Statistics}

Data are presented as mean \pm SD. The nonparametric Mann-Whitney signed-rank test was used for evaluating differences between the two groups. The criterion for significance was $p$ (two-tailed) $<0.05$.

\subsection{Results}

Table 6.1 shows that the two groups were comparable for age, weight and sex distribution. The mean $\mathrm{pH}$ and $\mathrm{PaCO}_{2}$ during the four hours on ECMO were significantly different $(p=0.000)$ between the two groups. They were $7.62 \pm 0.14$ and $2.11 \pm 0.54$ $\mathrm{kPa}$ in the hypocapnic group and $7.39 \pm 0.11$ and $4.79 \pm 0.51 \mathrm{kPa}$ in the normocapnic group. $\mathrm{PaO}_{2}$ and base excess in the hypocapnic group were $50.9 \pm 11.4 \mathrm{kPa}$ and $-3.83 \pm$ $4.95 \mathrm{mmol} / \mathrm{l}$, and respectively $48.2 \pm 12.7 \mathrm{kPa}$ and $-2.10 \pm 7.10 \mathrm{mmol} / \mathrm{l}$ in the normocapnic group (Table 6.1).

In neither of the two groups the lungs presented macroscopic evidence for atelectasis, haemorrhages or barotrauma. Analysis with light microscopy showed no clear signs of perivascular or alveolar edema, hyperinflation or pulmonary haemorrhage. The thickness of interlobular septa of the right upper lobe in the hypocapnic group was $32.5 \pm 18.0$ $\mu \mathrm{m}$ (a total of 35 measurements) and in the normocapnic group it was $29.7 \pm 12.5 \mu \mathrm{m}$ (a total of 34 measurements) (Table 6.2). Thus, there were no significant differences between lungs exposed to hypocapnia or normocapnia. 
Table 6.1 Sex distribution, age, weight and arterial blood gas tensions for the hypocapnic and normocapnic group. Values are presented as mean $\pm S D$.

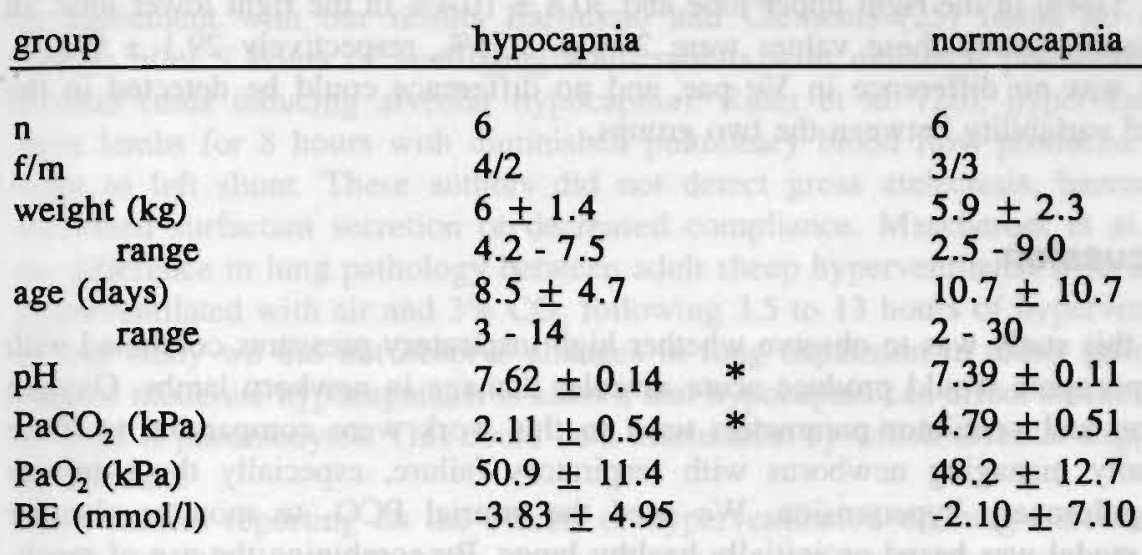

$* p<0.05$

Table $6.2 \mathrm{~A}$ comparison of the percentage parenchyma $(V v$ par) and the field-to-field variability (CV) of the measurements of these percentages in two areas of the lung in hypocapnic and normocapnic lambs. In addition, thickness of interlobular septa of the right upper lobe in the hypo- and normocapnic group are given. Values are presented as mean $\pm S D$.

\begin{tabular}{lll} 
group & hypocapnia & normocapnia \\
\hline Vv par rul & $28.4 \pm 5.04 \%$ & $24.6 \pm 3.75 \%$ \\
CV Vv par rul & $31.5 \pm 7.37 \%$ & $35.5 \pm 3.16 \%$ \\
Vv par rll & $30.8 \pm 10.4 \%$ & $29.1 \pm 9.00 \%$ \\
CV Vv par rll & $24.5 \pm 6.39 \%$ & $25.7 \pm 3.98 \%$ \\
Interlobular & & \\
lungsepta rul & $32.5 \pm 18.0 \mu \mathrm{m}$ & $29.7 \pm 12.5 \mu \mathrm{m}$ \\
\hline rul=right upper lobe; rll=right lower lobe. &
\end{tabular}


In addition, $\mathrm{Vv}$ par was determined as an alveolar expansion index in the right upper and lower lobe (Table 6.2). In the hypocapnic group the area occupied by parenchyma was $28.4 \pm 5.04 \%$ in the right upper lobe and $30.8 \pm 10.4 \%$ in the right lower lobe. In the normocapnic group these values were $24.6 \pm 3.75 \%$, respectively $29.1 \pm 9.00 \%$. Thus, there was no difference in Vv par, and no difference could be detected in the field-to-field variability between the two groups.

\subsection{Discussion}

The aim of this study was to observe whether high inspiratory pressures combined with alveolar hypocapnia would produce acute alveolar damage in newborn lambs. Oxygen concentration and ventilator parameters used in this work were comparable to those used clinically managing newborns with respiratory failure, especially those infants presenting pulmonary hypertension. We used the arterial $\mathrm{PCO}_{2}$ to monitor alveolar $\mathrm{PCO}_{2}$. Our model was based on initially healthy lungs. By combining the use of mechanical ventilation and V-V ECMO we could obtain two clear cut situations: alveolar hypocapnia and normocapnia. The $\mathrm{PaCO}_{2}$ level chosen in the hypocapnic group was comparable to that used in clinical situations. In our experiments we did not find significant differences between the two groups in lung morphology and alveolar expansion after 4 hours of mechanical ventilation. In the present study the parenchymalalveolar air area ratio is around $30 \%$ in both groups. Davies et al. (14) reported the volume density of septa in the respiratory region to be 25 to $48 \%$ in healthy sheep of 2 to 171 days of age. We did not observe haemorrhage, edema formation or lesions due to barotrauma. This is at variance with Kolobow et al. (5) who found irreversible lung tissue damage after only 10 minutes of severe hypocapnia. However, in this study $\mathrm{PaCO}_{2}$ was very low and $\mathrm{pH}$ reached values up to 8.0. It is possible that the level of hypocapnia reached in our study, $\left(\mathrm{PaCO}_{2}: 2.11 \pm 0.54 \mathrm{kPa}\right)$, was not low enough to induce alveolar damage. Borelli et al. (15) and Kolobow et al. (16) hyperventilated healthy adult sheep with $50 \mathrm{~cm} \mathrm{H}_{2} \mathrm{O}$ peak pressure, large tidal volume and, to ensure normocapnia, a low respiratory rate. They found during the first few hours a rise in the functional residual capacity and total lung compliance. Mild lung injury was detected after $18 \pm 12$ hours (15). When Kolobow et al. (16) supplemented room air with $3.8 \% \mathrm{CO}_{2}$ during hyperventilation, functional injury was delayed, but not prevented. These latter studies might indicate that our experimental period might have been too short to cause damage due to mechanical trauma or due to hypocapnia. However, Faridy et al. (17) showed in isolated dog lungs a decreased compliance and increased minimum surface tensions with increased tidal volumes for periods up to 4 hours. Other studies (18),(19),(20),(21),(22) reported that mechanical high positive pressure ventilation accompanied by hypocapnia led to severe pulmonary dysfunction earlier than 4 hours. The mechanism of impaired lung function was unclear; lung edema caused by microvascular injury was mentioned as a responsible factor 
(20),(21),(23),(24). However, in these experiments higher ventilation settings were used than in our experiments.

In agreement with our results Baritussio and Clements (25) found no macroscopic lesions after 7 hours of ventilating adult rabbits with unilateral pulmonary artery occlusion (thus inducing alveolar hypocapnia). Rider et al. (26), hyperventilated newborn lambs for 8 hours with diminished pulmonary blood flow produced by an atrial right to left shunt. These authors did not detect gross atelectasis, haemorrhage, nor increased surfactant secretion or decreased compliance. Mascheroni et al. (27) found no difference in lung pathology between adult sheep hyperventilated with air and sheep hyperventilated with air and $3 \% \mathrm{CO}_{2}$ following 3.5 to 13 hours of hyperventilation.

In our study we did not observe changes in lung expansion in either group of lambs, despite moderate hypocapnia. It is known that hypocapnia can affect surfactant secretion by type II pneumocytes. This could be a mechanism by which alveolar expansion might be affected.

Most studies reporting on the effects of hyperventilation on lung function used adult animal models. In adult rabbits increased alveolar surfactant was found after hyperventilation of up to 4 hours (25),(28). Oyarzún and Clements (28) suggested a burst of surfactant secretion during the first hours of hyperventilation, followed by inactivation or exhaustion of surfactant stores. In adult sheep decreased lung compliance was found as early as 6 to 12 hours after onset of hyperventilation (16). Alveolar saturated phosphatidyl pool sizes seem to be abundant in approximately 1 week old lambs (26). That finding might be the explanation for the absence of lung injury in our study, since we used newborn lambs.

The appliance of $5 \mathrm{~cm} \mathrm{H}_{2} \mathrm{O}$ PEEP in both groups might be another reason. It has been reported that during ventilation in vitro the increase in surface forces is inversely related to end-expiratory pressure (17). Wyszogrodski et al. (19) reported that hyperventilation of lungs promoted the release of surface active material from type II pneumocytes to alveolus in adult cats, but that there the surfactant was inactivated. When a PEEP of 2.5 $\mathrm{cm} \mathrm{H}_{2} \mathrm{O}$ was applied, inactivation was prevented. They suggested that maintenance of an elevated lung volume might have prevented surface film collapse attributable to lung volume decrease and subsequent surfactant inactivation.

In conclusion, the ventilatory strategy applied in this work, even when accompanied by moderate alveolar hypocapnia, did not produce evident alveolar damage after four hours of ventilating newborn lambs with initially healthy lungs. More research needs to be done, using this approach, on newborn lambs presenting lung pathology. 


\section{References}

1. Drummond WH, Gregory GA, Heymann MA, Phibbs RA. The independent effects of hyperventilation, tolazoline, and dopamine on infants with persistent pulmonary hypertension. J Pediatr 1981;98:603-611.

2. Fox WW, Duara S. Persistent pulmonary hypertension in the neonate: diagnosis and management. J Pediatr 1983;103:505-514.

3. Lyrene RK, Welch KA, Godoy G, Philips JB III. Alkalosis attenuates hypoxic pulmonary vasoconstriction in neonatal lambs. Pediatr Res 1985;19:1268-1271.

4. Schreiber MD, Heymann MA, Soifer SJ. Increased arterial pH, not decreased $\mathrm{PaCO}_{2}$, attenuates hypoxia-induced pulmonary vasoconstriction in newborn lambs. Pediatr Res 1986;20(2):113-117.

5. Kolobow T, Fumagalli R, Arosio P, Chen V, Buckhold D, Pierce J. Severe pulmonary capillary alkalosis during states of low pulmonary blood flow: a possible cause of lung damage. Life Support Systems. Proceedings IX Annual Meeting ESAO, Brussels, Belgium, 1982;169-171.

6. Kolobow T, Spragg R, Pierce J. Massive pulmonary infarction during total cardiopulmonary bypass in unanesthetized spontaneously breathing lambs. Int $\mathrm{J}$ Art Organs 1981;4(2):76-81.

7. Oyarzún MJ, Donoso P, Quijada D. Role of hypocapnia in the alveolar surfactant increase induced by free fatty acid intravenous infusion in the rabbit. Respiration 1986;49:187-194.

8. Shepard JW Jr, Hauer D, Miyai K, Moser KM. Lamellar body depletion in dogs undergoing pulmonary artery occlusion. J Clin Invest 1980;66:36-42.

9. Shepard JW, Dolan GF, Shiu YY. Factors regulating lamellar body volume density of type II pneumocytes in excised dog lungs. J Appl Physiol 1982;53(3):555-562.

10. Saunders BS, Shepard JW Jr, Jobe A, Miyai K, Moser KM, Gluck L. Alveolar $\mathrm{CO}_{2}$ tension as a mediator of lamellar body release in experimental left pulmonary artery occlusion. Chest 1977;72:411 (Abstract).

11. Cutillo A, Omboni E, Perondi R, Tana F. Effect of hypocapnia on pulmonary mechanics in normal subjects and in patients with chronic obstructive lung disease. Am Rev Respir Dis 1974;110:25-33.

12. Ingram RH Jr. Effects of airway versus arterial $\mathrm{CO} 2$ changes on lung mechanics in dogs. J Appl Physiol 1975;38:603-607.

13. Edmunds $\mathrm{LH}$, Holm JC. Effect of inhaled $\mathrm{CO}_{2}$ on hemorrhagic consolidation due to unilateral pulmonary arterial ligation. J Appl Physiol 1969;26:710-715.

14. Davies P, Reid L, Lister G, Pitt B. Postnatal growth of the sheep lung: a morphometric study. Anat Rec 1988;220:281-286.

15. Borelli M, Kolobow T, Spatola R, Prato P, Tsuno K. Severe acute respiratory failure managed with continuous positive airway pressure and partial extracorporeal carbon dioxide removal by an artificial membrane lung. Am Rev Respir Dis 1988;138:1480-1487. 
16. Kolobow T, Moretti MP, Fumagalli R, Mascheroni D, Prato P, Joris M. Severe impairment in lung function induced by high peak airway pressure mechanical pulmonary ventilation. An experimental study. Am Rev Respir Dis 1987;135:312-315.

17. Faridy EE, Permutt S, Riley RL. Effect of ventilation on surface forces in excised dogs' lungs. J Appl Physiol 1966:21;1453-1462.

18. Forrest JB. The effect of hyperventilation on pulmonary surface activity. $\mathrm{Br} \mathrm{J}$ Anaesth 1972;44:313-319.

19. Wyszogrodski I, Kyei-Aboagye K, Taeusch HW, Avery ME. Surfactant inactivation by hyperventilation: conservation by end expiratory pressure. J Appl Physiol 1975;38:461-466.

20. Webb HH, Tierney DF. Experimental pulmonary edema due to intermittent positive pressure ventilation with high inflation pressures. Protection by positive end expiratory pressure. Am Rev Respir Dis 1974;110:556-565.

21. Parker JC, Hernandez LA, Longenecker GL, Peevy K, Johnson W. Lung edema caused by high peak inspiratory pressures in dogs. Am Rev Resp Dis 1990;142:321-328.

22. Coker PJ, Hernandez LA, Peevy KJ, Adkins K, Parker JC. Increased sensitivity to mechanical ventilation after surfactant inactivation in young rabbit lungs. Crit Care Med 1992;20:635-640.

23. Peevy KJ, Hernandez LA, Moise AA, Parker JC. Barotrauma and microvascular injury in lungs of nonadult rabbits: Effect of ventilation pattern. Crit Care Med 1990;18:634-637.

24. Hernandez LA, Peevy KJ, Moise AA, Parker JC. Chest wall restriction limits high airway pressure-induced lung injury in young rabbits. J Appl Physiol 1989;66:2364-2368.

25. Baritussio A, Clements JA. Acute effects of pulmonary artery occlusion on the pool of alveolar surfactant. Respir Physiol 1981:45:323-331.

26. Rider ED, Jobe AH, Yamada T, Ikegami M, Seidner S, Ruffini L. Surfactant metabolism during hyperventilation of newborn lambs with atrial right to left shunts. Pediatr Res 1989;25(1):83-88.

27. Mascheroni D. Kolobow T, Fumagalli R, Moretti MP, Chen V, Buckhold D. Acute respiratory failure following pharmacologically induced hyperventilation: an experimental animal study. Intensive Care Med 1988;15:8-14.

28. Oyarzún MJ, Clements JA. Ventilatory and cholinergic control of pulmonary surfactant in the rabbit. J Appl Physiol 1977;43(1):39-45. 



\section{GENERAL DISCUSSION AND CONCLUSIONS}

\subsection{Sustained inflations}

\subsubsection{Sustained inflations as used in the present studies}

This work was designed after reviewing the work of Solca et al. (1). These authors reported an improvement of lung compliance and better survival of fetal lambs at gestational ages from 131 to 134 days by applying intermittent deep sustained inflations (SI) before cord occlusion. This of course was a very attractive proposal since it could mean, when applied in human premature infants, a decrease in the use of intermittent positive pressure ventilation (IPPV) with as a consequence less bronchopulmonary dysplasia. Since the procedure used in fetal lambs would be difficult to apply in human fetuses, we designed experiments using premature newborn lambs. We tried to reproduce different clinical situations, for example, immediately after cord occlusion, later after birth and even up to four hours postnatally. The latter to reproduce a situation in which infants are coming from peripheral hospitals. Lambs were used as model since in premature lambs (<135 days) it can be anticipated that they will develop a respiratory disease with functional and histological similarities to respiratory distress due to surfactant deficiency in the premature infant (2). Most lambs delivered at gestational ages of around 130 days will have a degree of respiratory failure very similar to that encountered clinically in premature infants (3),(4),(5). The size of the animal is large enough to make surgical techniques easy and their blood volume can tolerate frequent blood sampling. In the present study the lambs had gestational ages from 128 to 133 days and without the use of mechanical ventilation they would not have survived. All of the lambs in our study presented a clear respiratory distress as seen by the use of mean airway pressures around $15 \mathrm{~cm} \mathrm{H}_{2} \mathrm{O}$ to keep $\mathrm{PaCO}_{2}$ between 5,5-6 kPa. A third of the lambs developed a pneumothorax which needed to be drained, $\mathrm{PaO}_{2}$ values varied widely, but were around $30 \mathrm{kPa}$ while ventilated with $100 \% \mathrm{O}_{2}$, which reflects intrapulmonary right-to-left shunting.

The purpose of this investigation was to study whether applying sustained deep inflations prophylactically during the first hours of birth could enhance lung function and could be of use in the management of premature newborn lambs suffering from respiratory distress due to surfactant deficiency. We used the same technique as was introduced in the fetal lamb by Solca et al. (1) They reported beneficial effects of intermittent deep inflations on lung compliance in exteriorized fetal premature lambs. This technique was called "accelerated lung conditioning". The fact that the effect of lung conditioning was reported to be independent from surfactant mechanisms, and that changes in connective tissue rather than an increase in surfactant may be responsible for lung matura- 
tion under particular conditions (6),(7),(8) made the use of "lung conditioning" attractive for further study.

We studied the effect of lung conditioning in lambs applying a similar management used in the treatment of babies with respiratory distress syndrome (RDS). The questions were what was the optimal time of administering these sustained inflations postnatally and with which frequency should sustained inflations be applied. As reported in material and methods we designed a protocol consisting of 4 treatment and 3 control groups. Group 1) SI were applied immediately after cord occlusion, in group 2) SI were administered within 15 minutes after birth, in group 3) SI were applied more than once and in group 4) SI were applied as late as 4 hours after birth. With this protocol we thought to cover the most frequent clinical situations. The end-points of this study were evidence of improvement of lung function during the experimental period of eight hours after birth, morbidity and mortality. Lung function was evaluated by assessing gas exchange, lung compliance, ventilatory support for gas exchange and morphological findings.

By applying this protocol in premature lambs born with a section caesarean at gestational ages of 128 to 133 days, we did not find differences in lung function between the groups of lambs. Nor did lung morphology, morbidity and mortality differ compared to the two control groups. During the time of this study there was never a significant difference between the control groups and the lambs in which lung conditioning was applied. Frequency and time of administering lung conditioning did not influence lung function significantly.

This was in a way a surprise for us, because we expected to establish an early and adequate functional residual capacity (FRC) as was described by Solca et al. (1). Most probably we did recruit enough alveoli to establish a FRC, but obviously, looking at the results, we did not maintain the recruitment by letting mean airway pressure (MAP) drop. SI did have a short term effect, a higher MAP during SI did cause a temporary rise in $\mathrm{PaO}_{2}$. After SI a higher MAP could have been kept by increasing post endexpiratory pressure (PEEP). However, the election of this PEEP level was done following traditional conventional clinical practices where it is unusual to combine higher PEEP than $5 \mathrm{~cm} \mathrm{H}_{2} \mathrm{O}$ with IPPV. At the moment there is a tendency to use much higher PEEP's combined with new ventilation techniques like high frequency ventilation (HFV). The results are promising. This technique is totally dependent of adequate recruitment of alveoli, otherwise it does not work. This again suggests that alveolar recruitment is essential.

In conclusion sustained inflations as described by Solca et al. (1) applied postnatally did not have any effect on lung function in our study. Most probably the improved lung compliance reported by Solca et al. (1) was due to the rise in surfactant secretion which usually happens at birth and after lung inflation. Ikegami et al. (9) reported an increase in compliance (2.5-fold) after one hour of "lung conditioning" in exteriorized fetal lambs, but this advantage disappeared after cord clamping and mechanical ven- 
tilation with a conventional MAP-level. Probably MAP was too low to prevent derecruitment.

Among others possible explanations for the failure of finding an improvement in lung function could be:

1) The end-expiratory pressure applied after sustained inflations was not high enough to prevent de-recruitment of alveoli.

Alveolar expansion is in itself an important mechanism for preventing the development of secondary structural injury in the atelectasis-prone lung (10). In the surfactant deficient lung the pressure required to move the air-liquid interface into the alveoli exceeds the pressure that can be generated by the surface forces of a terminal bronchiole, causing overdistension of these small airways, epithelial disruption, increased permeability (11). Once alveolar expansion is achieved, this pressure imbalance disappears as alveolar radius increases, and the terminal airways can function as a duct for flow rather than be overdistended. This means that at end-expiration alveolar aeration should be maintained, so re-expansion of alveoli does not have to occur with each ventilatory cycle. In our study presumably much of the lung volume recruited during inspiration was not maintained during expiration. The limiting factor in the recruitment and maintenance of volume during mechanical ventilation is more likely to be the endexpiratory pressure rather than the opening forces.

2) Pressure given was not high enough to overcome the opening pressure of the collapsed lung segments.

In our study $35 \mathrm{~cm} \mathrm{H} \mathrm{H}_{2} \mathrm{O}$ was used during the inspiratory phase of SI. This is the resuscitation pressure recommended in the premature lamb (12). In the human neonate the general recommended upper limit is $30 \mathrm{~cm} \mathrm{H}_{2} \mathrm{O}$. However, when generating sufficient pressure to produce visible movement of the chest wall in 30 babies (22 premature), median mean pressure over the first 10 inflations was $40 \mathrm{~cm} \mathrm{H}_{2} \mathrm{O}$ (13),(14). As gestational age fell there was no tendency for higher pressures to be required, therefore we do not think that the inspiratory pressures used in the present study were not enough.

3) Occurrence of air traps which could lead to overdistension of open alveoli and compression of deflated parts of the lungs.

However, alveoli are interdependent as the walls of adjacent alveoli are mutually attached to each other. Therefore, it is physically difficult for one alveolus to contract without the other one contracting at the same time (15). This property of the lung helps to assure equality of alveolar size (16). The traditional concept, according to which the individual alveolus would, somehow, be able to adjust their surface tension with respect to their radius, establishing higher surface tension in larger alveoli than in smaller ones should probably be discarded. Lung collapse occurs below a critical lung volume as the structure becomes relaxed and surface tension stresses predominate.

\subsubsection{Prevention of de-recruitment of alveoli}

De-recruitment of alveoli during expiration can be prevented by the application of an adequate mean airway pressure. In the atelectatic lung the beneficial effects of positive 
end-expiratory pressure (PEEP), continuous positive airway pressure (CPAP) and high frequency ventilation (HFV) are well known.

The application of PEEP/CPAP increases the transpulmonary pressure at end-expiration, thereby increasing functional residual capacity (FRC) and thus decreasing intrapulmonary shunt and improving arterial oxygenation (17). PEEP expands collapsed alveoli. The consequent increase in lung volume may lead to an increase in compliance.

Besides this, mechanical ventilation and hyperventilation, particularly from low lung volume states, have been shown to result in decreased lung compliance, lung stability and bubble stability (18),(19),(20). This is believed to be related to surfactant inactivation (20) and disruption of the continuous surface active lining of the lungs $(18,19)$. The application of PEEP allows for continued release of surfactant with hyperventilation but prevents inactivation, presumably by preventing surface film collapse at low lung volumes (20).

However, end-expiratory pressure also has adverse effects. 1) Cardiac output is reduced, mainly due to a reduction in venous return. For example, the application of CPAP (11 $\mathrm{mm} \mathrm{Hg}$ ) caused an increase in central venous pressure from $7 \pm 1.4$ to $12 \pm 2.7 \mathrm{~mm} \mathrm{Hg}$ (mean \pm SEM), a decrease in venous return to the heart, and a fall of $15 \%$ in cardiac output (21). 2) PEEP shifts ventilation to a less compliant part of the deflation pressure-volume curve (22). Hence, possible complications of PEEP could be: 1) The risk of alveolar overdistension and rupture resulting in barotrauma. Hyperinflation of the more normal lung segments during attempts to ventilate the abnormal lung segments might occur (23). 3) PEEP may redistribute blood from normal areas of the lung to diseased segments (24). Extrapulmonary right-to-left shunting may occur in neonates if pulmonary vascular resistance is further elevated by a PEEP-induced increase in lung volume (25).

Clearly to prevent adverse effects of PEEP one has to prevent overdistension. This situation can be recognized by an increase in FRC and a decrease in compliance. In our study $5 \mathrm{~cm} \mathrm{H}_{2} \mathrm{O}$ has been used.

However, Keszler et al. (26) reported that in human babies a PEEP of 12 to $14 \mathrm{~cm}$ $\mathrm{H}_{2} \mathrm{O}$ safely prevents deterioration of pulmonary function during extracorporeal membrane oxygenation (ECMO) and results in more rapid lung recovery than traditional lung management with low PEEP. They suggested that high PEEP may better maintain alveolar volume and thereby lung compliance. Solca et al. (1) also used $15 \mathrm{~cm} \mathrm{H}_{2} \mathrm{O}$ between the intermittent deep insufflations in the fetal lamb.

\subsubsection{Reports on sustained inflations in other studies}

We have studied sustained inflations as a prophylactic tool in the management of the respiratory distress syndrome. Other investigators also have examined the effects of intermittent deep inflations with a prolonged inspiratory time on lung function in normal and diseased lungs. A short review follows:

Surfactant function can be altered by breathing at low lung volumes (27). Prolonged periods (30 minutes) of breathing without hyperinflations such as sighs or yawns 
increase lung recoil and consequently decrease FRC (28).(29). Only monolayer collapse may help to explain the loss of compliance during shallow breathing ( 30$),(31)$ and subsequent development of atelectas is (32),(33),(34),(35),(36). However, intermittent deep inflations did not produce any beneficial effects in total respiratory compliance or blood gas exchange in patients on prolonged positive pressure ventilation (37).

Anaesthesia influences the pressure-volume relationship of the respiratory system in the recumbent human (38),(39). The most likely mechanism contributing to reduction in static lung compliance in normal lungs after induction of anesthesia may be an alteration in surfactant function. However, repeated inflations of the lungs to high airway pressures do not reverse the reduction in lung compliance (39).

Attempts to improve oxygenation during conventional mechanical ventilation (CMV) by intermittent sustained inflations have also been made in patients with lung disease, but without clinical benefit. Novak et al. (40) concluded that periodic hyperinflations did not affect gas exchange or compliance in patients with established hypoxemic respiratory failure. In dogs with pulmonary edema, sighs produced inconsistent effects on FRC and compliance; $\mathrm{PaO}_{2}$ even decreased (41). Kolton et al. (42) and Hamilton et al. (43) have similarly found no improvement in either lung volume or oxygenation after a sustained inflation during large tidal volume CMV.

Uneven distribution of ventilation resulting from regional differences may be improved by the addition of a no-flow pause at the end of inspiration (EIP). However, in dogs with oleic acid-induced pulmonary edema, the addition of EIP to the ventilatory pattern had no beneficial effect on alveolar-arterial oxygen gradient (44). In the work of Fuleihan et al. (45) alveolar ventilation was improved, as seen by a decreased dead space and $\mathrm{PaCO}_{2}$, in proportion with the duration of EIP, but there was no significant effect on oxygenation. Jansson and Jonson (46) reported that ventilation to the poorly compliant regions was not improved with the addition of EIP.

\subsubsection{Sustained inflations used in high frequency ventilation}

Adequate pulmonary gas exchange can be maintained in animals and humans by artificial ventilation with high frequency (HFV) and small tidal volumes. As these volumes are smaller than the volume of the conducting airways, ventilation is achieved by mixing inspired and alveolar gas in large airways. The small volume excursions produce little stretching of epithelial surfaces. Therefore a higher mean airway pressure or volume can be used than during conventional mechanical ventilation (CMV) avoiding high peak distending volumes or pressures.

In these circumstances sustained inflations are reported to be essential. During HFV one or more sustained inflations are used to achieve alveolar expansion (42),(43),(47),(48),(49). Hamilton et al. (43) showed that the increase in $\mathrm{PaO}_{2}$ achieved with a single SI does not deteriorate even over a period of 20 hours. When disconnection from the ventilator allowed the lung to collapse to $\mathrm{FRC}$, a repeat SI after reconnection to the circuit resulted in an immediate and sustained improvement in $\mathrm{PaO}_{2}$ back to the previous level. However, Quan et al. (50) gave rabbits, whether 
ventilated by CMV or high frequency jet ventilation, a hyperinflation and saw no differences between rabbits who were given a hyperinflation and those who were not. In studies using HFV at pressures equal to or less than those used in CMV and without sustained inflations, outcome has been essentially the same as in CMV (51),(52).

\subsection{Cardiovascular changes during sustained inflations}

It is well known that during quiet breathing cyclic changes in heart rate and blood pressure occur. Heart rate increases with inspiration and decreases during expiration (respiratory sinus arrhythmia), which is attributed to rhythmic changes in the activity of cardiac vagal efferent myelinated fibres (53). The variations in blood pressure are determined by changes in venous return and pulmonary artery blood flow, i.e. an aspiration of blood toward the thorax with inspiration and a decrease with expiration. Venous return to the heart is proportional to the difference in mean systemic pressure and right atrial pressure (54). During inspiration produced by positive airway pressure, the pressure on the surface of the lungs and heart is elevated and therefore venous return decreases.

Sustained inflations as used in our study clearly produced cardiovascular effects among others dependent of the rise in pressure from baseline peak inspiratory pressure. The rapidly adapting pulmonary stretch receptors presumably responsible for these effects have a high volume threshold, a rapid rate of adaptation and an irregular pattern of discharge. Their activity evokes cough and protective reflexes from the tracheobronchial tree. Bronchial and pulmonary $\mathrm{C}$-fibre are also stimulated by hyperinflation and cause rapid shallow breathing, bronchoconstriction and increased airway secretion. Moreover, all these defense reflex responses include a profound reduction in blood pressure and heart rate as was also apparent in our study.

Time at which SI were applied influenced also the reaction to SI. Within 15 minutes after birth there was almost no reaction in central venous pressure during SI. This could be caused by the protective effect of a low lung compliance; pleural pressure is less elevated at the same airway pressure. Concluding that applying SI within 15 minutes of birth is safe with regard to cardiac function might be jumping to conclusions. Traverse et al (55), reported that in cats as mean airway pressure was raised, cardiac output decreased and pulmonary vascular resistance increased regardless of the degree of lung compliance. Similar findings in the swine during conventional ventilation and PEEP support the fact that airway pressure effects on cardiovascular hemodynamics are not blunted by low pulmonary compliance if poorly and normally compliant lungs are equally inflated (56). Furthermore, the potential for transmission of airway pressure in the recovering lung must always be closely monitored (57).

Although fluctuations in cardiovascular parameters occurred during SI we do not known if the amount of change has clinical relevance. However, in children susceptible to intraventricular haemorrhages cerebral blood flow values had changed by a mean of 
$4.0 \%$ per $\mathrm{mm} \mathrm{Hg}$ change in mean arterial blood pressure (58). Therefore each unnecessary fluctuation in blood pressure should be avoided in premature children.

\subsection{Alveolar hypocapnia}

We have applied sustained inflations with $5 \% \mathrm{CO}_{2}$ and $95 \% \mathrm{CO}_{2}$ as gas mixture. $\mathrm{CO}_{2}$ was added during SI to avoid extreme hypocapnia at the crucial moment of recruiting alveoli which presumably were not perfused. This was done empirically. In control group $4,100 \% \mathrm{O}_{2}$ was used to inflate the lungs with the same pressure as for sustained inflations, but with shorter inspiratory time. We did not find significant differences between the groups. No group was formed with lambs receiving $100 \% \mathrm{O}_{2}$ during sustained inflations, since the study of alveolar hypocapnia during SI was not an aim of this thesis.

However, hypocapnia, at a level which can be encountered in clinical settings did not produce lung damage in initially healthy lungs after hyperventilation for four hours (Chapter 6). Acute necrosis as described by Kolobow et al. (59),(60) who used extreme $\mathrm{PACO}_{2}$ levels, certainly did not occur.

We can not be certain that a reaction of inflammatory nature might haven started which would have been obvious after a longer study period. Also, although type II pneumocytes of the lung have an active metabolism that is highly susceptible to disturbances (61), other studies have shown that a disturbance of the synthesis of the phospholipids with a following decrease of surfactant concentration becomes clinically noticeable only after 24 to 30 hours (62),(63). Hence, our study should be repeated with a longer duration of hyperventilation or a long pause between hyperventilation and sacrifice. Furthermore, instead of term lambs surfactant deficient lambs should be used, as in these animals lungs are more subject to large ventilation/perfusion imbalances.

Most investigators used acute pulmonary artery occlusion in initially healthy lungs to produce an extreme ventilation-perfusion imbalance and a severe reduction in the alveolar carbon dioxide tension in the occluded lung. Thus, a more extensive and intense alveolar alkalosis existed then in our study.

However, a slight indication for some effect of hypocapnia has been found in our study. The correlation present in the normocapnic group between the right upper lobe and lower lobe was not present in the hypocapnic group. This abnormal finding was caused by a high parenchymal-alveolar air area ratio in three of the six animals of the hypocapnic group. As the effect of hypocapnia is most extreme in the upper lobe, where ventilation-perfusion ratio is increased, this might indicate some damaging effect on lung expansion. However, when comparing the ratios in the right upper lobe between the normo- and hypocapnic group there were no significant differences.

It is difficult to believe that in the normal lung hypocapnia might influence lung function as there are several mechanisms to reduce difference in alveolar gas composition throughout the lung. For example, if $10 \%$ of the alveoli are not perfused, according to 
standard analysis their PACO2 must be zero, because they can not eliminate any $\mathrm{CO} 2$. If these elements receive one-third of their inspired volume from the dead space $(90 \%$ of which originates from normally perfused alveoli, in which PACO2 $=40$, giving a $\mathrm{PCO} 2=36$ in the end-inspiratory dead-space gas), the unperfused alveoli still have a $\mathrm{PCO} 2=12$. The matter is further complicated though, by that segments of dead space may have each a different composition, and the fraction alveoli reinspire may differ between them (64). Besides this there is also the matter of collateral ventilation between alveoli. Local hypocapnia increases resistance to collateral flow (65) and hypercapnia decreases resistance to collateral flow (66),(67). Batra (68) reported that the effects of $\mathrm{CO}_{2}$ were greater in nondependent than dependent regions of the lung and concluded that probably the relative hypocapnia was responsible for the increased effect of $5 \% \mathrm{CO}_{2}$. This means that there is a homeostatic mechanism for increasing ventilation to a poorly ventilated part of the lung.

\subsection{Lung morphology in the premature and term lamb}

In chapter 5 and 6 morphometric measurement of lung expansion was used as a tool to assess lung damage. Quantitative evaluation of central sections of caudal lung lobes correlated with macroscopical qualitative assessment of the degree of lung damage and blood gases at the end of the experiment, but not with total static compliance. Peripheral sections did not correlate at all with clinical course. We recommend to use selective sampling for lung morphometry to avoid using peripheral located sections of lung tissue.

A striking fact is that in chapter 6 in term healthy lungs the same values for parenchymal-alveolar air area ratio were found as in premature surfactant deficient lungs in chapter 5. However, values for premature lambs were not different from those reported by others (69),(70). Also, postnatal lamb lung development has been recently described and the volume density of septa in the respiratory region was reported to be 25 to $48 \%$ in healthy sheep (71). It could be that intratracheal fixation (used in the premature lambs of the present study) might have overestimated alveolar air space (72), since during intratracheal fixation, the lining layer is displaced from its original location. Furthermore, it has been reported that in lambs of this gestational age and postnatal age alveoli do not distend but grow in number and that increase in lung volume is largely due to an increase in alveolar number and only minimally to an increase in alveolar size (70). 


\subsection{Conclusions}

In short, in premature newborn lambs applying sustained inflations to recruit alveoli without prevention of derecruitment does not improve lung function. Probably recruitment of alveoli does occur during SI, since there was a significant rise in $\mathrm{PaO}_{2}$ when comparing values before and after SI. Moreover, there is abundant proof of beneficial effects of SI combined with a high mean airway pressure to prevent de-recruitment as is used in high frequency ventilation.

A high mean airway pressure can produce significant changes in cardiovascular parameters, even in low compliant lungs, as is described in this thesis. These changes must be taken into consideration, whenever large sustained inflations are used in premature infants who are prone to intraventricular haemorrhages. 


\section{References}

1. Solca M, Kolobow T, Huang HH, Chen V, Buckhold DK, Pierce JE. Respiratory Distress Syndrome in immature lambs. Prevention through antenatal accelerated conditioning of the lung. Am Rev Respir Dis 1984;129:979-984.

2. Stahlman M, LeQuire VS, Young WC, Merril RE, Birmingham RT, Payne GA, Gray J. Pathophysiology of Respiratory Distress in Newborn Lambs. Am J Dis Child 1964;108:375-393.

3. Jobe A, Ikegami M, Jacobs H, Jones S. Surfactant pool sizes and severity of RDS in prematurely delivered lambs. Am Rev Respir Dis 1983;127:751-755.

4. Reynolds EOR, Jacobson HN, Motoyama EK et al. The effect of immaturity and prenatal asphyxia on the lungs and pulmonary function of newborn lambs: The experimental production of respiratory distress. Pediatrics 1965;35:382-392.

5. Sandberg K, Edberg K, Benton W, Silberberg A, Sladek M, Sundell HW. Surfactant improves gas mixing and alveolar ventilation in preterm lambs. Pediatr Res 1991;30(2):181-9.

6. Schellenberg JC. The development of connective tissue and its role in pulmonary mechanics. In: Reproductive and perinatal medicine (III), Respiratory control and lung development in the fetus and newborn. eds. Johnston BM, Gluckman PD. Perinatology press 1986, Ithaca NY, p 40-44.

7. Kitterman JA, Liggins GC, Campos GA et al. Prepartum maturation of the lung in fetal sheep: relation to cortisol. J Appl Physiol 1981;51:384-390.

8. Beck JC, Mitzner W, Johnson JWC, Hutchins GM, Foidart JM, London WT, Palmer AE, Scott R. Betamethasone and the rhesus fetus: effect on lung morphometry and connective tissue. Pediatr Res 1981;15:235-240.

9. Ikegami M, Jobe A, Berry D, Elkady T, Pettenazzo A, Seidner S. Effects of distension of the preterm fetal lamb lung on lung function with ventilation. Am Rev Respir Dis 1987;135:600-606.

10. McCulloch PR, Forkert PG, Froese AB. Lung volume maintenance prevents lung injury during high-frequency oscillatory ventilation in surfactant-deficient rabbits. Am Rev Respir Dis 1988;137:1185-1192.

11. Enhorning G, Robertson B. Lung expansion in the premature rabbit fetus after tracheal deposition of surfactant. Pediatrics 1972:50:58-66.

12. Vaughan RS, Mapleson WW, Rosen M, Laurence KM. Minimum artificial lung expansion necessary for resuscitation of the newborn lamb. $\mathrm{Br} \mathrm{J}$ Anaesth 1980;52:189-195.

13. Upton CJ, Milner AD. Endotracheal resuscitation of neonates using a rebreathing bag. Arch Dis Child 1991;66:39-42.

14. Milner AD. Resuscitation of the newborn. Arch Dis Child 1991;66:66-69.

15. Fung YV. Does the surface tension make the lung inherently unstable. Circ Res 1975;37:497-502.

16. Mead J, Takishima T, Leith D. Stress distribution in lungs: a model of pulmonary elasticity. J Appl Physiol 1970;28:596-608. 
17. Duncan AW, Oh TE, Hillman DR. PEEP and CPAP. Anaesth Intens Care 1986;14:236-250.

18. Faridy EE, Permutt S, Riley RL. Effect of ventilation on surface forces in excised dogs' lungs. J Appl Physiol 1966;21:1453-1462.

19. Forrest JB. The effect of hyperventilation on pulmonary surface activity. Br J Anaesth 1972;44:313-320.

20. Wyszogrodski I, Kyei-Aboagye K, Taeusch HW Jr, Avery ME. Surfactant inactivation by hyperventilation: conservation by end-expiratory pressure. J Appl Physiol 1975;38(3):461-466.

21. Furzan JA, Gabriele G, Wheeler JM, Fixler DE, Rosenfeld CR. Regional blood flows in newborn lambs during endotracheal continuous airway pressure and continuous negative pressure breathing. Pediatr Res 1981;15:874-878.

22. Field D, Milner AD, Hopkin IE. Effects of positive end expiratory pressure during ventilation of the preterm infant. Arch Dis Child 1985;60:843-847.

23. Baeza OR, Wagner RB, Lowery BD, Gott VL. Pulmonary hyperinflation. A form of barotrauma during mechanical ventilation. J Thoracic Cardiovasc Surgery 1975;70(5):790-805.

24. Kanarek DJ, Shannon DC. Adverse effect of positive end-expiratory pressure on pulmonary perfusion and arterial oxygenation. Am Rev Respir Dis 1975;112:457459.

25. Nelson RM, Egan EA, Eitzman DV. Increased hypoxemia in neonates secondary to the use of continuous positive airway pressure. J Pediatr 1977;91:87-91.

26. Keszler M, Ryckman FC, McDonald JV et al. A Prospective, multicenter, randomized study of high versus low positive end-expiratory pressure during extracorporeal membrane oxygenation. J Pediatr 1992;120:107-113.

27. Young SL, Tierney DF, Clements JA. Mechanism of compliance change in excised rat lungs at low transpulmonary pressure. J Appl Physiol 1970;29:780785.

28. Ferris BG, Pollard DS. Effect of deep and quit breathing on pulmonary compliance in man. J Clin Invest 1960;39:143-149.

29. Mead J, Collier C. Relation of volume history of lungs to respiratory mechanics in anesthetized dogs. J Appl Physiol 1959;14:669-678.

30. Wyszogrodski I, Kyei-Aboagye K, Taeusch Jr HW, Avery ME. Surfactant inactivation by hyperventilation: conservation by end-expiratory pressure. J Appl Physiol 1975;38:461-466.

31. Young SL, Tierney DF, Clements JA. Mechanism of compliance change in excised rat lungs at low transpulmonary pressure. J Appl Physiol 1970;29:780785.

32. Faridy EE. Fetal lung development in surgically induced prolonged gestation. Respir Physiol 1981;45:153-166.

33. Finley TN, Tooley WH, Swenson EW, Gardner RE, Clements JA. Pulmonary surface tension in experimental atelectasis. Am Rev Respir Dis 1964;89:372-378. 
34. Morris GS, Thliveris JA, Faridy EE. Development of fetal rat lung during prolonged gestation. Respir Physiol 1980;42:263-285.

35. Sekulic SM, Hamlin J, Ellison R, Ellison L. Pulmonary surfactant and lung circulation in experimental atelectasis. Am Rev Respir Dis 1968;97:69-75.

36. Williams JV, Tierney DF, Parker HR. Surface forces in the lung, atelectasis, and transpulmonary pressure. J Appl Physiol 1966;21:819-827.

37. Housley E, Louzada N, Becklake MR. To sigh or not to sigh. Am Rev Resp Dis 1970;101:611-614.

38. Rehder K, Mallow JE, Fibuch EE, Krabill DR, Sessler AD. Effects of isoflurane anesthesia and muscle paralysis on respiratory mechanics in normal man. Anesthesiology 1974;41:477-485.

39. Westbrook PR, Stubbs SE, Sessler AD, Rehder K, Hyatt RE. Effects of anesthesia and muscle paralysis on respiratory mechanics in normal man. J Appl Physiol 1973;34:81-86.

40. Novak RA, Shumaker L, Snyder JV, Pinsky MR. Do periodic hyperinflations improve gas exchange in patients with hypoxemic respiratory failure? Crit Care Med 1987;15(12):1081-1085.

41. Balsys AJ, Jones RL, Man SFP, Wells A. Effects of sighs and different tidal volumes on compliance, functional residual capacity and arterial oxygen tension in normal and hypoxemic dogs. Crit Care Med 1980;8(11):641-645.

42. Kolton M, Cattran CB, Kent G, Volgyesi G, Froese A, Bryan AC. Oxygenation during high-frequency ventilation compared with conventional mechanical ventilation in two models of lung injury. Anesth Analg 1982;61:323-332.

43. Hamilton PP, Onayemi A, Smyth JA, Gillan JE, Cutz E, Froese AB, Bryan AC. Comparison of conventional and high-frequency ventilation: oxygenation and lung pathology. J Appl Physiol 1983;55:131-138.

44. Cheney FW, Burnham SC. Effect of ventilatory pattern on oxygenation in pulmonary edema. J Appl Physiol 1971;31:909-912.

45. Fuleihan SF, Wilson RS, Pontoppidan H. Effect of mechanical ventilation with end-inspiratory pause on blood-gas exchange. Anesth and Analg 1976;55(1):122130.

46. Jansson L, Jonson B. A theoretical study on flow patterns of ventilators. Scand J Respir Dis 1972;53:237-246.

47. DeLemos RA, Coalson JJ, Gerstmann DR et al. Ventilatory management of infant baboons with hyaline membrane disease:the use of high frequency ventilation. Pediatr Res 1987;21:594-602.

48. Baum M, Mutz N, Putensen C, Klima G, Benzer H. Influence of high-frequency ventilation at different end-expiratory lung volumes on the development of lung damage during lung lavage in rabbits. Br J Anaesth 1989;63:65S-70S.

49. Walsh MC and Carlo WA. Sustained inflation during HFOV improves pulmonary mechanics and oxygenation. J Appl Physiol 1988;65(1):368-372.

50. Quan SF, Militzer HW, Calkins JM et al. Comparison of high-frequency jet 
ventilation with conventional mechanical ventilation in saline-lavaged rabbits. Crit Care Med 1984;12(9):759-763.

51. Truog WE, Standaert TA, Murphy J, Palmer S, Woodrum DE, Hodson WA. Effect of high-frequency oscillation on gas exchange and pulmonary phospholipids in experimental hyaline membrane disease. Am Rev Respir Dis 1983;127:585-589.

52. Carlo WA, Chatburn RL, Martin RJ. Randomized trial of high-frequency jet ventilation versus conventional ventilation in respiratory distress syndrome. $\mathrm{J}$ Pediatr 1987;110:275-282.

53. Anrep GV, Pascua W, Rössler R. Respiratory variations of the heart rate. I The reflex mechanism of the respiratory arrhythmia. Proc $\mathbf{R}$ Soc London Ser 1936;B119:191-217.

54. Guyton AC, Lindsey AW, Abernathy B, Richardson T. Venous return at various right atrial pressures and the normal venous return curve. Am J Physiol 1957; 189:609-615.

55. Traverse JH, Korvenranta H, Adams EM, Goldthwait DA, Carlo WA. Impairment of hemodynamics with increasing mean airway pressure during high-frequency oscillatory ventilation. Pediatr Res 1988;23(6):628-631.

56. Venus B, Cohen LE, Smith RA. Hemodynamics and intrathoracic pressure transmission during controlled mechanical ventilation and positive end-expiratory pressure in normal and low compliant lungs. Crit Care Med 1988;16(7):686-690.

57. Kinsella JP, Gerstmann DR, Clark RH et al. High-frequency oscillatory ventilation versus intermittent mandatory ventilation: early hemodynamic effects in the premature baboon with hyaline membrane disease. Pediatr Res 1991;29(2):160-166.

58. Pryds O, Greisen G, Lou H, Friis-Hansen B: Heterogeneity of cerebral vasoreactivity in preterm infants supported by mechanical ventilation. $J$ Pediatr 1989;115:638-645.

59. Kolobow T, Fumagalli R, Arosio P, Chen V, Buckhold D, Pierce J. Severe pulmonary capillary alkalosis during states of low pulmonary blood flow: a possible cause of lung damage. Life Support Systems. Proceedings IX Annual Meeting ESAO, Brussels, Belgium, 1982;169-171.

60. Kolobow T, Spragg R, Pierce J. Massive pulmonary infarction during total cardiopulmonary bypass in unanesthetized spontaneously breathing lambs. Int $\mathrm{J}$ Art Organs 1981;4(2):76-81.

61. Meyrick B, Reid L. The alveolar wall. Br J Dis Chest 1970;64:121-140.

62. Tierney DF, Clements JA, Trahan HJ. Rates of replacements of lecithin and alveolar instability in rat lungs. Am J Physiol 1967;213:671-676.

63. Avery ME, Chernick V. Alterations of alveolar lining layer in living rabbits. J Pediatr 1963;63:762-763.

64. Farhi LE. Ventilation-perfusion relationships. In: Handbook of Physiology, Section 3: The Respiratory System, volume IV: gas exchange, eds. Fishman AP, 
Farhi LE, Marsh Tenney S, Geiger SR. Am Physiol Society, Bethesda, Maryland, 1985, p 205.

65. Traystman RJ, Batra GK, Menkes HA. Local regulation of collateral ventilation by oxygen and carbon dioxide. J Appl Physiol 1976;40:819-823.

66. Chen C, Sealy WC, Seaber A. The dynamic nature of collateral ventilation J Thorac Cardiovasc Surg 1970;59:518-529.

67. Traystman RJ, Terry PB, Menkes HA. Carbon dioxide- a major determinant of collateral ventilation. J Appl Physiol 1978;45:69-74.

68. Batra G, Traystman R, Rudnick H, Menkes H. Effects of body position and cholinergic blockade on mechanics of collateral ventilation. J Appl Physiol 1981;50:358-362.

69. Alcorn DG, Adamson TM, Maloney JE, Robinson PM. A morphologic and morphometric analysis of fetal lung development in the sheep. Anat Rec 1981;201:655-667.

70. Docimo SG, Crone RK, Davies P, Reid L, Retik AB, Mandell J. Pulmonary development in the fetal lamb: Morphometric study of the alveolar phase. Anat Rec 1991;229:495-498.

71. Davies P, Reid L, Lister G, Pitt B. Postnatal growth of the sheep lung: a morphometric study. Anat Rec 1988;220:281-286.

72. Gil J, Bachofen H, Gehr P, Weibel ER. Alveolar volume-surface area relation in air- and saline-filled lungs fixed by vascular perfusion. J Appl Physiol 1979;47:990-1001. 


\section{Summary}

This thesis assesses the effect sustained lung inflations have on lung function and cardiovascular variables. It is especially aimed to evaluate the prophylactic use of sustained lung inflations in premature lambs at risk for respiratory distress syndrome. Sustained lung inflations are applied in such a manner as they might have been used to manage premature infants in a clinical situation.

In chapter 1 a short introduction is given to mechanisms necessary for the transition of fetus to newborn and the problems associated with premature birth and surfactant deficiency. Also the beneficial effect of sustained lung inflations or lung conditioning in the fetal lamb and possible mechanisms for the reported improvement of fetal lung function were described. The negative effect prolonged positive pressure inspiration might have on cardiac output was explained. Also an introduction was given to the mechanism of the possible negative effect of mechanical ventilation on alveolar $\mathrm{CO}_{2}$. Finally the reasons for choosing the premature lamb of around 130 days gestation as a experimental model were explained.

In chapter 2 and 3 the effect of time of application of sustained lung inflations or lung conditioning on lung function was evaluated. In chapter 3 sustained inflations were applied immediately after cord clamping as we thought it was perhaps crucial to facilitate the establishment of a functional residual capacity as soon as possible (a possible mechanism for the beneficial effect of lung conditioning). In chapter 2 the effect of single versus multiple application of sustained lung inflations on lung function was also assessed.

There were no significant differences in morbidity, mortality, total static compliance or pulmonary gas exchange between the treatment and control groups during the described experimental periods in all studies.

Chapter 4 evaluates the cardiovascular effects of sustained lung inflations by measuring mean central venous pressure, mean arterial blood pressure and heart rate. Sustained inflations can produce significant changes in these variables dependent on the time after birth they were applied and the height of increase in pressure during the inflations.

In chapter 5 lung morphology of 48 of the premature lambs used in this thesis was evaluated quantitatively and qualitatively. There were no significant differences between treatment and control groups in the degree of macroscopical lung damage and in parenchymal-alveolar space area ratio or field-to-field variability in the sections studied. The macroscopical qualitative and microscopical quantitative data measured centrally in the right lower lobe were correlated. However, qualitative evaluation was better correlated with blood gases and total static compliance. 
The effects of hypocapnia and of mechanical pulmonary stress on lung tissue in newborn lambs were assessed separately in chapter 6. Aim of this study was to evaluate possible differences in lung pathology between hypo- and normocapnic lambs to demonstrate possible lung injury due to extracellular alkalosis. The ventilatory strategy applied in this study, even when accompanied by moderate alveolar hypocapnia, did not result macroscopically in haemorrhages, barotrauma or widespread atelectasis nor did it produce evident alveolar damage after 4 hours of ventilating newborn lambs with initially healthy lungs.

In chapter 7 some of the aspects of this thesis are discussed in more detail and the following conclusions are drawn:

1) In premature newborn lambs applying sustained inflations to recruit alveoli without prevention of derecruitment does not improve lung function.

2) A high mean airway pressure can produce significant changes in cardiovascular variables, even in low compliant lungs. 


\section{Samenvatting}

Dit proefschrift behandelt het mogelijke effect dat het toedienen van verlengde inflaties van de longen kan hebben op longfunctie en cardiovasculaire variabelen. Met name wordt het prophylactisch gebruik van verlengde inflaties in prematuur geboren lammeren bestudeerd. Deze lammeren hebben een grote kans te zullen lijden aan het "respiratory distress syndrome". De verlengde inflaties van de longen zijn toegediend op een wijze zoals wij ons voorstelden dat ze in de kliniek ooit toegepast zouden kunnen worden.

In hoofdstuk 1 wordt een korte introductie gegeven tot de mechanismen nodig voor de transitie van foetus tot pasgeborene en de problemen samengaand met prematuur geboorte en surfactans deficiëntie. Tevens wordt het succes van toediening van verlengde inflaties in het foetale lam en mogelijke mechanismen voor de deze in de literatuur gerapporteerde verbetering van long functie beschreven. Het te verwachten negatieve effect op cardiac output van een 5 seconden lang met positieve beademingsdruk aangehouden inspiratoire fase werd verklaard en tevens werd het mogelijke negatieve effect van mechanische ventilatie op alveolaire kooldioxide tensie geintroduceerd. Tenslotte worden de redenen genoemd voor het kiezen van het prematuur geboren (zwangerschapsduur van \pm 130 dagen) lam als experimenteel model.

In hoofdstuk 2 en 3 wordt het effect van de tijd van toediening van verlengde inflaties of lung conditioning op long functie geëvalueerd. In hoofdstuk 3 werden verlengde inflaties van de longen direct na afklemming van de navelstreng toegediend. Dit om de mogelijk cruciale rol van vroege en vergemakkelijkte vorming van een functionele residuale capaciteit te beoordelen. Devorming van vroeg en adequaat functionele residuale capaciteit werd genoemd als én van de mogelijke mechanismen van het gunstige effect van verlengde inflaties in foetale lammeren. Hoofdstuk 2 behandelt ook het effect van eenmalig versus multipele toediening van verlengde inflaties op longfunctie.

Gedurende de experimenten werden geen significante verschillen in morbiditeit, mortaliteit, long compliantie en/of pulmonale gas uitwisseling tussen de behandelde en controle lammeren gezien.

In hoofdstuk 4 wordt het cardiovasculaire effect van verlengde inflaties bekeken door meting van gemiddelde centraal veneuze druk, arteriële bloeddruk en hartslag.

Lang aangehouden positieve longinflaties produceren significante veranderingen in deze variabelen. De tijd na de geboorte waarop de inflaties worden toegediend en de grootte van de verhoging van de beademingsdruk spelen een belangrijke rol hierin.

In hoofdstuk 5 werden de longen van 48 van de premature lammeren zowel quantitatief als qualitatief qua morfologie bestudeerd. Er was geen significant verschil 
in macroscopische schade aan de longen tussen behandelde lammeren en controle lammeren. Ook het quantitatief gemeten percentage parenchymale versus alveolaire ruimte en de varibiliteit van dit percentage verschilden niet tussen de groepen. De correlatie tussen macroscopische qualitatieve evaluatie en meting van percentage parenchym en variabiliteit centraal in de caudale rechter long lobus was significant aanwezig. Toch correleerde macroscopische evaluatie beter met de gemeten bloed gassen en long compliantie.

De effecten van hypocapnie en mechanische pulmonale stress in de longen werden afzonderlijk bestudeerd in hoofdstuk 6. Doel van deze studie was het verschil in long pathologie als gevolg van extracellulaire alkalose aan te tonen tussen lammeren met hypo- en normocapnische bloedgaswaarden. De ventilatie strategie welke wij hanteerden in deze pasgeboren lammeren met initieel gezonde longen resulteerde na 4 uur niet in longbloedingen, barotrauma of uitgebreide atelectase. Noch kon er duidelijke schade op alveolair niveau worden aangetoond.

In hoofdstuk 7 worden bepaalde resultaten van dit proefschrift meer in detail besproken en werd het volgende geconcludeerd:

1) In het prematuur geboren lam wordt de functie van de longen niet verbeterd door toediening van verlengde inflaties zonder preventie van derecruitering van alveoli.

2) Een hoge gemiddelde beademingsdruk kan resulteren in significante veranderingen in cardiovasculaire variabelen, zelfs in longen met een lage compliantie. 


\section{Curriculum Vitae}

\section{2-2-1960}

Born in Rheden in the Netherlands

\section{8}

Diploma V.W.O.

\section{8-1979}

Freshman student at Linfield College, McMinnville Oregon, USA

1979-1987

Study medicine at the University of Leiden

1987-1991

Research fellow at the Department of Neonatology of the University Hospital Maastricht

Since 1993

Clinical Research Physician at Wellcome Pharmaceuticals B.V. in Utrecht 


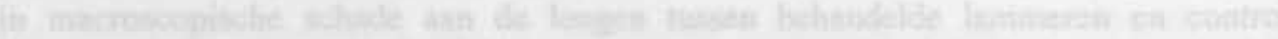

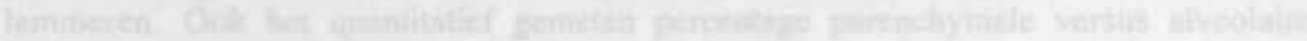

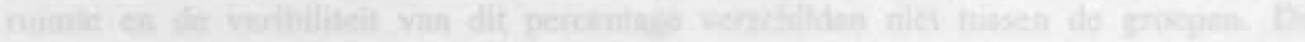

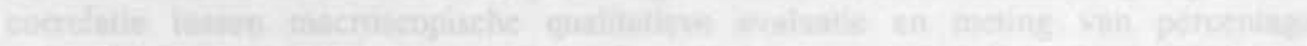

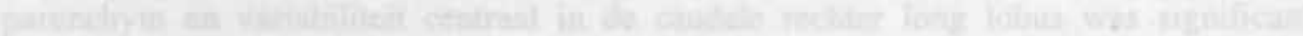

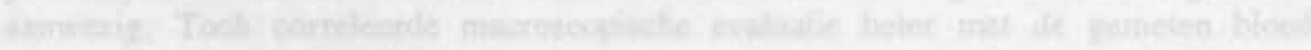

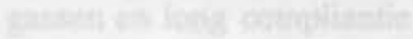

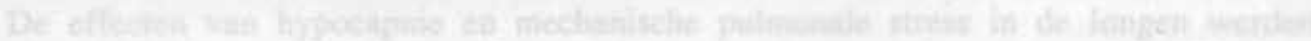

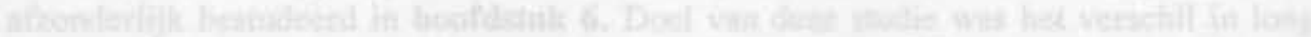

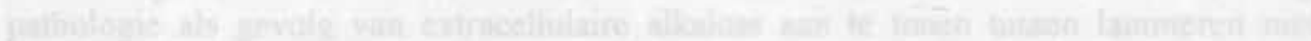

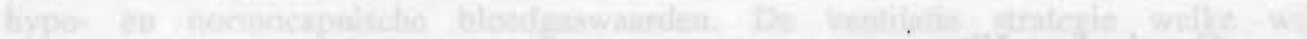

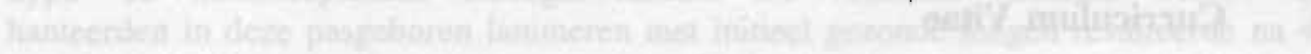

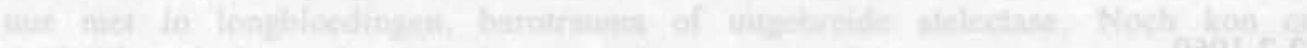

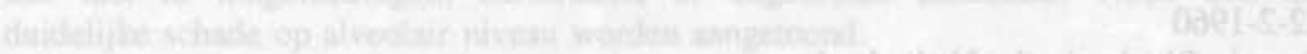

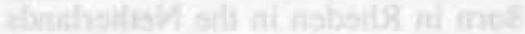

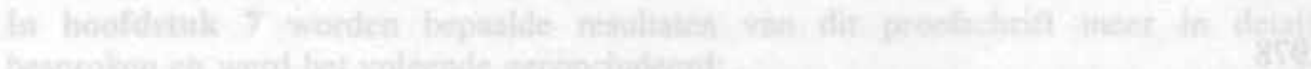

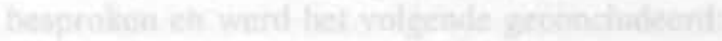

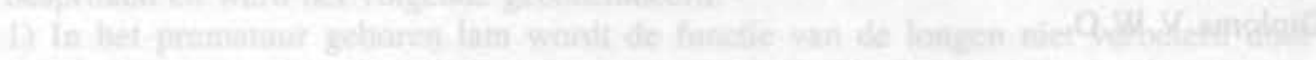

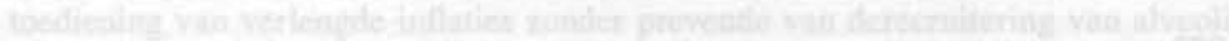

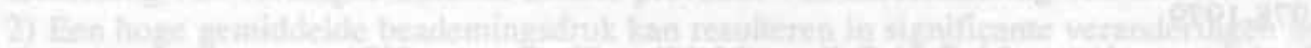

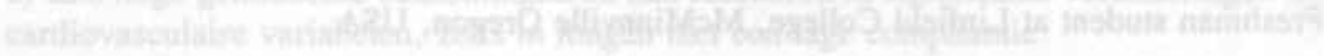

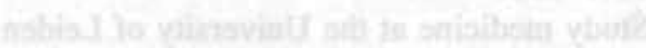

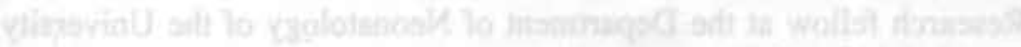

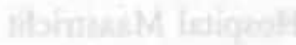

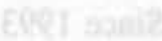

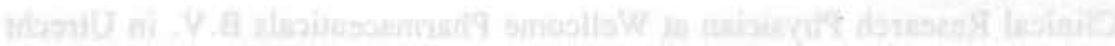




\section{Nawoord}

Het in deze dissertatie beschreven onderzoek is grotendeels verricht op het Biomedisch Centrum te Maastricht in de groep Perinatologie, een samenwerkingsverband van de vakgroepen Neonatologie, Gynaecologie en Obstetrie, Pulmologie en Genetica.

Dit proefschrift is mede tot stand gekomen door het geduld en de onvermoeibare inzet van Prof.dr. C.E. Blanco, mijn promotor. Carlos, bedankt.

Tevens wil ik ook de beoordelingscommissie bedanken voor hun moeite dit proefschrift kritisch door te lezen.

May Bost, Joyce Suyk, Frans Slangen, Peter Franssen, Theo van der Nagel, Jo Habets en Ruud Kruger wil ik bedanken voor hun oprechte toewijding aan het welzijn van de proefdieren en tevens voor hun bijdrage aan een gezellige werksfeer.

Daarnaast wil ik nog noemen mijn collega onderzoekers in de kliniek en het BMC en de vele anderen die mij bij het schrijven van dit proefschrift geholpen hebben hetzij door morele ondersteuning of op een meer pragmatische wijze. 
